\title{
Simulating fully-integrated hydrological dynamics in complex Alpine headwaters
}

\author{
Thornton, J.M. ${ }^{1}$, Therrien, R. ${ }^{2}$, Mariéthoz, G. ${ }^{3}$, Linde, N. ${ }^{4}$ and Brunner, P. ${ }^{1}$ \\ ${ }^{1}$ Centre for Hydrogeology and Geothermics, University of Neuchâtel, Switzerland \\ ${ }^{2}$ Department of Geology and Geological Engineering, University of Laval, Canada \\ ${ }^{3}$ Institute of Earth Surface Dynamics, University of Lausanne, Switzerland \\ ${ }^{4}$ Institute of Earth Sciences, University of Lausanne, Switzerland
}

This is a non-peer reviewed pre-print submitted to EarthArXiv on 26 February 2021.

The manuscript was submitted to Water Resources Research on 4 December 2020.

Corresponding author: J.M. Thornton (james.thornton@unine.ch)

\section{Key Points:}

- An integrated model of two adjacent steep, snow-dominated, geologically complex Alpine headwaters was developed and calibrated automatically

- Spatio-temporal dynamics and dependencies between snow, surface water, groundwater, and evapotranspiration processes are explicitly captured

- Such a simulation approach provides a basis for integrating novel datasets and generating more reliable climate change impact projections 


\section{Abstract}

2 Hydrological climate change impact assessments in mountainous areas still frequently rely upon highly simplified

3 approaches. Fully-integrated surface-subsurface codes would appear to hold far greater potential to represent the

4 distinctive regimes of steep, geologically complex headwaters. However, their application in mountainous terrain has

5 thus far been predominantly limited to crystalline catchments in western North America, leaving their utility in Alpine

6 contexts untested. Here, a model of two adjacent calcareous Alpine headwaters is presented that accounts for 2D

7 surface flow, 3D variably-saturated groundwater flow, and evapotranspiration. An energy balance-based

8 representation of snow dynamics contributes high-resolution forcing data, whilst a sophisticated 3D geological model

9 helped inform the subsurface structure. In the first known attempt to calibrate an integrated, catchment-scale model in

10 mountainous terrain automatically, numerous uncertain parameters were estimated. The salient features of the

11 hydrological regime were ultimately satisfactorily reproduced; over an independent 11-month evaluation period, a

12 Nash-Sutcliffe efficiency of 0.73 was attained at the principal streamflow gauge. The visualization of forcings and

13 simulated responses further confirmed the model's broad coherence. Closely replicating the somewhat contrasting

14 groundwater level signatures observed in close proximity to one another was more elusive, presumably due to

15 unresolved local subsurface heterogeneity. Finally, the impacts of various model simplifications on key predictions

16 were assessed. Overall, our work demonstrates the feasibility and numerous attractions of applying integrated models

17 - especially those that allow the stream network to evolve freely - in complex mountain systems, although certain

18 outstanding challenges remain to be overcome if their global uptake is to increase.

19

Key words: Alpine; integrated hydrological modelling; snow; geology; calibration; spatio-temporal 
Non-peer reviewed pre-print submitted to EarthArXiv

\section{Introduction}

Mountainous water resources hold considerable societal importance (Immerzeel et al., 2020; Viviroli et al., 2020). However, in the European Alps as elsewhere, two key hydrological system components - namely the glaciers and snowpacks - are declining rapidly in the face of ongoing warming (Beniston et al., 2018). In light of these profound changes, reliable projections of Alpine hydrological systems are urgently required to implement sound mitigation and adaptation measures. Yet Alpine hydrological systems are extremely complex; considerable elevation gradients and rugged topography drive pronounced spatio-temporal variability in meteorological conditions, water stored in solid form is released on highly contrasting timescales, and inherently complex bedrock architectures can influence groundwater flow patterns and by extension broader hydrological system functioning (e.g. via subsurface flows across topographic divides). Furthermore, contemporaneous changes in other system components, including forests and permafrost, could modulate more direct, climate-driven hydrological changes (e.g. Evans et al., 2015). The notoriously limited quantity and spatial representativeness of environmental data that can typically be obtained in such environments presents further complications.

Despite this high system complexity (but also perhaps partly because of limited data), most hydrological climate change impact assessments in mountainous areas continue to rely on "box-type" conceptual hydrological models (e.g. Jenicek et al., 2018; Wagner et al., 2017). Because the parameters of these models have very limited physical meaning, constraining them to plausible ranges is difficult. Consequently, whilst streamflows (which are traditionally the only data involved in calibration) can often be replicated well, care may be required when making interpretations or drawing inferences with respect to internal physical dynamics (e.g. Staudinger et al., 2017). Implicitly, this is precisely what is done when such tools are used in climate impact assessments. Indeed, such models are often especially challenged when the forcing conditions differ from those of the calibration period, as they likely would under such circumstances (Duethmann et al., 2020). In addition, when such models are only lumped or partially-distributed, distributed observations cannot be easily incorporated, nor the impacts of inherently spatial phenomena (e.g. vegetation change) considered (Speich et al., 2020). Finally, the suitability of the empirical, index-based snow modelling schemes that commonly feature in such models to reproduce complex Alpine snow dynamics is questionable (Warscher et al., 2013). Ultimately, the validity of resultant predictions may not be guaranteed.

More physically-based approaches exist. For instance, WaSiM (Schulla, 2017), TOPKAPI-ETH (Ragettli et al., 2014), and WEB-DHM-S (Shrestha et al., 2015) were all developed specifically for mountainous applications. Generally, topography is discretized regularly and the 1D soil water balance solved independently for each cell before routing functions are applied to generate streamflow hydrographs at specified points along predefined stream networks. Advanced "full-physics", multi-layer energy balance snowpack models - such as the semi-distributed (Hydrological Response Unit; HRU)-based Cold Regions Hydrology Model (CRHM) and the fully distributed Alpine3D (Lehning et al., 2006) - have also been extended to be able to generate streamflow estimates (e.g. DeBeer and Pomeroy, 2017; Brauchli et al., 2017). However, all of these more physically-based codes still rely on simple, non-mechanistic representations of groundwater storage and streamflow generation involving, for instance, lumped groundwater reservoirs (with either linear or non-linear storage-discharge relationships), and the neglection of lateral subsurface flows (Gallice et al., 2016: Fatichi et al., 2015). In these regards, they suffer many similar limitations as their simpler counterparts, leaving them no better placed to account for local geological influences; considerable mismatch certainly therefore exists between the sophistication of snow and (near) surface representation on the one hand, and the simplified representation of subsurface processes on the other. Whilst such simulation approaches may be appropriate in certain settings, for instance where soils are fairly homogenous, bedrock fairly homogenous or even impermeable, and few sizable permeable unconsolidated deposits present, elsewhere this may not be the case. It is also worth remarking that even highly advanced snow models like Alpine3D overlook some potentially important processes, such as the gravitational redistribution of snow from steep slopes (whose omission can produce undesirable artefacts in steep, rugged terrain; Freudiger et al., 2017), and - as with other distributed tools - are highly contingent upon the availably of good quality of meteorological forcing data (Förster et al., 2014). 
In the broader literature, partial differential equation-based, spatially distributed, fully-integrated (or fully-coupled) surface-subsurface models are becoming increasingly popular, with reported applications now spanning a considerable range of environmental settings, research questions, and spatial scales (Ala-aho et al., 2015; Hwang et al., 2018; Jaros et al., 2019; Maxwell et al., 2015; Smerdon et al., 2007; Sulis et al., 2011; Tolley et al., 2019). Such codes are capable of mechanistically simulating most potentially relevant hydrological processes, including 2D surface flow, 3D variably-saturated groundwater flow, and evapotranspiration, in a physically-based, distributed, transient, and internally coherent fashion. Consequently, runoff generation can arise from any combination of possible mechanisms (infiltration or saturation excess, groundwater discharge), removing the need for the imposition of a strong prior conception. In contrast to traditional groundwater models, recharge is computed internally. Besides these generic benefits, several features of integrated models would appear to make them especially well-suited to the simulation of distinctive Alpine hydrological regimes.

Firstly, they are capable of ingesting 3D information regarding the arrangement of subsurface formations, and so should enable any influence that complex Alpine geologies exert on broader catchment dynamics to be explicitly represented. Secondly, they can simultaneously account for surface water flows, which are important with respect to flood risk and sediment transport in steep terrain. Perhaps their greatest attraction, though, related to the free, bidirectional exchange between the surface and subsurface domains that they allow. In contrast to most hydrological models, require fixed stream locations to be defined a priori, some fully-integrated codes, such as HydroGeoSphere (HGS; Aquanty Inc., 2016), even allow the stream network to evolve dynamically in accordance with physical laws as a function of the boundary conditions and surface and subsurface properties prescribed. This is important because many headwater torrents and streams are intermittent (Durighetto et al., 2020; Van Meerveld et al., 2019) and/or demonstrate strong variability in "losing" and "gaining" patterns more broadly, with ecological (amongst other) implications. These integrated codes should therefore be well placed to replicate such dynamics.

Some studies seeking to exploit contemporary numerical models in mountainous contexts - including some integrated ones - have begun to emerge. Thus far, efforts have predominantly been focused on catchments underlain by crystalline and other low permeability/storage bedrock types that are encountered widely across western North America, where high water-tables are relatively high. In an early contribution, Gleeson and Manning (2008) conducted a series of synthetic experiments using HGS to unravel the influence of topography and hydrogeological properties on regional (i.e. inter-watershed) three-dimensional (3D) groundwater flow in idealized crystalline mountainous terrain. Although completely understandable given their aims, a number of real-word complexities were neglected, including "evapotranspiration, the role of the orographic effects on precipitation, the seasonal effects of snow accumulation and melting, ...transient conditions, such as perched ground-water conditions...[and] the role of alpine glaciers or permeable surficial geology units" (Gleeson and Manning, 2008; p. 4).

The first more detailed, distributed, catchment-scale representations of real mountain systems in which bedrock was not simply treated as impermeable emerged shortly thereafter: Huntington and Niswonger (2012) simulated the hydrology of three watersheds in the eastern Sierra Nevada, U.S., under future climate scenarios using GSFLOW (Markstrom et al., 2008), concluding that marked decreases in summertime stream discharge are likely. Voeckler et al. (2014) used MIKE SHE (Graham \& Butts, 2005) to demonstrate that a reasonable proportion of annual precipitation in a small headwater catchment in British Columbia, Canada, recharged the bedrock aquifer, calling into question the then-prevailing assumption that deep groundwater is a negligible water budget component in crystalline mountain catchments. Note that GSFLOW and MIKE SHE provide loosely coupled representations of surface-subsurface flows in which information is passed iteratively between the domains, in contrast to a single set of combined equations being solved (as in "globally implicit" fully-integrated models; see Maxwell et al., 2014).

Later, fully-integrated models were used to simulate a few 2D transects in hypothetical (Markovich et al. 2016) and real (Pribulick et al. 2016) mountain catchments. In the latter example, in the Upper Colorado River Basin, U.S., the simulated responses of each transect were also highly contrasting, highlighting that such transect simulations provide 
little insight into dominant processes and/or changes at catchment scale. 3D integrated models of real mountain basins naturally account for spatial variability in catchment properties and processes more explicitly, and their more development and application is accelerating. Ala-aho et al. (2017) established a 3D fully-integrated HGS model to develop insights into the spatio-temporal contributions of groundwater to runoff generation in very small $\left(3.2 \mathrm{~km}^{2}\right)$ headwater in the Scottish Highlands. Penn et al. (2016) altered vegetation parameters in a ParFlow.CML model to assess the hydrological impacts of mountain pine beetle-induced tree mortality in another Coloradoan headwater that of the Big Thompson River, while Carroll et al. (2019) developed a GSLOW model of the entire East River, Colorado, finding groundwater to be an important and stable contributor to mountain streamflow. Finally, Maina \& Siirila-Woodburn (2020) investigated hydrological responses following fire dynamics in a Californian watershed spanning a considerable elevational range using ParFlow.CLM.

Whilst these examples attest to much recent progress, the uptake of integrated models in mountainous areas elsewhere remains extremely limited, and their utility in steep, snow-dominated, geologically complex Alpine terrain is currently entirely untested. Being geologically younger and more widely sedimentary, the European Alps generally exhibit higher topographical, geological, and hydrological process complexity that mountainous basins of the Western U.S. and Canada. Simply whether integrated models can be successfully applied in Alpine systems remains unclear. Some of the assumptions used previously - either justified by the study sites' characteristics or simply expedient - may no longer hold. For instance, certain studies simply assumed bedrock to be impermeable (i.e. a no-flow boundary was imposed at its upper surface; Ala-aho et al., 2017; Camporese et al., 2019). Alternatively, single bedrock zones with homogeneous hydraulic conductivity (Markovich et al., 2016; Voeckler et al., 2014) or a few sub-parallel geological layers (Huntington \& Niswonger, 2012) have been considered sufficient, although Engdahl and Maxwell (2015) did employ a fuller representation. Even where bedrock flow was permitted, domains were typically limited vertically to only a few tens of meters below the surface, potentially limiting groundwater circulation depth; although hydraulic conductivity may indeed decline strongly with depth in crystalline settings (Welch \& Allen, 2014), field evidence for deep flows increasingly exists even here (Frisbee et al., 2017). In contrast, in calcareous parts of the Alps specifically, sequences of limestones, shales, and marls have been folded and faulted into complex arrangements. In these regions, groundwater flowpaths can be deep, with patterns strongly influenced aquifer-aquitard interface geometries besides topography (Thornton et al., 2018). Consequently, integrated models here should ideally be informed by 3D representations of structural geology. Datasets possessing the requisite attributes for hydrological/hydrogeological modelling have traditionally been severely lacking, but the situation is improving (e.g. Thornton et al., 2018).

In addition, in contrast to the application of Ala-aho et al. (2017), for instance, in which the small catchment size made it appropriate to apply spatially uniform forcing, in moderately sized, extremely steep and rugged catchments, forcing datasets that are highly resolved in space and time (i.e. $10 \mathrm{~s}-100 \mathrm{~s}$ of meters at most, depending on the domain area, and at an hourly time-step) would also ideally be applied. However, running complex integrated models with such highly resolved spatially distributed, transient boundary conditions remains unusual. As such, the potential benefit of applying highly temporally resolved forcings to such models remains largely unexplored. It is worth highlighting here that in contrast to other model classes, integrated codes generally lack convenient pre-processing routines to correct meteorological station data as necessary (e.g. for precipitation undercatch) and spatially interpolate it, whilst reanalysis products are generally too coarse and unreliable to be applied directly in small, rugged headwaters. Code limitations can also come into play; GSFLOW, for instance, runs exclusively on a daily time-step.

As already mentioned, representing snow dynamics is another important task in such terrain, given the dominant influence that snow exerts on both annual Alpine streamflow and groundwater recharge. Specifically, accurate snow simulations are crucial if spatio-temporal patterns of meltwater arrival at the land surface are to be captured. However, limited and uncertain meteorological data and process variability and complexity constitute major impediments. Interestingly, despite being highly advanced in most regards, and perhaps belying their origins in the groundwater modelling community, integrated models generally offer only empirical snow melt approaches (with the exception of ParFlow.CLM which implements an energy-balance scheme). Voeckler et al. (2014), for example, as well as recent 
applications in non-mountainous but snow-influenced settings (Cochand et al., 2019; Schilling, Park et al., 2019) involved temperature-index schemes, whilst Ala-aho et al. (2017) neglected snow processes altogether. No integrated surface-subsurface codes are known to incorporate snow redistribution processes. Far more so than with 3D geological modelling, intensive efforts are ongoing to ameliorate snow simulations, for example using physics-based, multilayered snow models (Brauchli et al, 2017), more hybrid physical-empirical models conditioned on various snow observations (Thornton et al., under revision), and other similar efforts (e.g. Griessinger et al., 2019; Schattan et al., 2020). However, these advancements have yet to be combined with coupled or integrated descriptions of surfacesubsurface flow dynamics.

Lastly, integrated models are notoriously computationally intensive. Long runtimes (often days to weeks; Miller et al. 2018) can confound formal automated calibration and uncertainty analyses, which require many forward iterations (von Gunten et al., 2014). Reflecting this, of all the mountainous integrated modelling studies discussed hitherto, only Ala-aho et al. (2017) attempted automated calibration, with others relying on - if anything - manual calibration and/or simple sensitivity analyses (see also Foster and Maxwell, 2019). Nonetheless, because "mountains do not give up their secrets easily" (Klemeš, 1990), the importance of calibration is arguably higher than elsewhere. Calibration can additionally provide opportunities for subsequent uncertainty analyses.

In this context, with a view to evaluating the general utility of integrated flow models in complex Alpine settings, the present paper seeks to develop, calibrate, and apply a fully-integrated model of two steep, adjacent, snow-dominated, and geologically-complex Swiss headwaters. Given the study region's characteristics, emphasis is placed on ensuring that the model structure employed is as suitable as possible. It this contains fewer simplifying assumptions than previous integrated mountain models. All of the aspects listed above that were omitted in the early synthetic study of Gleeson and Manning (2008) are now incorporated. More specifically, the following outstanding research questions are addressed:

1. How feasible is the development and application of integrated models in complex Alpine terrain in which structural simplifications are minimized?

2. To what extent can such models be calibrated automatically using streamflow and groundwater level timeseries?

3. What does making subsequent structural simplifications reveal about the degree of model complexity required in such settings?

The simplifications referred to in the final question pertain to both subsurface representation and spatio-temporal forcing data resolution. Whilst commonly made in modelling mountainous catchment, their effects remain largely untested.

\section{Methods}

\subsection{Study area and field instrumentation}

The $\sim 37 \mathrm{~km}^{2}$ study area is centered upon two adjacent headwater catchments in the western Swiss Alps - the Vallon de Nant and the Vallon de La Vare (Figure 1; see also Thornton et al., under revision). Elevations range from $950 \mathrm{~m}$ to over 3,050 $\mathrm{m}$ a.s.l, slopes are steep, and the topography rugged. Land cover is varied; with increasing elevation, dense forest gives way to open alpine pastures and then sparsely vegetated regions of unconsolidated rock and bedrock outcrops/cliffs. Debris flows and avalanches occur frequently, especially in the upper parts. Aside from in the valley bottoms, soils are generally thin or non-existent, and small glaciers persist in the highest sheltered, north-facing sections. Permafrost mapping using the method of Deluigi et al. (2017) indicates that while some can be expected at the highest elevations - an assessment corroborated by a geophysical survey (Giaccone et al., 2019) - it is unlikely to be extensive. In places, various unconsolidated Quaternary sediments thought likely to function as aquifers overly the bedrock. 
The area receives annual precipitation $\geq 1400 \mathrm{~mm}$, approximately $40 \%$ of which falls as snow. Snowmelt dominates total annual streamflow and also contributes significantly to groundwater recharge. Given the catchment's elevational range, its hydrological regime will probably be highly sensitive to air temperature shifts. Intense convective storms in summer are a further noteworthy feature of the region's meteorology. The surface hydrology of the Vallon de Nant is characterized by numerous temporary torrents, whose discharge responds rapidly to rainfall and snowmelt. Streams and other surface water features are less conspicuous in the upper part of the Vallon de La Vare, which is probably explained by it having more permeable near-surface bedrock types. The area remains in a highly natural state, making it rare in the context of the European Alps. Indeed, the Vallon de Nant has been a designated Natural Reserve since 1969. Whilst this is an attraction, the associated lack of long-term, systematic hydrometeorological observation and severely restricted vehicular access represented daunting challenges to the development of our holistic, data-hungry model.

Geologically, the region lies within the Nappe de Morcles; the lowest of a series of large nappe thrust folds that together constitute the Helvetic Nappes. Alternating sequences of fairly permeable and - in places - probably karstified limestones are interspersed with much lower permeability marls and shales (Badoux, 1971). These Mesozoic sequences have been folded and faulted into complex arrangements by tectonic forces, such that the geometries of the various (non-planar) aquifer-aquitard interfaces are expected to strongly influence groundwater flow patterns. As alluded to above, the two sub-catchments actually lie within different zones of the first order fold structure. Thornton et al. (2018) provide further information on the area's bedrock geology and known or hypothesized hydrological / hydrogeological functioning, which helped inform the catchment delineation.

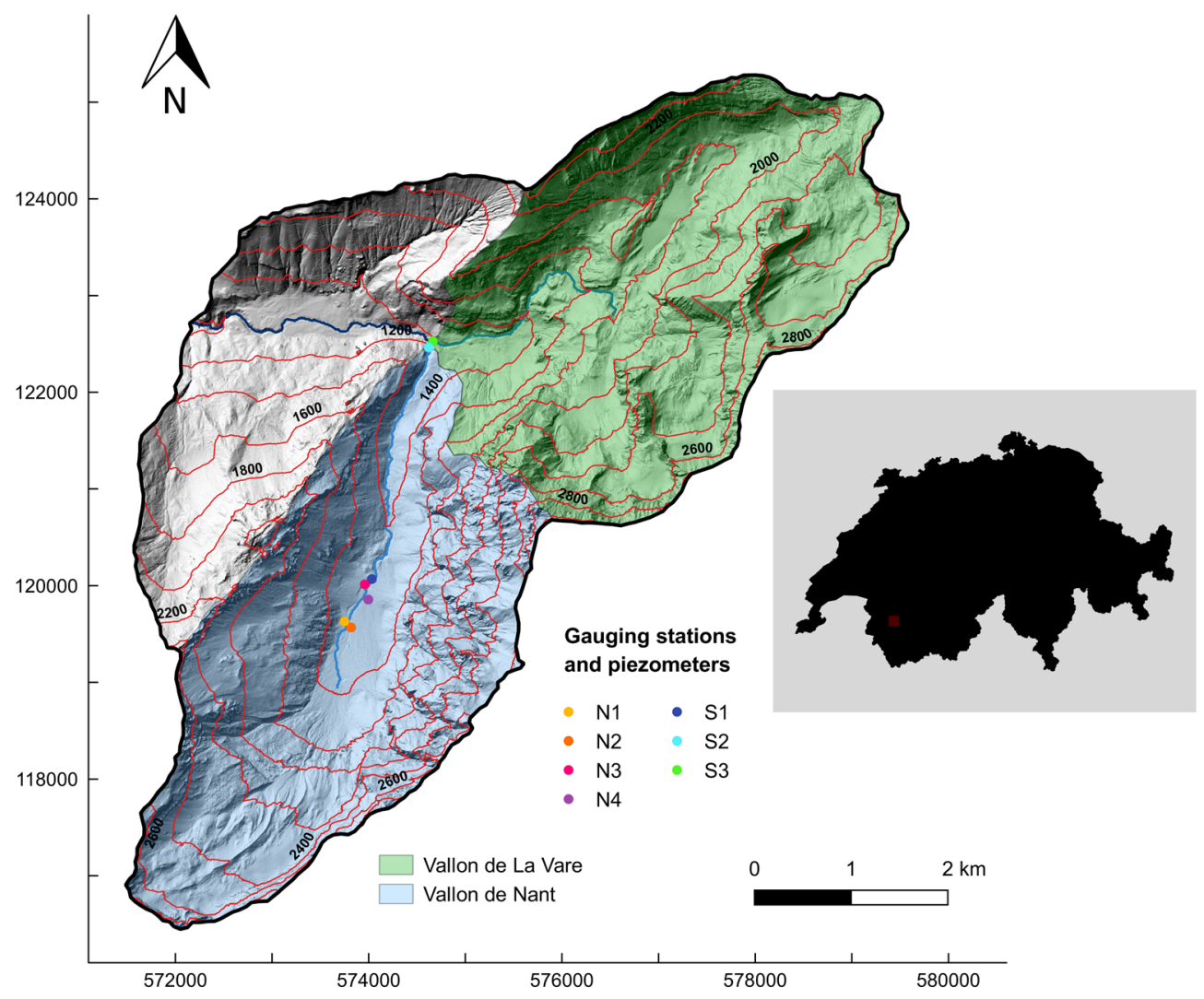

Figure 1. The study area and its situation within Switzerland. Stream discharge (S1-S3) and groundwater level (N1N4) measurement station locations are indicated. Elevation (in meters) is represented using contours, whilst the background hillshade map provides an impression of the steepness and ruggedness of the surface topography. Coordinates are in the projected CH1903 system (m). 
Because some precipitation falling within the topographical catchment of the Vallon de Nant on the north-western ridge is known to drain north-westerly through the subsurface to a spring (Le Rippaz), thereby bypassing the gauging station S2, to prevent the possible introduction of spurious boundary effects, the model domain was extended downstream of the limits of the two gauged sub-basins (see also Ameli et al., 2018). Some incident precipitation on the eastern cliffs of the Vallon de Nant may be similarly transported south-easterly across the topographic divide and ultimately emerge several kilometers away at a spring near Saillon, in the Rhône Valley (see Figure S6). However, for practical reasons (model runtimes and data availability), the domain was not extended to encompass this entire area.

The installation of a concrete weir downstream of Pont de Nant (S2 in Figure 1, see also Figure S1a) has placed a key role in opening up the area for quantitative hydrological investigations. Such gauging stations are rare on low-order Alpine streams, especially upstream of any anthropogenic influences. Automatic water level measurements were combined with a salt-dilution derived rating curve (Ceperley et al., 2018) to generate a fairly complete record of hourly discharge from April 2016 onwards. In addition to the "bypassing" mentioned above, substantial subsurface flow beneath gauging stations in some headwater streams can mean that measured surface streamflows do not represent total output fluxes across these section. However, this phenomenon understood to be insignificant here. (In any case, as an integrated model is used, observed streamflows can be compared with simulated surface fluxes). Shifting streambed configurations immediately upstream of the regular cross-section do however undermine the temporal consistency of the record somewhat, with potential biases and/or uncertainties afflicting estimates at both high and low flows. Stream water level measurements were also made at two additional locations, S1 and S3, but the resultant discharge series are not only shorter here but also more uncertain (due to lack of permanent, fixed cross-sections). None of the three streamflow gauging stations are situated at the outlet of the entire simulated domain; S1 is an internal site within the Vallon de Nant, whilst S2 is located further down L'Avançon de Nant, just above its confluence with Le Richard. The flow of Le Richard, which (at least partially) drains the Vallon de La Vare, is measured at S3.

To complement the stream discharge observations and provide some insight into internal hydrological processes, four small-diameter, relatively shallow (up to $6.5 \mathrm{~m}$ deep) groundwater piezometers (or observation wells) were installed in the vicinity of the large alluvial fan system in the central part of the Vallon de Nant (N1-N4 in Figure 1; see also Figure S1). The piezometers were screened over at least their lower halves, and were equipped with the pressure loggers in June 2017. They yield half-hourly observations, although at three of the four sites, groundwater levels fell below the piezometer base elevations for considerable periods.

\subsection{Model setup}

HGS (Aquanty Inc., 2016) is a fully-integrated simulator that simultaneously solves the diffusion wave approximation to the Saint-Venant equations for shallow 2D surface flow and a modified form of Richards' equation for 3D variablysaturated subsurface flow. The coupling between these domains was conceptualized here using the first-orderexchange method (Ebel et al., 2009). Although some formations are expected to be karstified and soil macropores are also likely to be present, the subsurface was treated as an Equivalent Porous Media (EPM). As such, parameters must be considered effective at the elemental scale. Interception and evapotranspiration are simulated according to Kristensen and Jensen (1975) as a function of atmospheric demand (i.e. potential evapotranspiration; $E T_{\mathrm{p}}$ ), surface and near-surface moisture conditions, and vegetation properties. HGS was chosen over possible alternatives on account of its support for (partially, in this case) unstructured finite element meshes, which allow better representation of the study area's complex topography and other physical features than regular discretisation scheme, as well as the 


\subsubsection{Finite element mesh generation}

A 2D triangular mesh was initially generated by employing the techniques of multi-level optimization and Delaunay refinement in the Algomesh software (HydroAlgorithmics, 2016). Accounting for the extension described above, the catchment boundary and theoretical stream polylines were generated via a terrain analysis. The swissALTI ${ }^{3 \mathrm{D}}$ Digital Terrain Model (DTM), which has a horizontal resolution of $2 \mathrm{~m}$, was employed. These vectors represented the primary constraints for the surface mesh generation. To capture the morphology of the incised mountain watercourses, nodes were spaced at approximately 20-25 m intervals along the streamlines, with separation increasing with distance from the riparian areas. The mesh was also refined in very steep areas. Nodes were placed at precisely the same locations as the in situ observation points. To minimize any potential biases that can be induced in such terrain if low-order streams and ridges are smoothed out (Wang et al., 2018), it was necessary that the resultant surface mesh (Figure S2) be fairly finely resolved. It is comprised of 11,349 nodes (22,077 triangular elements). Surface node elevations were then extracted directly from the DTM; the presence of topographically closed basins in the limestone landscape of the Vallon de La Vare meant that usual terrain pre-processing steps (Käser et al., 2014) were unsuitable. Thereafter, the mesh was extruded vertically in 23 layers, giving a 3D mesh comprised of 272,376 nodes (507,771 prismic elements) (Figure 2). (Note: HGS automatically adds an extra node sheet at the surface under the "dual nodes" approach applied; Aquanty Inc., 2016).

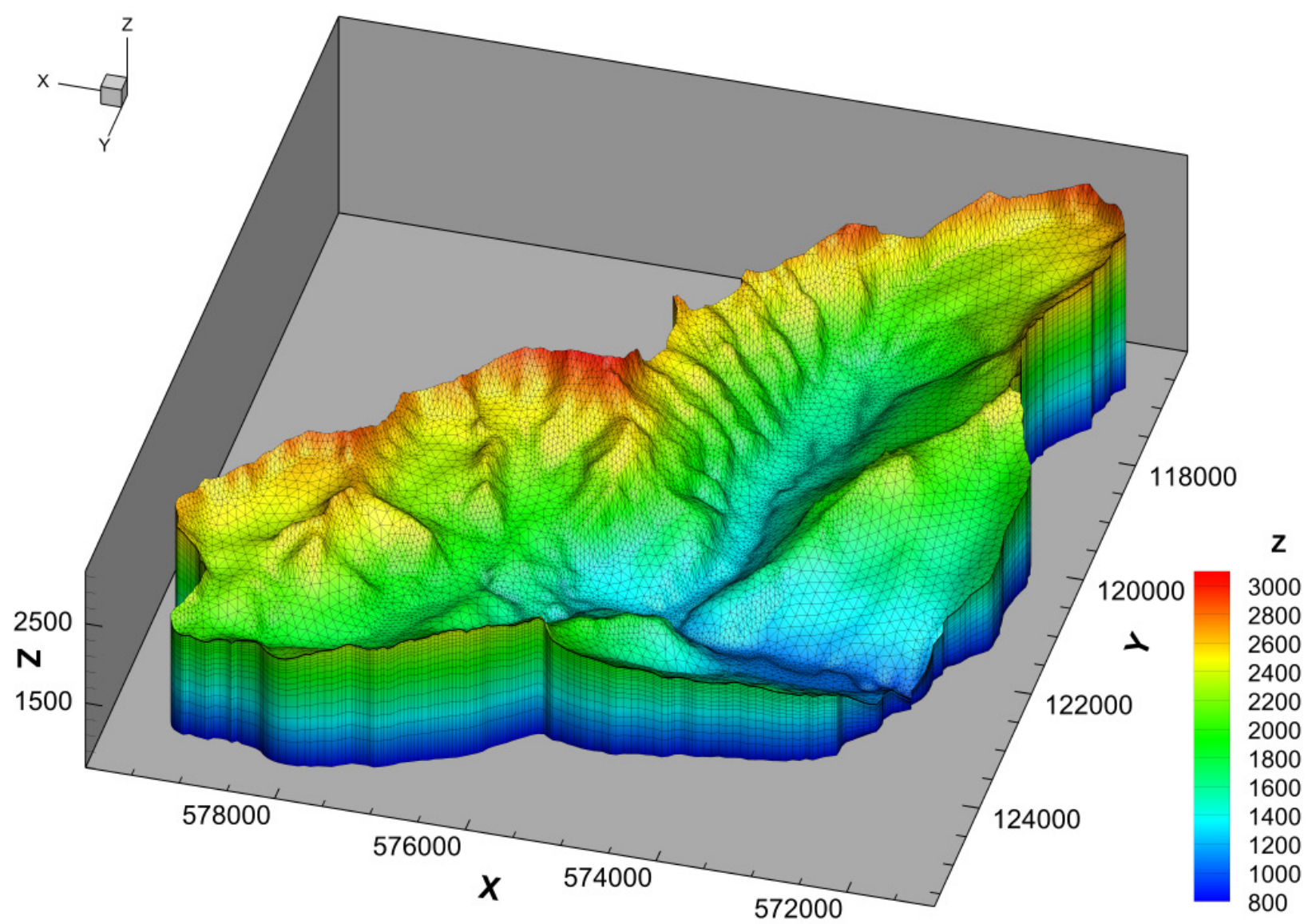

Figure 2. The partially-unstructured 3D prismic mesh. The Z-variable denotes elevation in meters above sea level (a.s.l.). The surface mesh was locally refined close to the streams and in very steep areas. Discretization in the vertical plane was finest near the surface and coarsened with depth. Coordinates are in the projected CH1903 system (m).

Vertical resolution was highest near the surface, with sheets created $0.25,0.5,1.0,2.0,4.0$, and $6.0 \mathrm{~m}$ depths. This approach sought to ensure that near-surface wetting / drying fronts could be captured, and that there were both layers 
that coincided with the assumed soil thicknesses (see the next subsection) and nodes at approximately the same depths as the in situ groundwater pressure transducers. The next three layers were spaced at $5 \mathrm{~m}$ intervals, except within the major unconsolidated feature extents (see Supplementary Text S1); there, the lowermost of these three layers correspondes to the estimated feature bases (i.e. depth to bedrock in all apart from the Nant alluvial fan), with the remaining two layers "stretched" such that they were equally distributed between that and the $6.0 \mathrm{~m}$ layer. The spacing between the 14 remaining lower, sub-parallel layers at $20 \mathrm{~m}$ and increased with depth until the constant specified base elevation of $800 \mathrm{~m}$ a.s.l was reached. The decision to represent such an extensive vertical range and employ relatively high vertical resolution was driven by the nature of the regional geology (i.e. the folder and faulted sequences of hydraulically contrasting formations, including some thin layers); deep flowpaths are considered possible here. Although some loss of structural information is inevitable as the pre-existing spatially continuous 3D geological model is resampled or transferred onto the layered partially-unstructured mesh (again, see the next subsection), the relatively fine vertical resolution sought to minimize this. That said, some compromise was required to keep the computation demands manageable; before settling on the final mesh, several alternatives were developed and tested with a view to achieving an appropriate balance between the representation of physical features, good numerical convergence, and

\subsubsection{Definition of surface and subsurface zones}

The overall intention was to constrain the model's structure as tightly as possible before proceeding to consider certain associated parameter values. A land cover map developed from swisstopo data (see Figure S3) was used to define the surface and evapotranspiration zones (i.e. spatial regions assigned uniform parameter values). Because the resolution of the map exceeded that of the mesh, all faces were assigned to a distinct zone according to the dominant land cover class within each (Tables S1 and S2). A map of estimated permafrost extent in both consolidated and unconsolidated sediments developed using the methodology of Deluigi et al. (2017) was superimposed upon this classification (i.e. permafrost presence or absence was treated as a sub-category in the zonation scheme). Because permafrost presence in rock walls (i.e. consolidated sediments) depends strongly on air temperatures and can therefore generally be determined with high confidence, the underlying permafrost map represented it binarily. As predicting the spatial distribution of permafrost occurrence in unconsolidated sediments is much more demanding, permafrost occurance in unconsolidated sediments was represented probabilistically. For the purposes of the model, only pixels with probabilities $>0.5$ were treated as permafrost, however.

Subsurface zones were defined according to three information sources. The first is a 3D model of bedrock geology that represents 18 distinct formations and their associated features like major faults and secondary folds (Thornton et al., 2018; Figure S4). Geological datasets with the requisite attributes for spatially explicit subsurface flow modelling have traditionally been severely lacking in the Alps, and it was unclear at the outset of that study whether developing such a representation would even be possible. This is now demonstrably the case in even the most complex Alpine settings, and more generally the potential that exists to augment the wealth of high-quality (if decades old) geological information that exists is high. To transfer the bedrock information on the mesh, identifiers of the geological formation present (see Table S3) at each element centroid were extracted. As with the land cover map and previously mentioned, some information loss during this process was inevitable.

Estimated volumes of five unconsolidated Quaternary features likely to host important aquifers constituted the second subsurface information source. A simple geomorphometrical method was applied, complemented in one formation the main alluvial fan aquifer (Nant) - by inferences from geophysics (see Supplementary Text S1). The formation identifiers of any elements whose centroids fell within one of the five unconsolidated feature volumes were overwritten with those of the respective Quaternary formation (this reassignment being necessary because all elements were initially assigned an identifier from the bedrock model, the bedrock model being "filled" to the surface). Beyond the extents of these major unconsolidated formations where bedrock did also not outcrop according to surficial geological maps, a generic "moraine"/cover layer with an assumed thickness of $2 \mathrm{~m}$ was defined to represent the thin

354 superficial hillslope cover present. 
The third information source is a very simple assumed soil depth map (Figure S5) that was prepared in the absence of any more detailed information on the spatial distribution of soil depths and their associated textural or hydraulic properties - the existing "official" spatially distributed soil data (OFAG, 1980) being dated and of questionable suitability. Soils were considered to form a single, homogenous zone, and the same "overwriting" process as previously was applied attribute the appropriate elements. Whilst volumetrically the soil zone is very small compared to the unconsolidated and consolidated geological formations, being situated at the surface, in such simulations (as in reality), it is likely to exert a disproportionately strong hydrological influence (via its influence on the partitioning of incident liquid water into runoff and infiltration).

In total, 24 distinct subsurface zones were defined. The main remaining structural uncertainties relate to the soil and unconsolidated aquifer volumes.

\subsubsection{Boundary conditions}

Given the complexity and importance of snow processes at the steep and rugged study site, the representation of snow dynamics required careful consideration. Currently, HGS offers only a simple temperature-index snow module, and moreover provides no capabilities for pre-processing meteorological station data. Therefore, forcing datasets that were previously generated externally (but specifically with a view to being used in this model) were applied (Thornton et al., under revison). For the snow component, a spatially distributed energy balance-based model was used to derive hourly snowmelt inputs at $25 \mathrm{~m}$ resolution. The model additionally accounted for gravitational snow redistribution from steep slopes was established and several uncertain parameters were optimized with respect to two complementary types of snow observations - snow extent maps derived from Landsat 8 imagery, and reconstructed snow water equivalent (SWE) time-series at two station locations. Commensurate datasets pertaining to glacier melt, rain falling on snow / ice free surfaces, and $E T_{\mathrm{p}}$ (using the Penman-Monteith method) datasets were also produced (Thornton et al., under revision).

These datasets were compiled to produce gridded representations of i) "all liquid water arriving at the land surface" (i.e. snowmelt, ice melt, firn melt, and rain), and ii) $E T_{\mathrm{p}}$ over the period 1 October 2014 to 30 September 2019 (and therefore partially coinciding with the in situ streamflow and groundwater level data. They were additionally aggregated to daily and monthly values, enabling to be applied flexibly as "rain" and "potential evapotranspiration" boundary conditions respectively across these frequencies.

To allow water to leave the domain, a "critical depth" boundary condition was applied to all surface boundary nodes. This condition forces the flow depth at these locations to be equal to the critical depth, i.e. the depth at which for a given discharge, specific energy is minimal (Froude number $=1$ ). The base and sides of the domain were treated as "no flow" boundaries (i.e. flow across these faces is assumed negligible).

\subsubsection{Initialization}

The initialization of catchment-scale integrated models can be time-consuming and challenging (Ajami et al., 2015). Beginning from a prescribed set of initial conditions, one must run the given model using either steady or recursive transient forcing data until a state of equilibrium (or "dynamic equilibrium", in transient cases) is attained. Traditional options for the initial conditions are a water table that is coincident with the surface (a so-called "wet start"), a completely dry domain (a "dry start"), or a water table configured to some shallow but arbitrary constant depth beneath the surface (e.g. 1-5 m; Seck et al., 2015). In HGS, an initial water table surface can also be generated as a function of elevation, which theoretically enables concepts such as the Topographic Wetness Index (TWI; Beven \& Kirkby, 1979) to be applied. However, the annual mean water table distribution here was expected to take a complex form, being influenced not only by topography but also by geology. For example, unsaturated zones beneath mountain ridges may be thick. As such, one of the aforementioned approaches would likely have resulted in very lengthy simulation times being required to approach (dynamic) equilibrium. 
A customized initial water table was therefore generated by interpolating, in $3 \mathrm{D}$, surface coordinates $(x, y, z)$ sampled along normally perennial steams, springs, and wetland locations (i.e. where the water table is at / near the surface). As the hydrological regime under consideration here is highly transient, the model (with the initial parameter estimates) was then initialized by applying the forcing data corresponding to the 2014/2015 hydrological year at monthly frequency recursively. When the simulated surface water hydrographs and groundwater levels at the various observation points ceased to demonstrate marked inter-annual trends, the process was considered complete.

\subsection{Calibration strategy and historical runs}

Many of the model's parameters are highly uncertain, at least at model elemental scales (if not more fundamentally), with those relating to the inaccessible mountain subsurface being essentially unknown. Some form of calibration was required. Whilst manual trial-and-error procedures are applied in the integrated modelling literature, this approach is unobjective and would regardless have been confounded here by the large number of parameters involved (which is itself a function of the complex geology and diverse land cover). An automated approach was therefore pursued.

Based on a combination of lithological descriptions (for the bedrock formations), relevant previous studies, and informed judgement, an initial parameterization scheme was devised. A subset of parameters numbering 46 in total were then identified as calibration targets (see Tables S1 to S3). The model was linked with PEST_HP (v17) (Doherty, 2020) - a code-independent, gradient-based parameter estimation tool that employs the Levenberg-Marquardt (L-M) algorithm to minimize an objective function (in a least-squares sense). As model outputs are generally non-linear with respect to varied parameter values, calibration is an iterative process. Being a gradient-based method, the L-M algorithm may converge to local minima. Nevertheless, its efficiency in terms of the total number of forward runs required is a critical quality when seeking to optimize such computationally intensive models. For every PEST model run (i.e. parameter set proposed), a "re-initialization period" beginning on 1 October 2014 (approximately 18 months before the first available observations) was simulated to try to equilibrate the system state to the new parameters. All available hourly (mean) streamflow measurements and half-hourly (instantaneous) groundwater level measurements from 9 April 2016 (i.e. the start of measurements at S2) until 31 October 2017 contributed to the objective function. As already highlighted, data coverage was not continuous throughout this period at all sites. Following a split-sample strategy, the remaining observations (i.e. those from November 2017 to September 2018 inclusive) were retained for independent evaluation.

The objective function (OF) developed is expressed in Eq. 1:

$$
\begin{aligned}
\text { OF }=\sum_{i=1}^{20409}\left[w G W L\left(G W L_{s i m}-G W L_{o b s}\right)^{2}\right] & +\sum_{i=1}^{13184}\left[w Q S_{2}\left(Q S_{2 s i m}-Q S_{2 o b s}\right)^{2}\right] \\
& +\sum_{i=1}^{60533}\left[w Q S_{1,3}\left(Q S_{1,3 \text { sim }}-Q S_{1,3 o b s}\right)^{2}\right]
\end{aligned}
$$

where $w G W L, w Q_{S 2}$, and $w Q_{S 1,3}$ are the relative weights that were assigned to each "observation group", i.e. the groundwater levels, the streamflows at $\mathrm{S} 2$, and the streamflows at $\mathrm{S} 1$ and $\mathrm{S} 3$, respectively. Here, $w G W L=0.38$, $w Q_{S 2}=5.50 \times 10^{-5}$, and $w Q_{S 1,3}=9.00 \times 10^{-5} . G W L_{s i m}$ and $G W L_{o b s}, Q S 2_{s i m}$ and $Q S 2_{o b s}$, and $Q_{S 1,3 s i m}$ and $Q_{S 1,3 o b s}$ are the corresponding simulated and observed values at N1-4, S2, and S1 and S3, respectively.

Given the contrasting number, magnitudes, and units of observations within the different groups, as well as the unknown degree of initial mismatch, the final observation weights could only be determined after running the model once with the initial parameters. This was done with PEST's PWTADJ1 utility. Normally, the goal would be to approximately equilibrate the contributions of the respective observation groups to the OF. However, whilst the 
streamflow measurements (being spatially integrated) and groundwater level measurements (being spatially explicit) can generally be considered complementary (Paniconi \& Putti, 2015), in complex unconsolidated settings such as those under consideration here, groundwater levels can be heavily influenced by extremely local phenomena. As such, it was realized that it would be essentially impossible for our model to reproduce the distinct groundwater responses that were observed within close proximity to one another without introducing sub-zone heterogeneity in material properties/parameters, which lay beyond the present scope. Therefore, to prevent the calibration process potentially magnifying this model deficiency, the groundwater levels were only assigned modest weights such that their combined contribution to the initial objective function was around $11 \%$. In other words, most emphasis was placed on streamflows, whilst each observation group maintained at least some "visibility" to the process.

As Ala-aho et al. (2017) also found, various model simplifications were found to be necessary to facilitate the automated calibration of the model. The first, that the re-initialization and calibration periods described above were relatively short, is not really a simplification, since the availability of the observational data and a desire to maintain an independent evaluation period dictated this. However, the feasibility of the calibration overall obviously increases as the length of the period that must be simulated iteratively (i.e. re-initialization plus calibration period) decreases. That said, given the pronounced seasonality of these catchments' hydrological regimes, it was considered crucial that the calibration period exceeded one year.

Runtimes were found to increase substantially with the temporal frequency at which the forcing data were applied. Therefore, in one major simplification, the calibration runs were undertaken using monthly frequency (but still distributed, $25 \mathrm{~m}$ ) forcing data. Perhaps slightly surprisingly, the simulated seasonal dynamics are not extremely sensitive to whether monthly or daily forcings are applied (Figures S13 and S14), which provides some justification for this strategy. In another simplification aimed at reducing runtimes, the unsaturated zone (pressure head-saturation, and saturation-relative hydraulic conductivity) relationships for all subsurface zones, except the soil, were represented as tabular data with a small number of data points and made less non-linear. The poorly understood nature of these relationships in consolidated, potentially fractured, and/or karstified bedrock justifies this. For the soil, the van Genuchten parameters (van Genuchten, 1980) listed in Table 1 were applied. The slope term in the surface water flow equations was assumed equal to the topographic slope, and thereby also linearized, and the HGS model's convergence criteria were relaxed for calibration (Newton absolute $=1 \times 10^{-3} \mathrm{~m}$, Newton residual $=500 \mathrm{~m}$ ) before being re-tightened for the subsequent runs with optimized parameters (Newton absolute $=1 \times 10^{-3} \mathrm{~m}$, Newton residual $=150 \mathrm{~m}$ ). The latter settings led to a mean mass balance error, expressed as a percentage of liquid water input, of $\lesssim 5 \%$. Finally, the "coupling length" parameter for all surface zones except the streambed was set to a somewhat higher (and fixed) value $(0.1 \mathrm{~m})$ than ordinarily; values closer to zero are generally recommended to approximate the Continuity of Pressure (COP) approach, but typically increase runtimes (Liggett et al., 2012). Sensitivity tests revealed that model outputs of interest were not substantially affected by this choice. To mimic the enhanced surface-subsurface disconnection that the fine layer of silty streambed sediments that was often observed in the field could induce, the streambed zone coupling length was fixed to the higher value of $1.0 \mathrm{~m}$.

The calibration runs were carried out on a Windows machine (Intel(R) Xeon(R) CPU E-2699 v4 @ 2.20 GHz, 64.0 GB RAM, 44 cores with 12 agents running in parallel, i.e. not using the entire resource). Each instance of HGS was also distributed across two cores. As a result of the process, the OF was reduced to 0.60 of its original value (although the degree of reduction obtained depends on the initial values selected). The optimized model was then run in two different configurations: i) for the full four-year simulation period with daily frequency forcing, and ii) for the final two-year period with hourly frequency forcing. The latter enabled the impact of forcing frequency on the simulated hydrological responses to be further investigated. 
Next, a series of sensitivity experiments were undertaken to assess the impacts that making various structural simplifications - some of them common in the existing mountainous integrated modelling literature (e.g. due to lack of data, or perhaps to reduce runtimes) - might have on key model predictions of interest in such terrain. To achieve this, streamflow and groundwater level outputs generated in these experiments are considered with respect to those generated by the "full complexity" model described above. The key characteristics of each configuration are listed below.

Scenario A. Subsurface entirely impermeable, no ET: This extremely simple scenario assumes that the subsurface is entirely impermeable (i.e. no infiltration or groundwater processes can occur), and that no water is returned to the atmosphere via $E T$. As such, all incident liquid water at the land surface (i.e. rainfall + snowmelt + ice melt) directly flows freely over the surface according to the discretized topography and surface parameters.

Scenario B. Limited $(30 \mathrm{~m})$ vertical extent: This scenario involves running the full integrated surface-subsurface model (with $E T$ ) but limiting the vertical extent (or watershed "thickness") to a uniform $30 \mathrm{~m}$ below the surface. As explained in the Introduction, such a setup is presently fairly common (e.g. Foster \& Maxwell, 2019), although the impacts on simulated hydrological dynamics remain unclear (Condon et al., 2020).

Scenario C. Spatially uniform forcing: Catchment-scale integrated models are sometimes forced with spatiallyuniform (i.e. catchment-averaged) meteorological boundary conditions (e.g. Ala-aho et al., 2017). This could be because distributed meteorological/snowmelt data are unavailable, in which case measurements made at a single meteorological station within or near a given study catchment may be considered representative of conditions across it. Alternatively, a given catchment may only correspond to a single downscaled pixel of reanalysis products (which must often be relied up in the absence of in situ data) or climate model projections. Clearly, in very small and/or fairly flat catchments, these approaches are likely to work well. In larger and more topographically complex mountain headwaters catchments such as those under consideration here, it could be instructive to elucidate the impacts of such an assumption. Thus, for this scenario, the distributed ( $25 \mathrm{~m}$ resolution) forcing datasets at daily frequency used to being applied.

Scenario D. No permafrost: Finally, a "no permafrost" simulation was undertaken in which the coupling length parameter in permafrost areas was set back from $50 \mathrm{~m}$ to the value of $0.1 \mathrm{~m}$ assigned elsewhere.

Each of these simplified models were derived from the calibrated "full complexity" version and forced with daily frequency data. As such, comparing these outputs with those presented in Section 3.1.1 is apposite.

\section{3. Results}

522 3.1. Full complexity integrated model

\subsubsection{Daily frequency forcing}

524 Streamflow and groundwater level time-series simulated by the calibrated, "full complexity" integrated model using observations in Figures 3 and 4. 

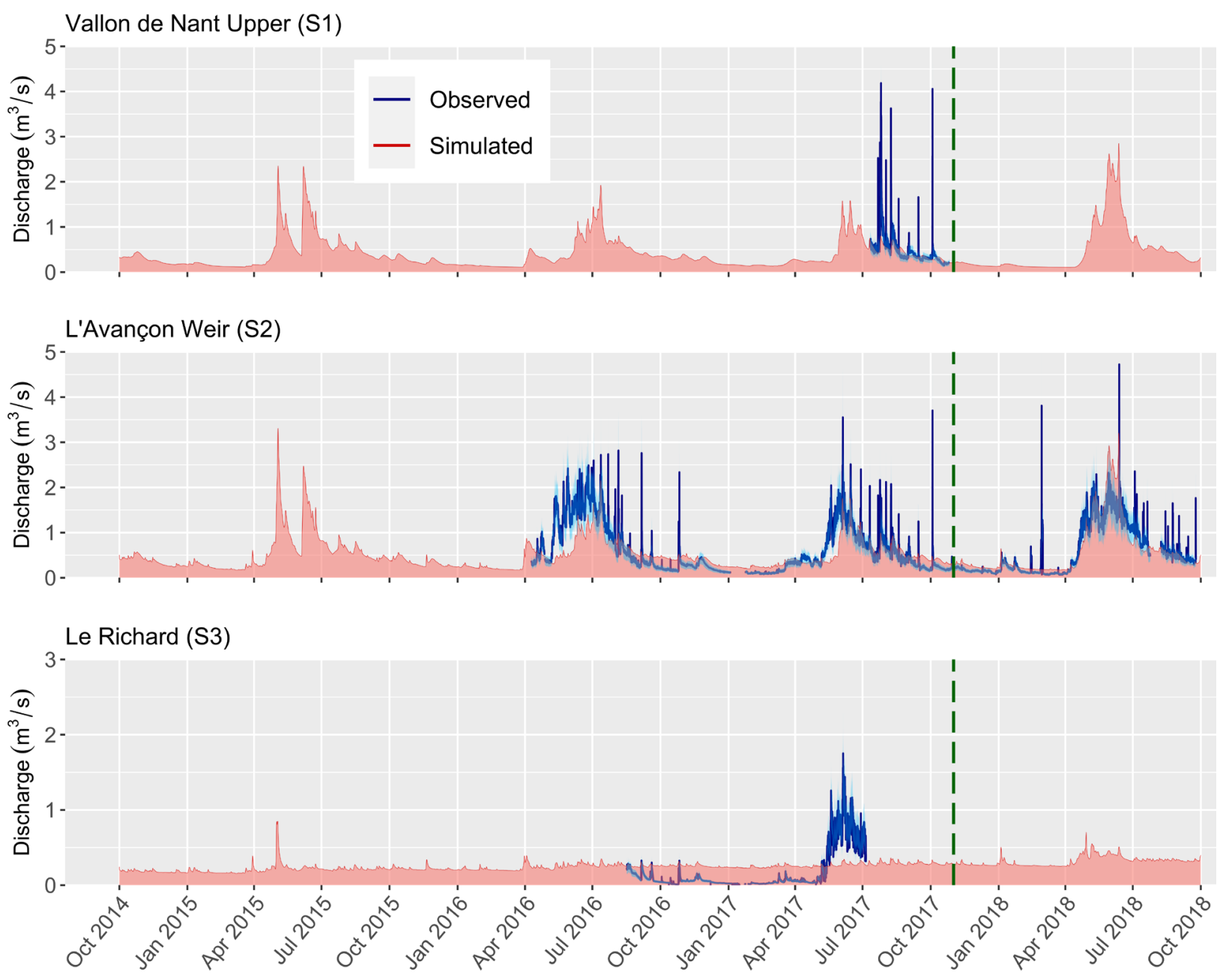

Figure 3. Streamflows simulated by the fully-integrated model using daily frequency, $25 \mathrm{~m}$ resolution forcing data at the three gauging station locations vs. observations over the period 1 October 2014 - 1 October 2018. The dashed green line distinguishes the calibration (left) and evaluation (right) periods. Note: the observed data in this figure retain their original, hourly frequency. Estimated uncertainty in the observed streamflow data is represented by a shaded region (light blue) corresponding to $\sim \pm 30 \%$.

The seasonality of streamflow is reproduced reasonably well at S1 and S2. Because daily frequency forcing data were applied, it is not necessarily unexpected that the sharp observed peaks could not be reproduced (these having been plotted at their underlying frequency). At S2, which has the most extensive observed record, the general annual water balance seems to have been well captured, though the onset of high spring flows is delayed in the model with respect to observations in 2016 and, to a lesser extent, 2017. S2 baseflow also seems slightly overestimated, though uncertainty in baseflow observations is also a consideration. At S1, the higher station in the Vallon de Nant, any such underestimation is much less evident (if present at all), at least based on the reduced observations here. For the main snowmelt-spring driven peak, the fit achieved at S2 over the independent evaluation period (i.e. November 2017 September 2018 inclusive; to the right of the green dashed line) is very good, even if the preceding baseflows remain marginally overestimated. The simulation at $\mathrm{S} 3$ is poor, bearing little resemblance to the observations. The simulated series is too constant in comparison to the more dynamic (if short) observational record. Interestingly, the seemingly rapid observed streamflow response at S3 occurs despite the bedrock formations in Vallon de La Vare being considered relatively permeable. 

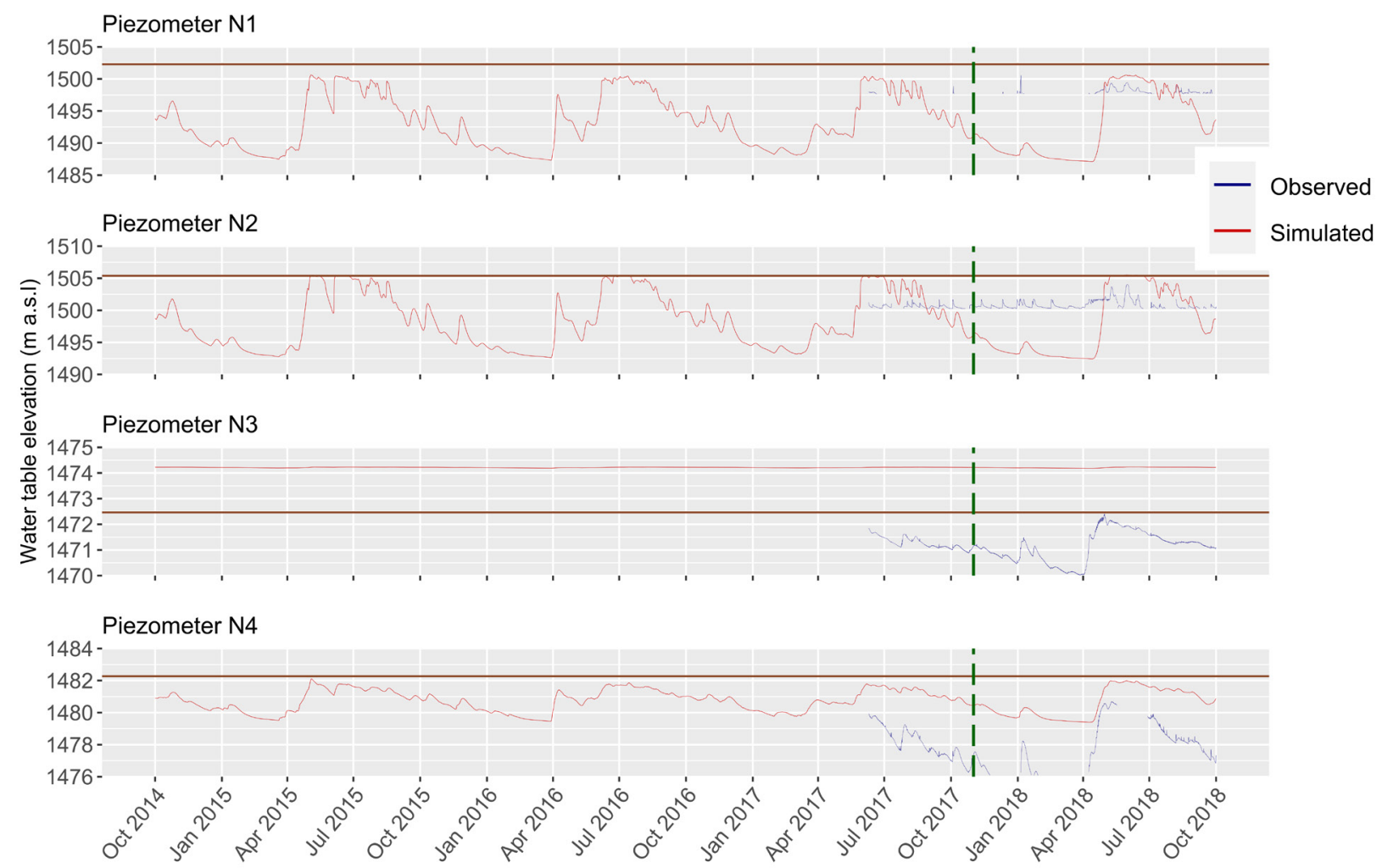

Figure 4. Groundwater levels simulated by the fully-integrated model using daily frequency, $25 \mathrm{~m}$ resolution forcing data at the four piezometer locations vs. observations over the period 1 October $2014-1$ October 2018. The horizontal brown line corresponds to the surface elevation. The dashed green line distinguishes the calibration (left) and evaluation (right) periods. Note: the observations in this figure retain their original, half-hourly frequency.

Figure 4, which shows groundwater levels, again reveals a strong seasonal signal in the simulations comprised of a peak associated with snowmelt followed by a more gradual decline. In this sense, the observed trends at N4, which could perhaps be considered the most representative site, if not the precise levels themselves, are generally well captured. Again, whilst rainfall-related peaks are superimposed upon the recession in the observations (at N4 in particular), one would not necessarily expect these to be reproduced at this stage (i.e. using the daily forcing frequency).

These plots show clearly the point raised in Section 2.3; that although the groundwater observation sites are situated fairly close to one another within a very small part of the entire domain, the exhibit quite contrasting dynamics. In contrast, with the exception of N3, the simulated dynamics are more similar between sites. The simulations at the higher elevation sites, N1 and N2, demonstrate slightly more variability. The distinctive signals at N2, and to a lesser extent, N1, could not be well reproduced. That said, the pairwise plot presented in Figure S7 suggests that overall water table elevations across the alluvial fan zone are reasonably well approximated.

One key benefit of comprehensive integrated models is that comparisons and diagnostics are not limited to time-series or scatterplots at observation points. Rather, spatio-temporal patterns in forcing data and numerous simulated internal state variables responses (pertaining to the surface, subsurface, and evapotranspiration "domains") can be visualized and/or extracted arbitrarily. This capability conveys the powerful capabilities of such a simulation approach, and enables the coherency of the numerical representation to be assessed intuitively. It moreover provides considerable scope for a variety of datasets with complementary characteristics (e.g. spatially distributed vs. integrated, quantitative vs. "soft) to be introduced into their calibration and/or evaluation. Here, three examples are provided that illustrate some of these possibilities. 
577 A thermal image of the central part of the Vallon de Nant captured using a drone early on 7 December 2016 is

578 considered first. No precipitation had fallen in the preceding 10 days, and - unusually for the time of year - the ground

579 remained snow free. As such, all water in the channel could be confidently (and exclusively) identified as emergent

580 groundwater. Because groundwater is several degrees warmer than the dry land surface under these circumstances

581 (i.e. early morning in winter), the region of groundwater exfiltration from the streambed into the channel can be clearly

582 identified (Figure 5a). A direct comparison can thus be made with i) the simulated spatial pattern exchange flux, and

583 ii) the simulated spatial pattern of surface water presence in the same area on the same date (Figures $5 \mathrm{~b}$ and c). One

584 observes that groundwater emerges approximately the same location in the model as in reality. Moreover, surface

585 water is present from this point downstream in the simulation, which is again consistent with the data (since the

586 discrete "warm" region continues downstream in the thermal image).

Secondly, Movie S1 (see Supporting Information) shows the spatio-temporal variability of the model's meteorological 589 boundary conditions (i.e. "all liquid water" and potential evapotranspiration) alongside the simulated response of two 590 important variables - surface water depth and actual evapotranspiration $\left(E T_{\mathrm{a}}\right)$ - over the hydrological year 2017/2018. 591 During the first period, dynamics are subdued as the catchment gradually drains. As snowmelt onset occurs at 592 progressively higher locations, the surface water network begins to expand. A strong elevation (i.e. temperature) effect 593 is visible in both prescribed $E T_{\mathrm{p}}$ and simulated $E T_{\mathrm{a}}$. Some surface water bodies do still form in areas of the Vallon de 594 Le Vare, including at the location of a high elevation lake/wetland $(578653,123594)$.

Finally, Movie S2 shows the interplay between simulated saturation, both at the surface and (using slices) at depth and the simulated surface water level response at S2. Throughout the snowmelt period, the near-surface saturation levels gradually increase, followed by the arrival of the annual peak in simulated water level. This animation also clearly shows that the water table is generally lower in the Vallon de La Vare than the Vallon de Nant, and so this

600 could provide an indication of an aspect to focus on in future to improve the time-series fit at S3. Lastly, the shallow 601 simulated (and indeed observed) surface water depths at S2 highlight that even under the present climate, this system 602 - presumably like many other small Alpine headwaters - lies fairly close to the "wet-dry limit". 


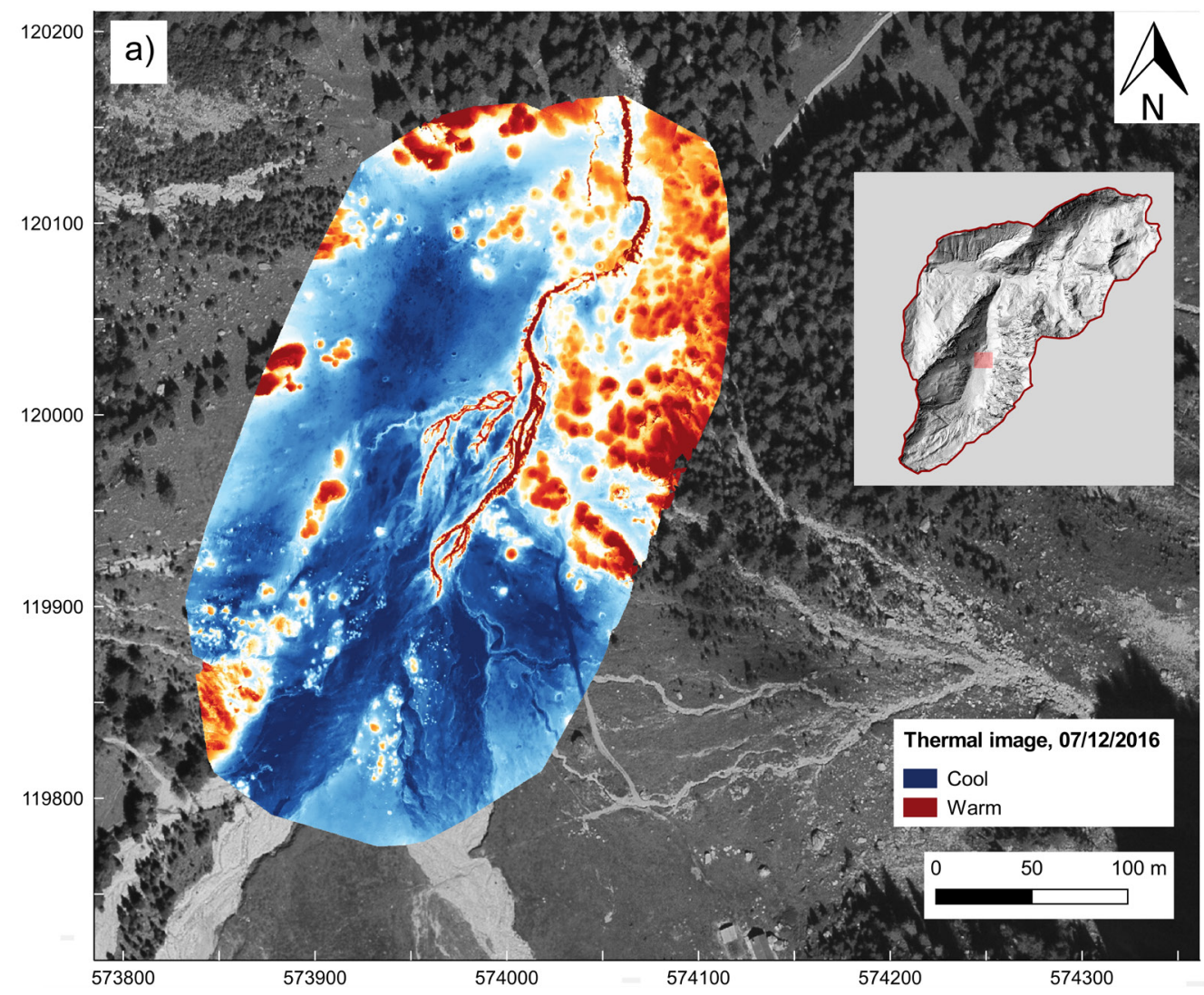

b)

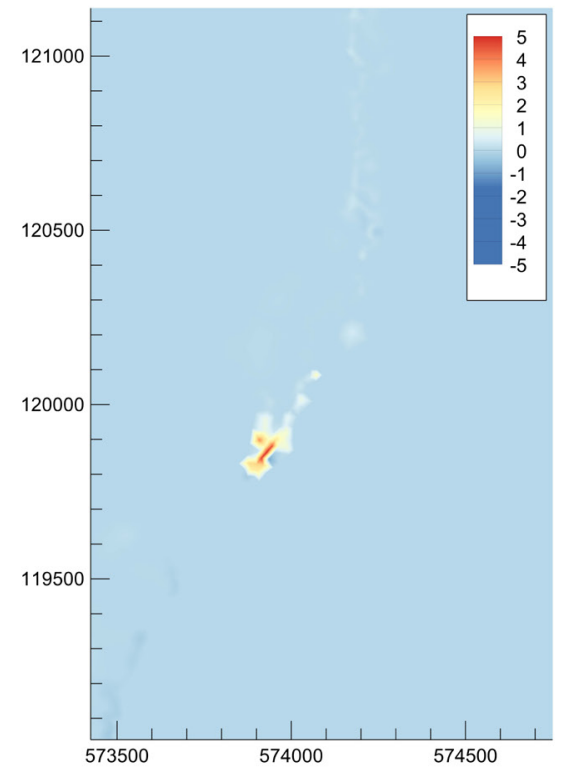

c)

Log depth

(m)
Figure 5. Spatial pattern of: a) Relative surface temperature in the distal part of the Nant alluvial fan on 7 December 2016 from which "observed" subsurface-surface exchange flux and surface water presence were inferred. Note that the stream appears warmer than the surroundings. Red circular patterns correspond to trees that appear warmer because of solar illumination at this moment. b) Subsurface-surface exchange flux simulated by the model (positive values correspond to surface water exfiltration, and c) Simulated surface water presence, indicated by the simulated surface water depth (both on the same date). Note that the footprint of map a) is different to that of b) and c). 


\subsubsection{Hourly frequency forcing}

611 Figure 6 presents streamflow and groundwater level results simulated by the calibrated integrated model forced with 612 hourly frequency data over the period of 1 October $2016-1$ October 2018 at S2 and N4, respectively. Figure 7, 613 meanwhile, focuses more closely on streamflow at S1 and S2 over the shorter period of spring and summer 2018. The 614 generally good streamflow correspondence obtained with the daily forcing data is maintained with hourly forcing data. 615 Indeed, with the hourly data, a Nash-Sutcliffe Efficiency (NSE) coefficient of 0.73 was attained over the independent 616 evaluation period, denoting good performance. Sharp flow peaks associated with convective thunderstorms are 617 represented slightly better than in the daily case (in which the quantities are distributed evenly over 24-hour periods).

618 That said, they are still generally insufficiently accentuated compared with the observations. Figure 7 also illustrates 619 that at this forcing frequency, diurnal variations in both streamflow and groundwater levels associated with spring 620
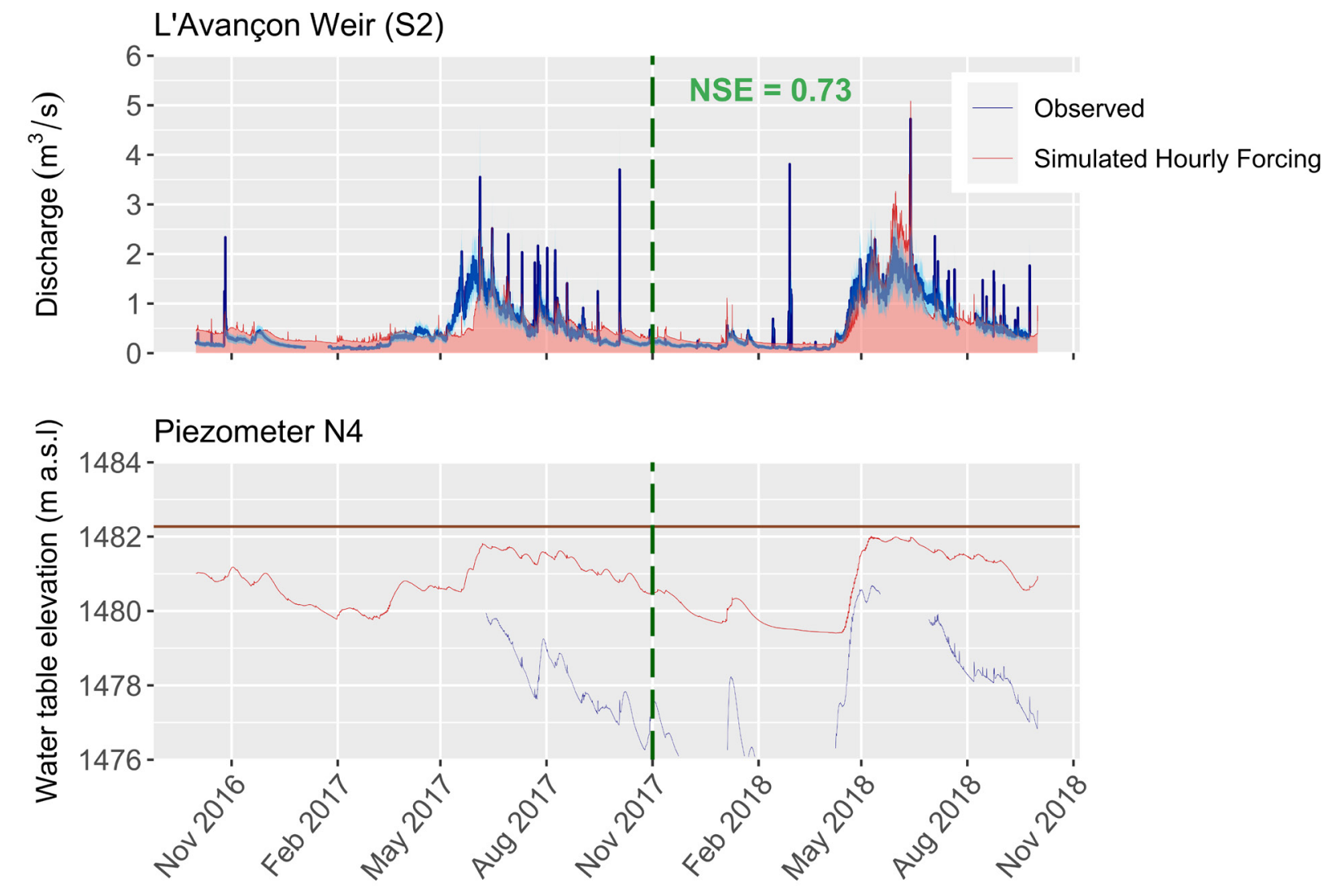

Figure 6. Streamflow and groundwater levels simulated by the fully-integrated model using hourly frequency, $25 \mathrm{~m}$ resolution forcing at S2 and N4, respectively, vs. observations over the period 1 October 2016 - 1 October 2018. Note that the observations retain their original frequency. Again, estimated uncertainty in the observed streamflow data is represented by a shaded region (light blue) corresponding to $\sim \pm 30 \%$, and the dashed green lines separate the calibration and evaluation periods. 

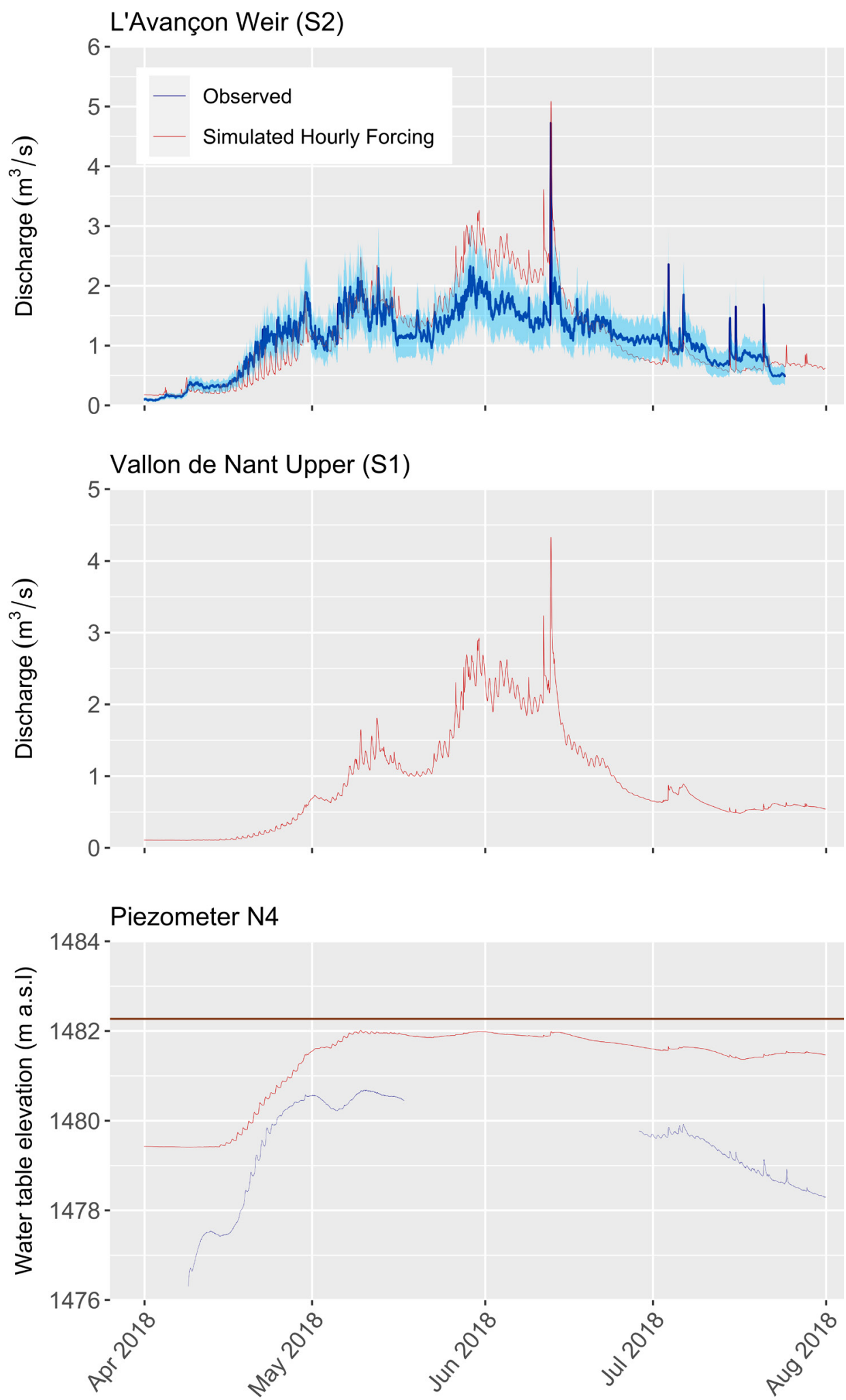

Figure 7. Streamflow and groundwater levels simulated by the fully-integrated model using hourly frequency forcing at S2, S1, and N4, respectively, vs. observations over the period 1 October 2016 - 1 October 2018. Note that the observations retain their original frequency. Estimated uncertainty in the observed streamflow data is represented by a shaded region (light blue) corresponding to $\sim \pm 30 \%$. 


\subsubsection{Scenario A: Impermeable matrix, no evapotranspiration (daily forcing)}

Figure 8 presents streamflows simulated under the "impermeable matrix" assumption (with $E T$ also deactivated), using daily frequency forcing. The correspondence between the simulated and observed peaks - both in terms of timing and general flow magnitudes - is good, which provides further reassurance that the previously generated gridded liquid water inputs (Thornton et al., under revision) are reasonable. Of course, under this assumption, there is under/overestimation with respect to the observations, but the temporal pattern in these deviations agree well with expectations. Overall, a degree of "overestimation" these simulated streamflows relative to observations does seem apparent, especially at S3. Unsurprisingly, the spatial outputs (not shown) revealed that with this configuration, a
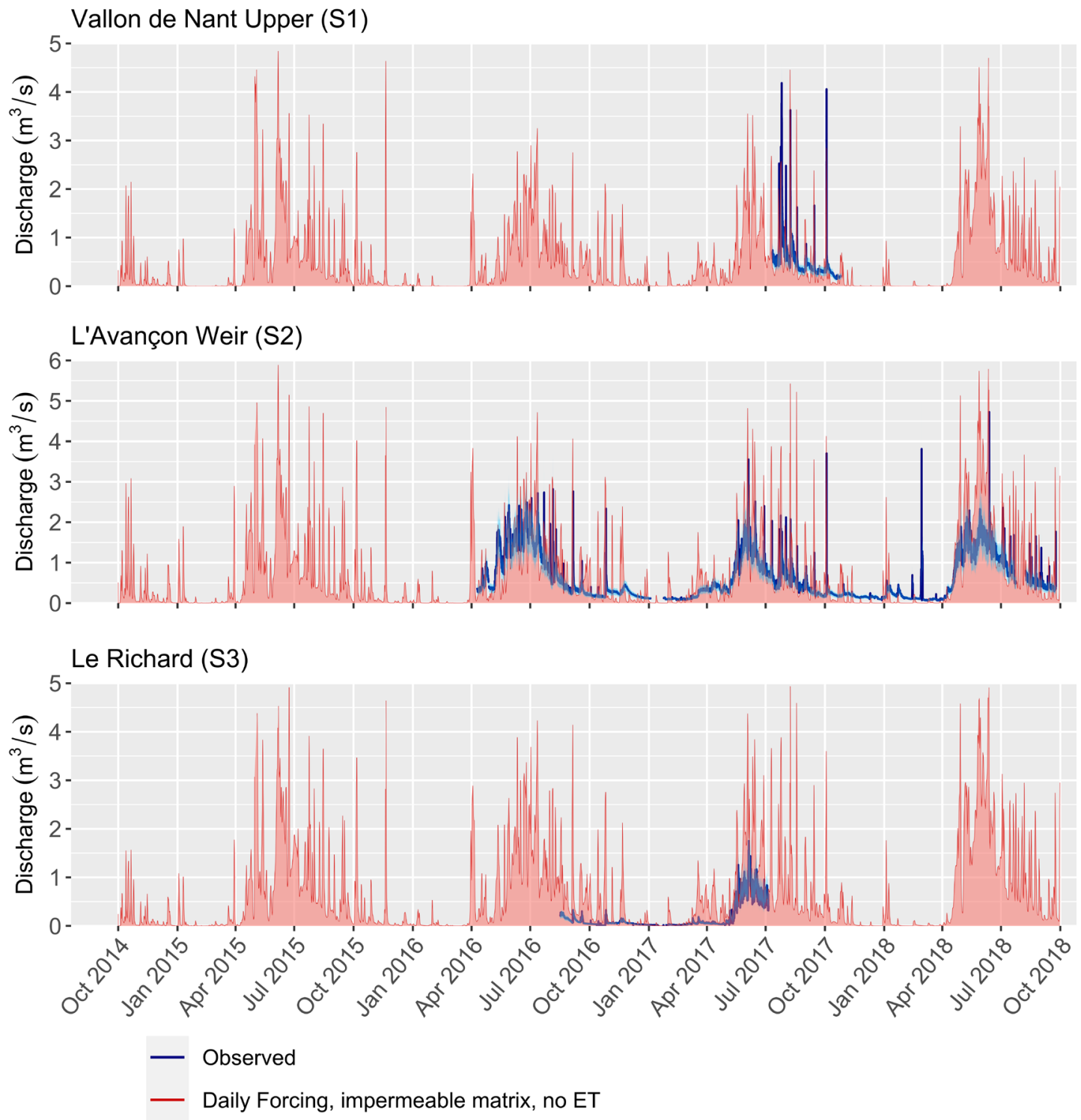

Figure 8. Simulated streamflow at each of the three gauging stations over the four-year historical period under an "impermeable matrix", i.e. "surface only" assumption, with subsurface flow and evapotranspiration $(E T)$ deactivated. In this case, the forcing data were applied at daily frequency. Estimated uncertainty in the observed data is represented by a shaded region (light blue) corresponding to $\sim \pm 30 \%$. 


\subsubsection{Scenario B: Limited $(30 \mathrm{~m})$ vertical extent}

652

653

654

655

656

In Figures 9 and 10, the effect of limiting the vertical extent upon predictions of streamflow and groundwater levels, respectively, is illustrated. Under this assumption, peak flows are accentuated appreciably while baseflows are reduced compared with the baseline simulation with full vertical extent (i.e. the regime becomes "flashier"). Annual peak groundwater levels are hardly affected, but recession rates are noticeably more rapid and annual minima are lower.
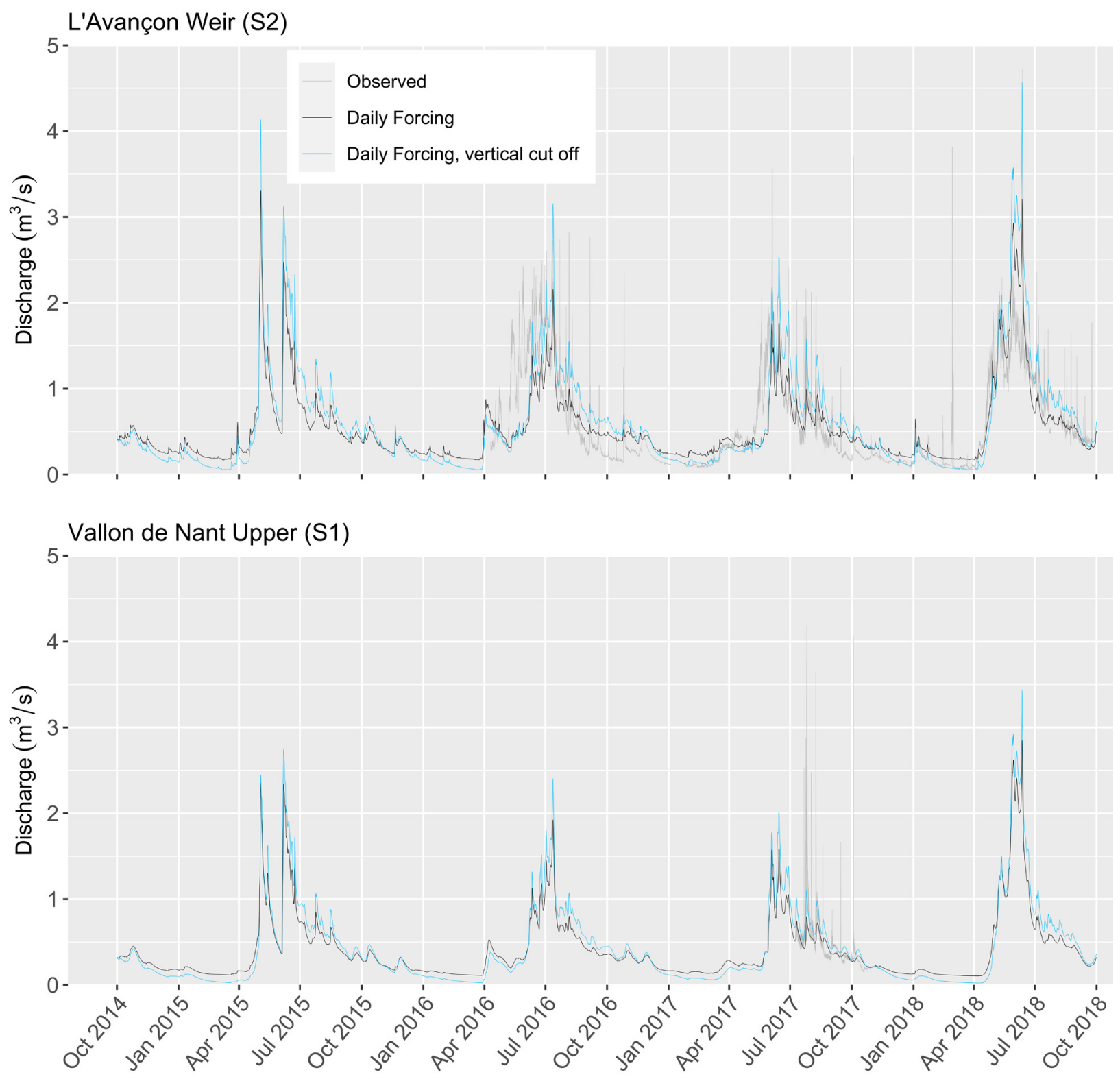

Figure 9. Streamflows simulated with a version of the fully integrated model whose depth (i.e. vertical extent) is 


\section{Piezometer N1}

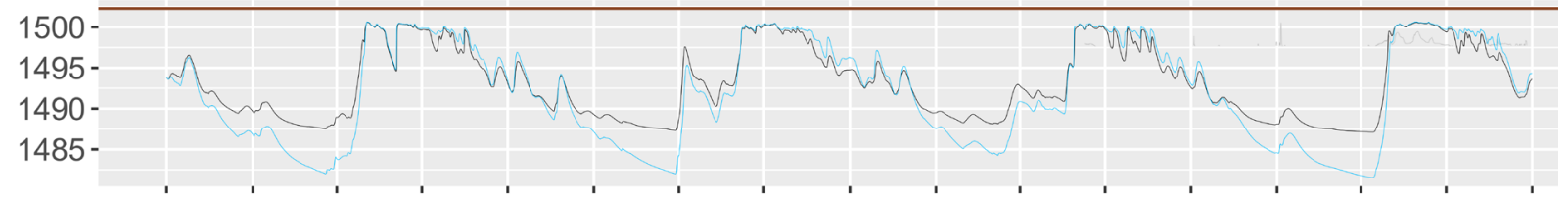

\section{Piezometer N2}

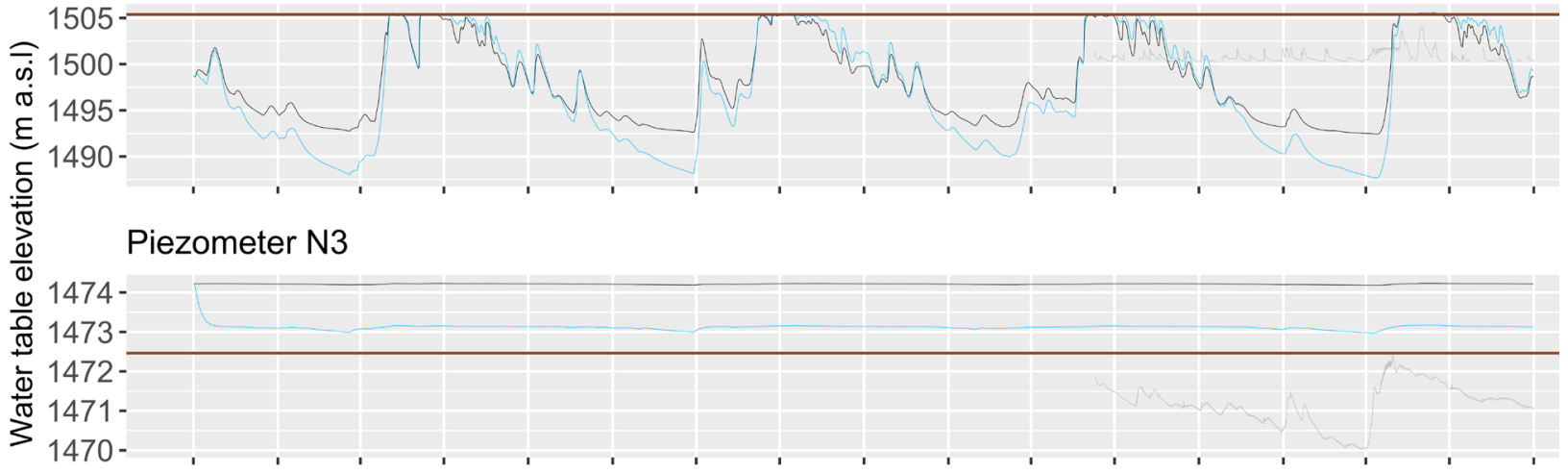

\section{Piezometer N4}

663

664

665

666

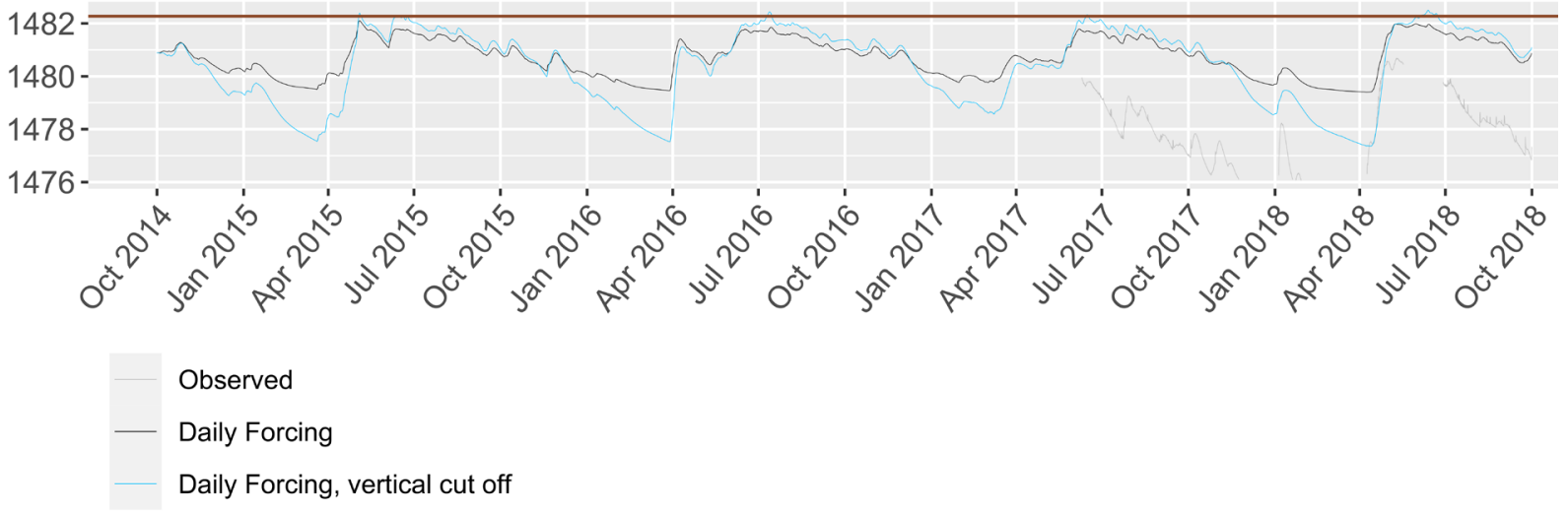

Figure 10. Groundwater levels simulated with a version of the fully integrated model whose depth (i.e. vertical extent) is limited to a uniform $30 \mathrm{~m}$ beneath the surface (elements beneath this were deactivated, which is akin to applying a "no flow" boundary condition). In this case, daily frequency, $25 \mathrm{~m}$ resolution forcing data were applied. 


\subsubsection{Scenario C: Spatially-uniform forcing}

668

669

670

671

672

Figure 11 shows the effect of applying spatially uniform forcing data in the Vallon de Nant sub-catchment. This produces noticeably lower spring peaks, especially at the higher site (S1). The effect of applying spatially uniform catchment-averaged forcing on groundwater levels (not shown) was found to be more modest and less variable over the annual cycle.
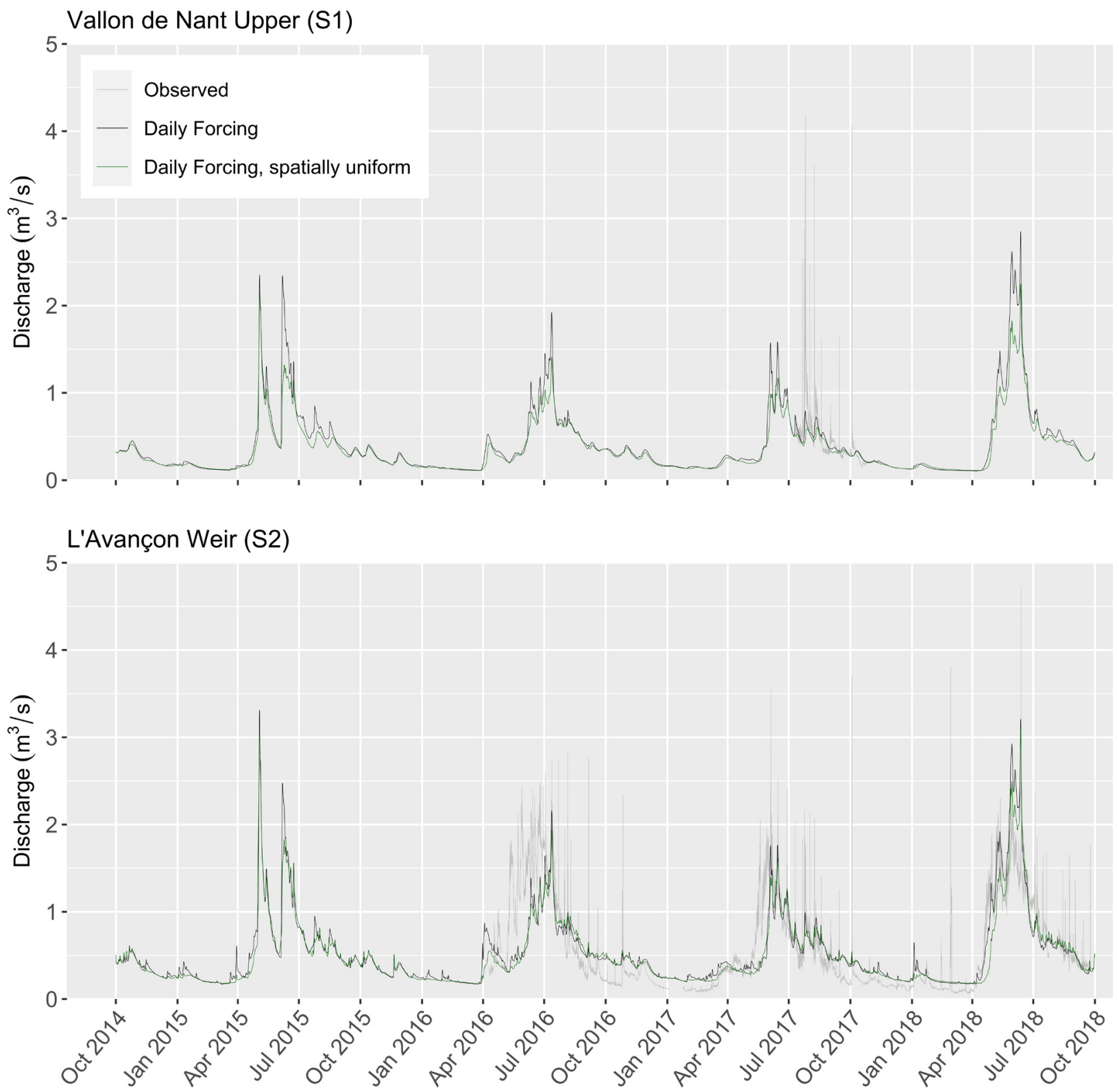

Figure 11. Comparisons between simulated streamflows generated using $25 \mathrm{~m}$ resolution spatially distributed forcing data and those generated using spatially-uniform (i.e. catchment-averaged) data. In both cases, the forcing data had daily frequency.

\subsubsection{Scenario D: No permafrost}

For the final simplification - "no permafrost" - no discernible differences between the streamflows and groundwater levels simulated at the various observation points by the full complexity model were apparent. As such, no plots are 
682 presented here. An additional "end member" test (also not shown) in which the coupling length parameter was set to $50 \mathrm{~m}$ across the entire catchment revealed only relatively minor differences with the main model results.

\section{Discussion}

685 4.1. General utility and reproduction of historical time-series using the full complexity model

686 None of the main phases involved - that is, obtaining the extensive data necessary to build this particular model, ensuring that it ran smoothly in acceptable timeframes, and then calibrating it such that the available observations could be reproduced with some skill, were straightforward. Mendoza et al. (2015) highlight that the levels of data fit attainable with such complex, physically-based models are often lower than those possible with simpler, more datadriven alternatives. As such, it is satisfying that the general dynamics of observed streamflow could be reproduced with daily forcing at S1 and S2 (Figure 3). The improved correspondence between observations and simulations over the independent evaluation period compared with the calibration period may seem slightly counterintuitive, but perhaps the forcing data were better estimated over the evaluation period (in Thornton et al., under revision; e.g. due to more complete/local input data being available). Provided it is not an artefact associated with an observational bias, another interesting feature of Figure 3 - that baseflows appear to be overestimated more at S2 than S1 - may enable potential deficiencies in the model to be attributed spatially, i.e. it could indicate a slight issue in the geometries and/or parameterizations of those zones (surface or subsurface) that only influence flow downstream of S1.

The poor fit at S3 is likely due to the extreme geological complexity of this sub-catchment, on which data remains lacking, being insufficiently represented in the model. In reality, the high, topographically closed basin of La Varre, which is naturally dammed to a height of around $20 \mathrm{~m}$, clearly does drain through the subsurface as no lake is present in the depression; there is merely a wetland at coordinates $(576859,123516)$. It may be that in the initial parameterization, the unduly high effective hydraulic conductivities that were favored here in order to prevent a deep lake forming in the simulation, inducing a water table across the entire Vallon de La Vare sub-catchment that was unduly low. In turn, this may have enabled too much infiltration and recharge, at the expense of more rapid surface and shallow subsurface runoff, resulting in the overly constant simulated streamflow signal. In fact, La Varre may drain via a discrete fracture that bypasses several otherwise impermeable formation and potentially also gauging station S3 (Lugeon \& Gagnebin, 1928). A "duality" in the hydrological functioning of this valley could therefore be posited, whereby snowmelt generated and rainfall incident in the upper part drain directly into the subsurface or else arrive at La Varre via surface torrents, whence they disappear into the subsurface. Some of this water may ultimately arrive in Le Richard (S3) via slow pathways, although the proportion (if any) is unknown. Meanwhile, based on the fairly flashy observed streamflow at S3, snowmelt and rainfall falling in the lower part would seem to be transmitted much more rapidly (e.g. via surface torrents). Essentially, in its current configuration, it seems that both aspects (i.e. no deep lake and a flashy streamflow response) cannot be captured in a single simulation. Superimposing discrete conduits / fractures on the porous media domain may be necessary to address any discrete subsurface flows in karstic condutis, and whilst this is theoretically possible in HGS, obtaining the information necessary to locate and parameterize these features in remote Alpine settings would be difficult.

Essentially, given the post calibration results at S3, it would appear that the inversion algorithm used in the calibration and/or its practical implementation are incapable of "overcoming" any deficiencies associated with the model structure or initial parameterization prescribed in the Vallon de La Vare portion of the domain. If the model could have been made to run more quickly, (e.g. by developing a more efficient mesh or by some other means), it could have could have been possible to calibrate the model using daily or even hourly frequency forcing data instead of monthly, which would have been more satisfactory. It is also possible that the solution to the inverse problem (i.e. the calibration) reaches a local minimum, and/or that the bounds imposed on the effective parameter values of subsurface formations in the Vallon de La Vare region were too tight. Finally, it is conceivable that even if improved parameter values were proposed by PEST (i.e. those which would ordinarily produce to a more rapid streamflow response and hence a better 
match at S3), the 18-month re-initialization period that was simulated prior to each calibration run may not have been long enough for the internal storages to re-equilibrate with the adjusted parameters. Ideally, a lengthier re-initialization period would have followed every change in parameter values, with this strictly continuing until a (close to) perfect "dynamic steady state" was re-established. However, due to the model's runtimes (which also depend on the parameter values), such an approach would have precluded automated calibration altogether and was therefore impractical here. Interestingly, the interplay between initial conditions, parameter updates, and re-equilibration within automated optimization frameworks have received very little attention in the integrated modelling literature to date, and should be investigated more thoroughly.

Regarding the groundwater levels (Figure 4), it is satisfying that the simulated dynamics at N4 generally correspond with the observations well, even if the simulated level is slightly high. This is because, being the nearest site to the main gravelly part of the alluvial fan, $\mathrm{N} 4$ can perhaps be considered to provide the most spatially representative data of all four piezometers. Besides the general points related to the calibration discussed above, one main reason can be proposed as to why model performance is generally fairly limited with respect to groundwater levels; namely the influence of local-scale heterogeneity in hydraulic properties. Specifically, whilst all the piezometers are located fairly close to one another (and are moreover in only a tiny part of the entire domain), the observed signals at each are rather distinctive. The flashy response of groundwater at N2, for instance, is understood to be an effect of it being in a former stream channel, with a relatively impermeable underlying clay-rich layer perhaps responsible for the remarkably constant lower level. Crucially, since all these sites are situated within a single model zone (the "Nant" alluvial fan system) to which homogenous material properties were assigned, it is unsurprising that the contrasting responses observed at each could not be reproduced. Indeed, the groundwater level data (which were relatively few to start with) were deliberately de-weighted in the calibration to prevent this structural deficiency being compensated for at the expense of the coherence of the broader numerical representation. To improve these fits, one would have to introduce sub-zone heterogeneity, but this may not greatly alter the simulation of catchment-scale dynamics. That said, it may be achievable, for instance, by employing the Iterative Ensemble Smoother (IES) approach of White (2018), which theoretically enables a very large number of parameters to be estimated (e.g. hydraulic conductivity per element) with relatively few model runs.

Figures 6 and 7, meanwhile, demonstrate that applying forcing data with extremely high (hourly) temporal resolution, which is rarely done with HGS, brings some benefits in terms of reproducing diurnal fluctuations and sharp streamflow peaks. At first glance, one could hypothesize that the slight residual underestimation of some peaks could be associated with the localized convective events which drive them may have been "missed" by the gauge network from which the forcing datasets were generated, or that some of the many small, steep torrents which transmit snowmelt and rainfall extremely efficiently to larger channels are not represented explicitly enough in the mesh (cf. Ala-aho et al., 2017). However, the fact that streamflow peaks are reproduced well under the "impermeable matrix" assumption (Figure 8) suggests that neither explanation is likely. This provides an example of the insight that simpler model versions can provide. Rather, it is perhaps more likely that the surface and near-surface permeability may generally remain too high (leading to insufficient overland flow generation) and/or interception and evaporative losses being overly pronounced. Whatever the reason, Movie S1 suggests that small torrents do not appear to form extensively enough in the model compared with field experience compared to reality (field observations) - at least with the daily forcing frequency used here. Unfortunately, the monthly forcing data used for calibration did not contain information on these highfrequency dynamics, preventing parameters being adjusted to give better peak matches. Resolving the topography of small torrents in even more detail also could have helped, but under the established meshing approach would have resulted in an even larger mesh and hence even longer runtimes. Nevertheless, as it was, parameters from all three "domains" could be calibrated and initial the multi-component OF specified was reduced somewhat, indicating modest success.

Lastly, the shallow simulated water depths shown in Movie S2 at the gauging station S2 (and indeed the corresponding observations) reveal that for much of the year in question, and presumably other years also, the stream network lies 
close to the "wet-dry limit" even under present climatic conditions, and may therefore be highly sensitive to future change. Reproducing this "borderline" using such a numerical model is arguably much more difficult than replicating more voluminous flows along larger rivers.

\subsection{Insights from systematically simplified models}

Only by initially developing complex models as baselines, as we do here, can one assess the impact of subsequent simplifications and conduct sensitivity analyses (see also Rapp et al., 2020; Schreiner-McGraw \& Ajami, 2020). In Scenario A (Figure 8), the temporal pattern under/overestimation with respect to the observations align well with expectations; with infiltration and subsurface storage and discharge precluded here, the simulated spring and summer rainfall peaks are higher than their observed counterparts, whilst baseflows later in the year (which are clearly sustained by groundwater discharge in reality) are underestimated.

The certain degree of overestimation in the simulated streamflows evident at S1 and S2 with respect to the observations is expected, since in reality (and also in the fully-integrated version of the model presented already), a certain proportion of incident precipitation will be returned to the atmosphere via $E T_{\mathrm{a}}$ and hence never becomes streamflow, but this is not accounted for in this simulation. In fact, the results at the highest gauging station, S1, are particularly interesting. They definitively demonstrate that even ignoring any evapotranspirative losses, were it not for the sustaining influence of groundwater discharge, streamflow would frequently become negligible in summers/autumns following snow-poor winters such as 2016/2017. As such, they confirm the insight into the importance of groundwater discharge to baseflow that Figure 5(a) revealed.

That streamflows are most overestimated at S3 under this configuration is likely related to the bedrock geology in the Vallon de La Vare, which - as explained above and by Thornton et al. (2018) - is understood to be eminently permeable, unlike the substrate of the Vallon de Nant. Indeed, almost a century ago now, Lugeon and Gagnebin (1928) proved a hydrogeological connection between the topographically closed basin of La Varre and La Chambrette - a spring which joins the main channel below S3 - meaning that some water must bypass the station entirely. Hence, whilst in reality subsurface flow paths (in the upper part especially) should be longer and deeper, when all water is forced to flow overland (as in this scenario), streamflows are significantly overestimated.

The findings presented in Figures 9 and 10 (Scenario B) also make good conceptual sense; the imposition of a "no flow" boundary at $30 \mathrm{~m}$ depth forces the water table to be higher and enhances runoff generation during periods of snowmelt and intense rainfall. Due to reduced overall subsurface storage volumes, recessions are more pronounced and minimum levels are lower than the baseline case. As it is quite common for vertical domain extents to be limited when applying computationally intensive integrated hydrological models to real mountainous catchments, this sensitivity represents an important finding. In some previous studies, manual calibration may have compensated for this effect, which could partially undermine their subsequent predictions. The sensitivity of outputs to the vertical extent assumed should therefore be routinely assessed (see also Condon et al., 2020).

The fairly large differences between the simulations during the spring in Figure 11 (Scenario C) suggest that using spatially distributed forcing is important to reproduce spring flow peaks, especially at higher points along headwater stream networks. This is because snowmelt is generated at sequentially higher elevations and on different slope aspects as the melt season progresses. One would expect the difference seen when using catchment-averaged forcings to be amplified with increasing catchment area. It should be highlighted that the spatially uniform forcing dataset was generated by averaging the distributed outputs of Thornton et al. (under revision) at each time-step, meaning the difference could be even larger if "truly uniform" datasets are used.

Finally, the results of Scenario D (not shown) suggest that, probably given the presently limited permafrost extent here, its thaw would not have a major impact on streamflows. However, a full "thermally enabled" simulation that 
accounts for pore water freeze-thaw and thermally modified hydraulic conductivities, rather than the simple coupling length approach used here, would probably have enabled greater confidence in this conclusion. Still, had this study intended to specifically evaluate the influence of permafrost on integrated hydrological processes, an alternative (higher elevation) study site and more permafrost-focused modelling strategy would certainly have been adopted.

\subsection{Main novelties}

This study is associated with several novelties. The first relates to the subsurface structure employed, especially the incorporation of an accurate, high-resolution 3D model of bedrock geology (Thornton et al., 2018) to represent a vertically extensive domain with a fairly finely resolved mesh. The second lies in the application of forcing datasets with high spatial resolution. The snowmelt component in particular, which was generated previously using an energy balance-based snow model that additionally accounts for gravitational redistribution and was conditioned upon two complementary types of snow observations (Thornton et al., under revision), extends well beyond the approaches usually taken in integrated surface-subsurface modelling.

The underlying forcing data are highly resolved in both space and time. This enabled the impact of varying the frequency to be assessed. Prediction sensitivity to a range of other model simplifications was also evaluated. This study represents the first known attempt to calibrate an integrated hydrological model of a mountainous catchment in an automated fashion. Furthermore, detailed HGS models of real (as opposed to synthetic) mountainous catchments have not previously been presented. This is important because in contrast to some other integrated codes, HGS permits the free evolution of surface water network. It also supports flexible tetrahedral meshes, which can arguably represent complex topography more efficiently than the regular structured meshed employed by other popular integrated codes (but see Maxwell, 2013).

Finally, in contrast to many related previous studies (e.g. Carroll et al., 2019; Engdahl \& Maxwell, 2015; Markovich et al., 2016; Penn et al., 2016; Pribulick et al., 2016), explicit time-series comparisons between simulations and historical observations are presented. In those studies, hydrological predictions made under modified conditions were only compared to simulated historical baselines. Whilst the physical basis of the models involved largely supports such an approach, actually demonstrating that historical observations can be reproduced (with plausible parameter values), as is done here, enhances confidence in the robustness of the model and simulated results. Through visualization of the simulations was also helpful in this regard and should not be overlooked, as tends to be the case presently.

\subsection{Fully-integrated hydrological models in complex mountainous settings: potential next steps}

Based on this work, numerous recommendations for future research can be made (some of which have already been alluded to). Firstly, the interplay between initial conditions, parameter updates, and the (minimum) length of reinitialization periods (i.e. the periods that should be simulated with every new set of parameters prior to the commencement of calibration) when employing integrated models in automated calibration frameworks should be investigated. Secondly, when applying unstructured mesh-enabled integrated models to such topographically and geologically complex settings, mesh efficiency should be further improved. The mesh employed here - in which the same (surface constrained) mesh was replicated in every vertical layer - was a major limiting factor. Ideally, a fullyunstructured mesh refined according to surface features (streams, topography, etc.) in the upper few meters below the surface only, but then transitions to a mesh that is concordant only with geological formation interfaces beneath, can be envisaged. To ensure numerical stability, high quality element shapes must be maintained, however, which is unlikely to be trivial (depending on the degree of subsurface complexity). Associated improvements in runtimes could open many possibilities for calibrating such models over longer periods with higher frequency forcing data than those used here. 
Accurate, spatially continuous (3D) data pertaining to the subsurface (in mountain regions but also elsewhere) also remains severely lacking, and thus acts as a major impediment to the more widespread uptake of integrated models. Few catchment or regional scale 3D models of the bedrock with appropriate attributes for groundwater or integrated hydrological models currently exist in global mountain regions, but can now be developed (Thornton et al., 2018). Approaches to estimate the geometries properties of numerous unconsolidated sedimentary features (i.e. across entire rugged, inaccessible headwaters), which are increasingly understood to play an important hydrological role, are also limited (see Supplementary Text S1). Finally, distributed (or even 3D) data on soil hydraulic properties is also lacking, even in relatively populated and developed mountain ranges such as the European Alps. As already noted, soils control water partitioning at the land surface, and so high-quality data are crucial for developing meaningful computational representations. With continued developments in satellite remote sensing, the already considerable disparity between the amount and quality of surface vs. subsurface data availability is only widening. Finally, applying integrated models to mountainous settings such as the Hindu Kush Himalaya or the Andes, where the effects of ongoing climate change are likely to be even more marked that previously studies settings, could also prove useful.

It has hopefully been demonstrated above that, besides offering considerable visualization possibilities, such models allow one to apply physical reasoning to identify numerical representations that may still be deficient, and therefore prioritize future improvements and/or conceptual model refinements. Building upon this, there is great potential for numerous novel, complementary datasets to be combined with integrated models of mountainous catchments more formally for multi-objective calibration and evaluation (including spatially explicit elements). Such datasets could include remotely sensed ET maps (e.g. Allen et al., 2007), this being a generally uncertain water balance component, and estimates of seasonal groundwater storage determined via gravimetry (e.g. Arnoux et al., 2020), which would provide more spatially integrated, representative information that the piezometer measurements used here (see also Schilling, Cook et al., 2019). Employing the temporal evolution of the observed stream network as it expands and contracts (e.g. captured using drone photography) as a model constraint could also represent an attractive avenue. Ultimately, combining integrated models and such diverse datasets could reduce the extent to which equifinality afflicts such models and finally realize the vision of Grayson \& Blöschl (2001). However, what constitutes "good", "acceptable", and "poor" model-data fits for various metric and variable combinations when employing such tools in complex mountainous systems remains to be established, including for basic time-series (as many similar studies did not present them).

\section{Conclusions}

This paper has presented a fully-integrated surface-subsurface hydrological model of a steep, snow-dominated mountainous catchment that incorporates both a dedicated 3D model of bedrock geology and an energy balance-based representation of snow processes: two structural advancement over previous mountain integrated modelling efforts that, given the region's characteristics, were deemed important.

In one of the first such attempts, the model was calibrated in an automated fashion with respect to observed streamflows and groundwater levels. Setting up and running such a model was found to be feasible, and after calibration the hydrological dynamics of the system could generally be replicated satisfactorily. These results suggest integrated models do indeed have utility in complex Alpine settings. It was additionally demonstrated that applying hourly instead of daily frequency forcing data enabled streamflows associated with snowmelt and rainfall, as well as diurnal fluctuations in streamflow and groundwater levels, to be reproduced.

The capacities that integrated codes offer, via spatio-temporal data visualization and/or extraction, to develop improved understanding of complex hydrological system - including the possibility to diagnose the aspects in which a given numerical representation may remain deficient - were also exploited. For example, a "soft evaluation" in which simulated patterns of surface-subsurface exchanges fluxes were compared with those inferred from a thermal 
drone image was undertaken, and further reinforced our view of the model's coherence in capturing observed surfacesubsurface flow dynamics.

Closely replicating observed streamflow at one site and the distinctive signals of groundwater levels observed in very close proximity to one another at the groundwater observation points was not possible with this model configuration, presumably due to the sub-catchment's distinctive geology and very local scale heterogeneities in hydraulic properties not being sufficiently represented, respectively. As such, here, the groundwater level data, which were also limited in quantity, contributed relatively little to the overall process. A risk of post-calibration non-uniqueness remains. This issue was not addressed here, with runtimes being the main impediment.

Subsequently simplifying the "full complexity" model in a series of sensitivity tests revealed that:

- Were it not for the sustaining influence of groundwater discharge, streamflow would frequently become negligible in summers following snow-poor winters;

- Limiting the model's vertical extent significantly affects simulated streamflows and groundwater levels, meaning care should be taken to ensure that simulation domains are sufficiently deep;

- Applying spatially uniform forcing data affects simulated streamflow peaks at higher elevations along the stream network;

- The thawing of all permafrost would have an almost indistinguishable impact on hydrological predictions (although the fairly simplistic way in which permafrost was represented in the base model somewhat limits the confidence that can be placed in this assertion).

Physically-based, integrated flow models thus provide an excellent basis for exploring the impacts of simplifications/approaches used across the full spectrum of hydrological model complexities, including those related to forcing data frequency.

Several other recommendations for future research have emerged, such as i) investigating more fully the interplay between initial conditions and re-initialization simulation times, ii) developing dedicated methods to generate more efficient, fully-unstructured meshes for surface-subsurface models, ii) developing and applying methods to better describe the 3D geometries and hydraulic properties of unconsolidated subsurface formations, and iv) routinely testing the sensitivity of predictions to assumed watershed base depth. Additionally, many possibilities exist to introduce a range of complementary datasets constraints during multi-objective calibration processes, especially variables (besides streamflow) that provide spatially integrated information.

In summary, this contribution attests to both the great potential and remaining challenges associated with applying fully-integrated models in very complex mountainous settings. Subsequently, the model will be used in conjunction with plausible future climate and vegetation scenarios to assess hydrological impacts in a more comprehensive fashion than has hitherto been possible. As such, this model in particular, and the framework more generally, may enable more reliable and comprehensive assessments to be made as to the hydrological impacts of future change in the European Alps and other similar regions globally than have hitherto been possible. That said, given the efforts required and difficulties associated with developing and calibrating, it is suggested that applications in exceptionally important or ecologically sensitive catchments, or else where much of the requisite data already exists, are prioritized.

\section{Acknowledgments, Samples, and Data}

J.M.T, G.M. and P.B were financed by the Swiss National Science Foundation (IntegrAlp project; CR23I2_162754). The Authors wish to thank Dr. N. Deluigi for the provision of the permafrost map, R. Vallat for the provision of the permafrost map and thermal image, Drs. E. Voytek and L. Baron for their assistance with the geophysical survey and data processing, and the groups of Prof. B. Schaefli and Prof. T. Battin for the streamflow data. The authors declare 
no conflict of interest. The calibrated model with daily forcing data is provided, along with the animations and Supplementary Figures, at: https://doi.org/10.6084/m9.figshare.13332650. To run the model, a HydroGeoSphere license would be required (contact sales@aquanty.com). The other model configurations described are available from the corresponding author upon request.

\section{Author contributions}

J.M.T. conducted the vast majority of the work, including making the groundwater measurements, sourcing the inputs datasets, setting up and calibrating the model, planning and executing the subsequent simulations, preparing the figures (except Figure S12), and writing the manuscript. R.T. provided advice and technical contributions regarding HydroGeoSphere. N.L. enabled the geophysics fieldwork and conducted the geophysical inversion. P.B. and G.M. were responsible for funding acquisition and provided advice and support at all stages. All authors contributed to the finalization of the manuscript.

\section{References}

Ajami, H., McCabe, M. F., Evans, J. P., \& Stisen, S. (2014). Assessing the impact of model spin-up on surface watergroundwater interactions using an integrated hydrologic model. Water Resources Research, 50(3), 2636-2656. https://doi.org/10.1002/2013WR014258

Ala-aho, P., Rossi, P. M., Isokangas, E., \& Kløve, B. (2015). Fully integrated surface-subsurface flow modelling of groundwater-lake interaction in an esker aquifer: Model verification with stable isotopes and airborne thermal imaging. Journal of Hydrology, 522, 391-406. https://doi.org/10.1016/j.jhydrol.2014.12.054

Ala-aho, P., Soulsby, C., Wang, H., \& Tetzlaff, D. (2017). Integrated surface-subsurface model to investigate the role of groundwater in headwater catchment runoff generation: A minimalist approach to parameterisation. Journal of Hydrology, 547, 664-677. https://doi.org/10.1016/j.jhydrol.2017.02.023

Ameli, A. A., Gabrielli, C., Morgenstern, U., \& McDonnell, J. J. (2018). Groundwater Subsidy From Headwaters to Their Parent Water Watershed: A Combined Field-Modeling Approach. Water Resources Research, 54(7), 5110-5125. https://doi.org/10.1029/2017WR022356

Aquanty Inc. (2016). HydroGeoSphere User Manual. https://doi.org/10.1007/s13398-014-0173-7.2

Arnoux, M., Halloran, L. J. S., Berdat, E., \& Hunkeler, D. (2020). Characterizing seasonal groundwater storage in alpine catchments using time-lapse gravimetry, water stable isotopes and water balance methods. Hydrological Processes, 34(22), 4319-4333. https://doi.org/10.1002/hyp.13884

Badoux, H. (1971). Carte et notice explicative, Feuille 1305 - Dt. de Morcles, Atlas géologique de la Suisse (1:25,000).

Beniston, M., Farinotti, D., Stoffel, M., Andreassen, L. M., Coppola, E., Eckert, N., ... Vincent, C. (2018). The European mountain cryosphere: a review of its current state, trends, and future challenges. The Cryosphere, 12(2), 759-794. https://doi.org/10.5194/tc-12-759-2018

Beven, K. J., \& Kirkby, M. J. (1979). A physically based, variable contributing area model of basin hydrology. Hydrological Sciences Bulletin, 24(1), 43-69. https://doi.org/10.1080/02626667909491834

Brauchli, T., Trujillo, E., Huwald, H., \& Lehning, M. (2017). Influence of slope-scale snowmelt on catchment response simulated with the Alpine3D model. Water Resources Research, 53(12), 10723-10739. https://doi.org/10.1002/2017WR021278

Camporese, M., Paniconi, C., Putti, M., \& McDonnell, J. J. (2019). Fill and Spill Hillslope Runoff Representation With a Richards Equation-Based Model. Water Resources Research, 55(11), 8445-8462. https://doi.org/10.1029/2019WR025726 
Carroll, R. W. H., Deems, J. S., Niswonger, R., Schumer, R., \& Williams, K. H. (2019). The importance of interflow to groundwater recharge in a snowmelt-dominated headwater basin. Geophysical Research Letters, 46(11), 5899-5908. https://doi.org/10.1029/2019GL082447

Ceperley, N., Michelon, Anthony Escoffier, N., Mayoraz, G., Boix Canadell, M., Horgby, A., Hammer, F., ... Boss, S. (2018). Salt gauging and stage-discharge curve, Avançon de Nant, outlet Vallon de Nant catchment. https://doi.org/10.5281/zenodo. 1154798

Cochand, F., Therrien, R., \& Lemieux, J. M. (2019). Integrated Hydrological Modeling of Climate Change Impacts in a Snow-Influenced Catchment. Groundwater, 57(1), 3-20. https://doi.org/10.1111/gwat.12848

Condon, L. E., Markovich, K. H., Kelleher, C. A., McDonnell, J. J., Ferguson, G., \& McIntosh, J. C. (2020). Where Is the Bottom of a Watershed? Water Resources Research, 56(3). https://doi.org/10.1029/2019WR026010

Deluigi, N., Lambiel, C., \& Kanevski, M. (2017). Data-driven mapping of the potential mountain permafrost distribution. Science of the Total Environment, 590-591, 370-380. https://doi.org/10.1016/j.scitotenv.2017.02.041

Doherty, J. (2020). PEST_HP: PEST for Highly Parallelized Computing Environments. Brisbane, Australia. Retrieved from http://www.pesthomepage.org/Downloads.php

Duethmann, D., Blöschl, G., \& Parajka, J. (2020). Why does a conceptual hydrological model fail to correctly predict discharge changes in response to climate change? Hydrology and Earth System Sciences, 24(7), 3493-3511. https://doi.org/10.5194/hess-24-3493-2020

Durighetto, N., Vingiani, F., Bertassello, L. E., Camporese, M., \& Botter, G. (2020). Intraseasonal Drainage Network Dynamics in a Headwater Catchment of the Italian Alps. Water Resources Research, 56(4). https://doi.org/10.1029/2019WR025563

Ebel, B. A., Mirus, B. B., Heppner, C. S., VanderKwaak, J. E., \& Loague, K. (2009). First-order exchange coefficient coupling for simulating surface water-groundwater interactions: parameter sensitivity and consistency with a physics-based approach. Hydrological Processes, 23(13), 1949-1959. https://doi.org/10.1002/hyp.7279

Engdahl, N. B., \& Maxwell, R. M. (2015). Quantifying changes in age distributions and the hydrologic balance of a high-mountain watershed from climate induced variations in recharge. Journal of Hydrology, 522, $152-162$. https://doi.org/10.1016/j.jhydrol.2014.12.032

Evans, S. G., Ge, S., \& Liang, S. (2015). Analysis of groundwater flow in mountainous, headwater catchments with permafrost. Water Resources Research, 51(12), 9564-9576. https://doi.org/10.1002/2015WR017732

Fatichi, S., Rimkus, S., Burlando, P., Bordoy, R., \& Molnar, P. (2015). High-resolution distributed analysis of climate and anthropogenic changes on the hydrology of an Alpine catchment. Journal of Hydrology, 525, 362-382. https://doi.org/10.1016/j.jhydrol.2015.03.036

Foster, L. M., \& Maxwell, R. M. (2019). Sensitivity analysis of hydraulic conductivity and Manning's n parameters lead to new method to scale effective hydraulic conductivity across model resolutions. Hydrological Processes, 33(3), 332-349. https://doi.org/10.1002/hyp.13327

Frisbee, M. D., Tolley, D. G., \& Wilson, J. L. (2017). Field estimates of groundwater circulation depths in two mountainous watersheds in the western U.S. and the effect of deep circulation on solute concentrations in streamflow. Water Resources Research, 53(4), 2693-2715. https://doi.org/10.1002/2016WR019553

Giaccone, E., Luoto, M., Vittoz, P., Guisan, A., Mariéthoz, G., \& Lambiel, C. (2019). Influence of microclimate and geomorphological factors on alpine vegetation in the Western Swiss Alps. Earth Surface Processes and Landforms, 44(15), 3093-3107. https://doi.org/10.1002/esp.4715 
1041

1042

1043

1044

1045

1046

1047

1048

1049

1050

1051

1052

1053

1054

1055

1056

1057

1058

1059

1060

1061

1062

1063

1064

1065

1066

1067

1068

1069

1070

1071

1072

1073

1074

1075

1076

1077

1078

1079

1080

1081

Gleeson, T., \& Manning, A. H. (2008). Regional groundwater flow in mountainous terrain: Three-dimensional simulations of topographic and hydrogeologic controls. Water Resources Research, 44(10). https://doi.org/10.1029/2008WR006848

Graham, D. N., \& Butts, M. B. (2005). Flexible, integrated watershed modelling with MIKE SHE. In V. P. Singh \& D. K. Frevert (Eds.), Watershed Models (pp. 245-272). CRC Press.

Grayson, R. B., \& Blöschl, G. (2001). Spatial patterns in catchment hydrology: Observations and modelling. Cambridge: Cambridge University Press.

Griessinger, N., Schirmer, M., Helbig, N., Winstral, A., Michel, A., \& Jonas, T. (2019). Implications of observationenhanced energy-balance snowmelt simulations for runoff modeling of Alpine catchments. Advances in Water Resources, 133, 103410. https://doi.org/10.1016/j.advwatres.2019.103410

Huntington, J. L., \& Niswonger, R. G. (2012). Role of surface-water and groundwater interactions on projected summertime streamflow in snow dominated regions: An integrated modeling approach. Water Resources Research, 48(11). https://doi.org/10.1029/2012WR012319

Hwang, H. T., Park, Y. J., Sudicky, E. A., Berg, S. J., McLaughlin, R., \& Jones, J. P. (2018). Understanding the water balance paradox in the Athabasca River Basin, Canada. Hydrological Processes, 32(6), 729-746. https://doi.org/10.1002/hyp.11449

HydroAlgorithmics. (2016). AlgoMesh User Guide, 257. Retrieved from https://static1.squarespace.com/static/569e33fad82d5e0d877c25d7/t/57b28ab6579fb3a225563e6e/147131880 5055/AlgoMesh+User+Guide+v1.2.pdf

Ilja Van Meerveld, H. J., Kirchner, J. W., Vis, M. J. P., Assendelft, R. S., \& Seibert, J. (2019). Expansion and contraction of the flowing stream network alter hillslope flowpath lengths and the shape of the travel time distribution. Hydrology and Earth System Sciences, 23(11), 4825-4834. https://doi.org/10.5194/hess-23-48252019

Immerzeel, W. W., Lutz, A. F., Andrade, M., Bahl, A., Biemans, H., Bolch, T., ... Baillie, J. E. M. (2020). Importance and vulnerability of the world's water towers. Nature, 577(7790), 364-369. https://doi.org/10.1038/s41586-019$1822-\mathrm{y}$

Jaros, A., Rossi, P. M., Ronkanen, A. K., \& Kløve, B. (2019). Parameterisation of an integrated groundwater-surface water model for hydrological analysis of boreal aapa mire wetlands. Journal of Hydrology, 575(November 2018), 175-191. https://doi.org/10.1016/j.jhydrol.2019.04.094

Jenicek, M., Seibert, J., \& Staudinger, M. (2018). Modeling of Future Changes in Seasonal Snowpack and Impacts on Summer Low Flows in Alpine Catchments. Water Resources Research, 54(1), 538-556. https://doi.org/10.1002/2017WR021648

Käser, D., Graf, T., Cochand, F., McLaren, R., Therrien, R., \& Brunner, P. (2014). Channel Representation in Physically Based Models Coupling Groundwater and Surface Water: Pitfalls and How to Avoid Them. Groundwater, 52(6), 827-836. https://doi.org/10.1111/gwat.12143

Klemeš, V. (1990). The modelling of mountain hydrology: the ultimate challenge. Hydrology of Mountainous Areas (Proceedings of the Strbské Pleso Workshop, Czechoslovakia, June 1988), (190), 29-44. https://doi.org/10.1641/0006-3568(2001)051[0227:HIOEPA]2.0.CO;2

Kristensen, K. J., \& Jensen, S. E. (1975). A model for estimating actual evapotranspiration from potential evapotranspiration. Hydrology Research, 6(3), 170-188. https://doi.org/10.2166/nh.1975.0012

Lehning, M., Völksch Ingo, I., Gustafsson, D., Nguyen, T. A., Stähli, M., \& Zappa, M. (2006). ALPINE3D: A detailed 
1082

1083

1084

1085

1086

1087

1088

1089

1090

1091

1092

1093

1094

1095

1096

1097

1098

1099

1100

1101

1102

1103

1104

1105

1106

1107

1108

1109

1110

1111

1112

1113

1114

1115

1116

1117

1118

1119

1120

1121

model of mountain surface processes and its application to snow hydrology. In Hydrological Processes (Vol. 20, pp. 2111-2128). https://doi.org/10.1002/hyp.6204

Liggett, J. E., Werner, A. D., \& Simmons, C. T. (2012). Influence of the first-order exchange coefficient on simulation of coupled surface-subsurface flow. Journal of Hydrology, 414-415, 503-515. https://doi.org/10.1016/j.jhydrol.2011.11.028

Lugeon, M., \& Gagnebin, E. (1928). L'origine des sources de la Chambrette aux Plans sur Bex (Alpes Vaudoises). Bulletin de La Société Vaudoise Des Sciences, 56.

Maina, F. Z., \& Siirila-Woodburn, E. R. (2020). Watersheds dynamics following wildfires: Nonlinear feedbacks and implications on hydrologic responses. Hydrological Processes, 34(1), 33-50. https://doi.org/10.1002/hyp.13568

Markovich, K. H., Maxwell, R. M., \& Fogg, G. E. (2016). Hydrogeological response to climate change in alpine hillslopes. Hydrological Processes, 30(18), 3126-3138. https://doi.org/10.1002/hyp.10851

Markstrom, S. L., Niswonger, R. G., Regan, R. S., Prudic, D. E., \& Barlow, P. M. (2008). GSFLOW—Coupled Ground-Water and Surface-Water Flow Model Based on the Integration of the Precipitation-Runoff Modeling System (PRMS) and the Modular Ground-Water Flow Model (MODFLOW-2005). U.S. Geological Survey, (Techniques and Methods 6-D1), 240. Retrieved from http://pubs.er.usgs.gov/publication/tm6D1

Maxwell, R M, Condon, L. E., \& Kollet, S. J. (2015). A high-resolution simulation of groundwater and surface water over most of the continental US with the integrated hydrologic model ParFlow v3. Geoscientific Model Development, 8(3), 923-937. https://doi.org/10.5194/gmd-8-923-2015

Maxwell, Reed M. (2013). A terrain-following grid transform and preconditioner for parallel, large-scale, integrated hydrologic modeling. Advances in Water Resources, 53, 109-117. https://doi.org/10.1016/j.advwatres.2012.10.001

Maxwell, Reed M., Putti, M., Meyerhoff, S., Delfs, J.-O., Ferguson, I. M., Ivanov, V., ... Sulis, M. (2014). Surfacesubsurface model intercomparison: A first set of benchmark results to diagnose integrated hydrology and feedbacks. Water Resources Research, 50(2), 1531-1549. https://doi.org/10.1002/2013WR013725

Miller, K. L., Berg, S. J., Davison, J. H., Sudicky, E. A., \& Forsyth, P. A. (2018). Efficient uncertainty quantification in fully-integrated surface and subsurface hydrologic simulations. Advances in Water Resources, 111(June 2017), 381-394. https://doi.org/10.1016/j.advwatres.2017.10.023

OFAG. (1980). Carte des aptitudes des sols de la Suisse. Retrieved from https://files.be.ch/bve/agi/geoportal/geo/lpi/BEK_2000_02_LANG_FR.PDF

Paniconi, C., \& Putti, M. (2015). Physically based modeling in catchment hydrology at 50: Survey and outlook. Water Resources Research, 51(9), 7090-7129. https://doi.org/10.1002/2015WR017780

Penn, C. A., Bearup, L. A., Maxwell, R. M., \& Clow, D. W. (2016). Numerical experiments to explain multiscale hydrological responses to mountain pine beetle tree mortality in a headwater watershed. Water Resources Research, 52(4), 3143-3161. https://doi.org/10.1002/2015WR018300

Ragettli, S., Cortés, G., Mcphee, J., \& Pellicciotti, F. (2014). An evaluation of approaches for modelling hydrological processes in high-elevation, glacierized Andean watersheds. Hydrological Processes, 28(23), 5674-5695. https://doi.org/10.1002/hyp.10055

Rapp, G. A., Condon, L. E., \& Markovich, K. H. (2020). Sensitivity of Simulated Mountain-Block Hydrology to Subsurface Conceptualization. Water Resources Research. https://doi.org/10.1029/2020wr027714

Schattan, P., Schwaizer, G., Schöber, J., \& Achleitner, S. (2020). The complementary value of cosmic-ray neutron 
sensing and snow covered area products for snow hydrological modelling. Remote Sensing of Environment, 239(December 2019), 111603. https://doi.org/10.1016/j.rse.2019.111603

Schilling, O. S., Cook, P. G., \& Brunner, P. (2019). Beyond Classical Observations in Hydrogeology: The Advantages of Including Exchange Flux, Temperature, Tracer Concentration, Residence Time, and Soil Moisture Observations in Groundwater Model Calibration. Reviews of Geophysics, 57(1), 146-182. https://doi.org/10.1029/2018RG000619

Schilling, O. S., Park, Y. J., Therrien, R., \& Nagare, R. M. (2019). Integrated Surface and Subsurface Hydrological Modeling with Snowmelt and Pore Water Freeze--Thaw. Groundwater, 57(1), 63-74. https://doi.org/10.1111/gwat.12841

Schreiner-McGraw, A. P., \& Ajami, H. (2020). Impact of uncertainty in precipitation forcing datasets on the hydrologic budget of an integrated hydrologic model in mountainous terrain. Water Resources Research, (541), 0-3. https://doi.org/10.1029/2020WR027639

Schulla, J. (2017). WaSiM (Water balance Simulation Model) Model Description. Zürich. Retrieved from http://www.wasim.ch/downloads/doku/wasim/wasim_2015_en.pdf

Seck, A., Welty, C., \& Maxwell, R. M. (2015). Spin-up behavior and effects of initial conditions for an integrated hydrologic model. Water Resources Research, 51(4), 2188-2210. https://doi.org/10.1002/2014WR016371

Shrestha, M., Koike, T., Hirabayashi, Y., Xue, Y., Wang, L., Rasul, G., \& Ahmad, B. (2015). Integrated simulation of snow and glacier melt in water and energy balance-based, distributed hydrological modeling framework at Hunza River Basin of Pakistan Karakoram region. Journal of Geophysical Research: Atmospheres, 120(10), 4889-4919. https://doi.org/10.1002/2014JD022666

Smerdon, B. D., Mendoza, C. A., \& Devito, K. J. (2007). Simulations of fully coupled lake-groundwater exchange in a subhumid climate with an integrated hydrologic model. Water Resources Research, 43(1), 1416. https://doi.org/10.1029/2006WR005137

Speich, M. J. R., Zappa, M., Scherstjanoi, M., \& Lischke, H. (2020). FORests and HYdrology under Climate Change in Switzerland v1.0: a spatially distributed model combining hydrology and forest dynamics. Geoscientific Model Development, 13(2), 537-564. https://doi.org/10.5194/gmd-13-537-2020

Sulis, M., Paniconi, C., \& Camporese, M. (2011). Impact of grid resolution on the integrated and distributed response of a coupled surface-subsurface hydrological model for the des Anglais catchment, Quebec. Hydrological Processes, 25(12), 1853-1865. https://doi.org/10.1002/hyp.7941

Thornton, J. M., Mariethoz, G., Brauchli, T. J., \& Brunner, P. (n.d.). Efficient multi-objective calibration and uncertainty analysis of distributed snow simulations in rugged alpine terrain. Journal of Hydrology. Under revision.

Thornton, J. M., Mariethoz, G., \& Brunner, P. (2018). A 3D geological model of a structurally complex alpine region as a basis for interdisciplinary research. Scientific Data, 5, 1-20. https://doi.org/10.1038/sdata.2018.238

Tolley, D., Foglia, L., \& Harter, T. (2019). Sensitivity Analysis and Calibration of an Integrated Hydrologic Model in an Irrigated Agricultural Basin With a Groundwater-Dependent Ecosystem. Water Resources Research, 55(9), 7876-7901. https://doi.org/10.1029/2018WR024209

van Genuchten, M. T. (1980). A closed-form equation for predicting the hydraulic conductivity of unsaturated soils. Soil Science Society of America Journal, 44, 892-898. Retrieved from https://hwbdocuments.env.nm.gov/Los Alamos National Labs/TA 54/11569.pdf

Viviroli, D., Kummu, M., Meybeck, M., Kallio, M., \& Wada, Y. (2020). Increasing dependence of lowland 
populations on mountain water resources. Nature Sustainability. https://doi.org/10.1038/s41893-020-0559-9

1164

1165

1166

1167

1168

1169

1170

1171

1172

1173

1174

1175

1176

1177

1178

1179

1180

1181

1182

1183

1184

1185
Voeckler, H. M., Allen, D. M., \& Alila, Y. (2014). Modeling coupled surface water - Groundwater processes in a small mountainous headwater catchment. Journal of Hydrology, 517, 1089-1106. https://doi.org/10.1016/j.jhydrol.2014.06.015

von Gunten, D., Wöhling, T., Haslauer, C., Merchán, D., Causapé, J., \& Cirpka, O. A. (2014). Efficient calibration of a distributed pde-based hydrological model using grid coarsening. Journal of Hydrology, 519(PD), 3290-3304. https://doi.org/10.1016/j.jhydrol.2014.10.025

Wagner, T., Themeß1, M., Schüppel, A., Gobiet, A., Stigler, H., \& Birk, S. (2017). Impacts of climate change on stream flow and hydro power generation in the Alpine region. Environmental Earth Sciences, 76(1), 4. https://doi.org/10.1007/s12665-016-6318-6

Wang, C., Gomez-Velez, J. D., \& Wilson, J. L. (2018). The Importance of Capturing Topographic Features for Modeling Groundwater Flow and Transport in Mountainous Watersheds. Water Resources Research, 54(12), 10,313-10,338. https://doi.org/10.1029/2018WR023863

Warscher, M., Strasser, U., Kraller, G., Marke, T., Franz, H., \& Kunstmann, H. (2013). Performance of complex snow cover descriptions in a distributed hydrological model system: A case study for the high Alpine terrain of the Berchtesgaden Alps. Water Resources Research, 49(5), 2619-2637. https://doi.org/10.1002/wrcr.20219

Welch, L. A., \& Allen, D. M. (2014). Hydraulic conductivity characteristics in mountains and implications for conceptualizing bedrock groundwater flow. Hydrogeology Journal, 22(5), 1003-1026. https://doi.org/10.1007/s10040-014-1121-5

White, J. T. (2018). A model-independent iterative ensemble smoother for efficient history-matching and uncertainty quantification in very high dimensions. Environmental Modelling and Software, 109(March), 191-201. https://doi.org/10.1016/j.envsoft.2018.06.009 


\title{
Simulating fully-integrated hydrological dynamics in complex Alpine headwaters
}

\author{
Thornton, J.M. ${ }^{1}$, Therrien, R. ${ }^{2}$, Mariéthoz, G. ${ }^{3}$, Linde, N. ${ }^{4}$ and Brunner, P. ${ }^{1}$ \\ ${ }^{1}$ Centre for Hydrogeology and Geothermics, University of Neuchâtel, Switzerland \\ ${ }^{2}$ Department of Geology and Geological Engineering, University of Laval, Canada \\ ${ }^{3}$ Institute of Earth Surface Dynamics, University of Lausanne, Switzerland \\ ${ }^{4}$ Institute of Earth Sciences, University of Lausanne, Switzerland
}

\section{Contents of this file}

Figures S1 to S15

Text $\mathrm{S} 1$

\section{Additional Supporting Information (Files uploaded separately)}

Captions for Tables S1 to S3

Captions for Movies S1 to S3

\section{Introduction}

This file contains supplementary figures, describes the methods taken to estimate unconsolidated sedimentary formation geometries, and provides captions for supplementary tables and animations. 

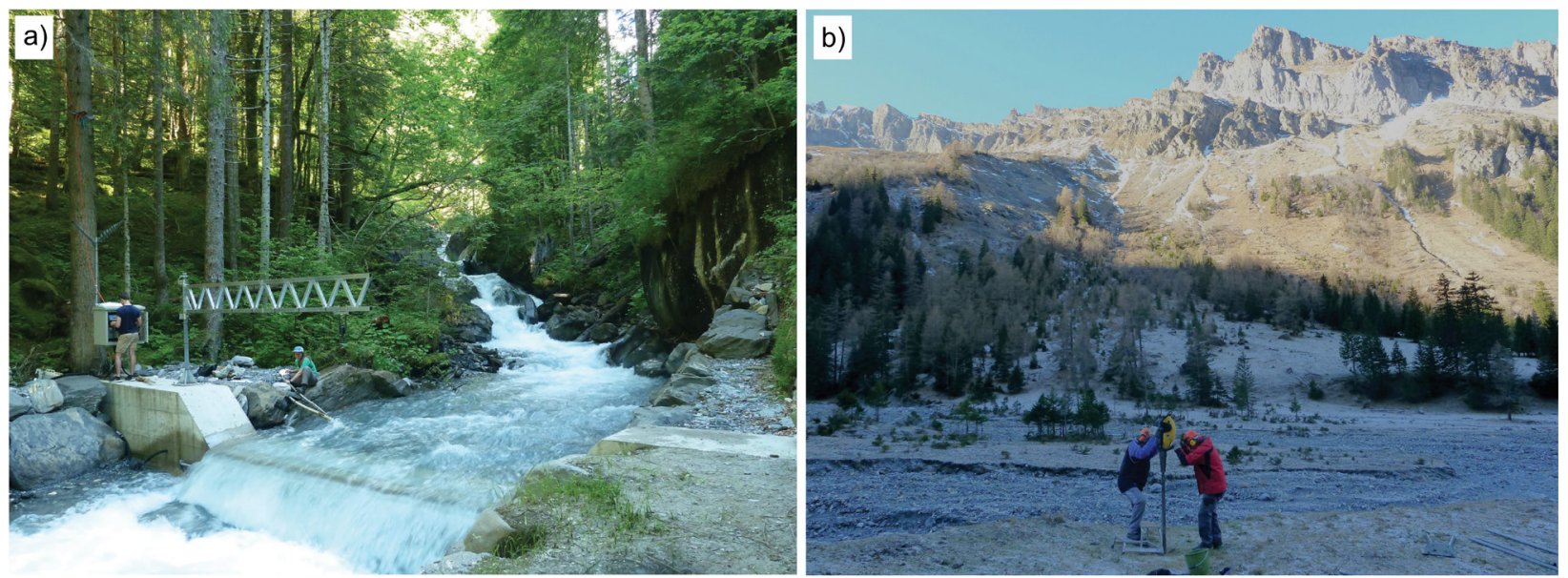

Figure S1. Photographs showing a) the concrete weir gauging station S2, and b) the installation of piezometer N4. 


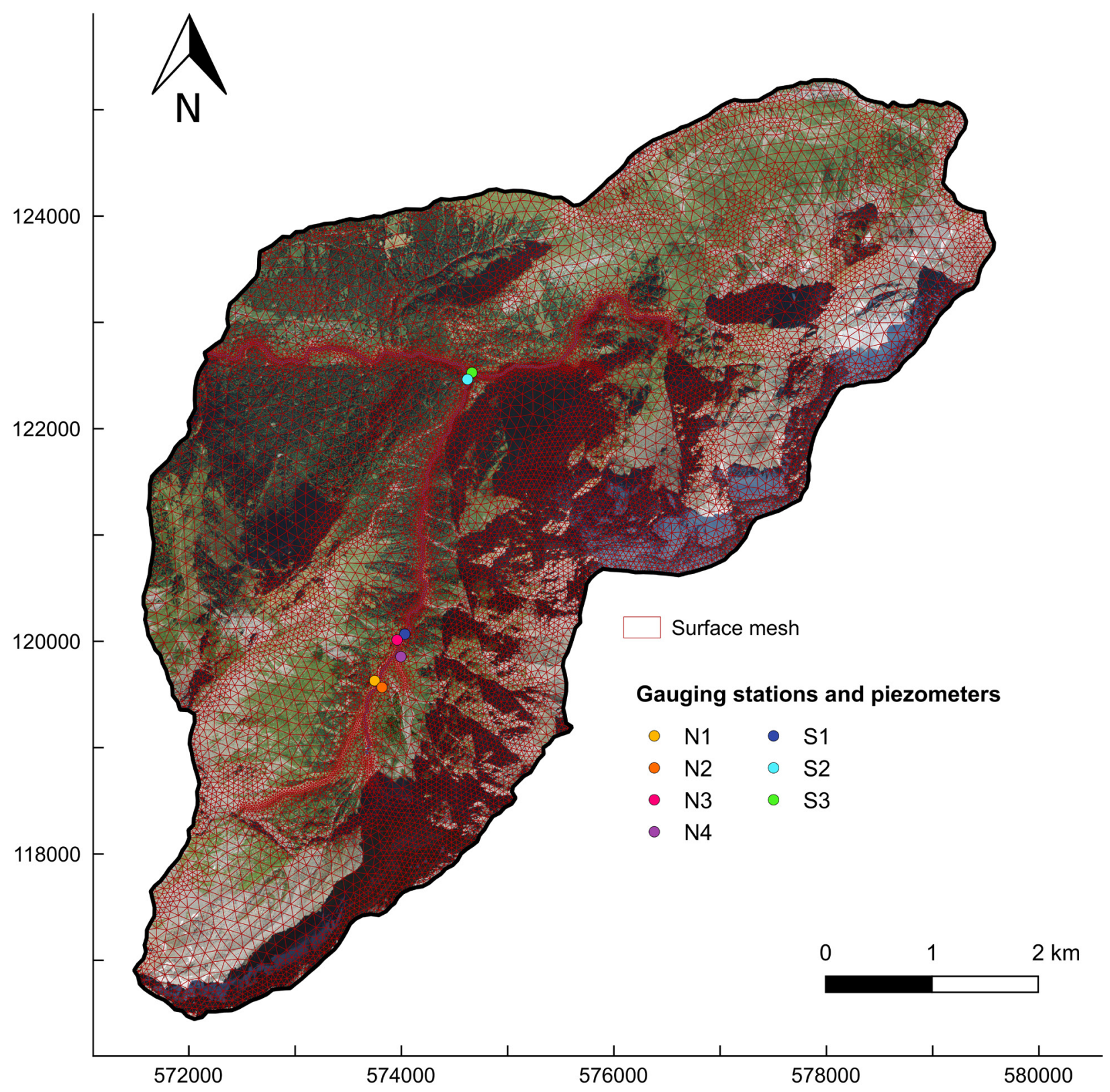

Figure S2. The 2D surface triangular mesh, underlain by a high resolution aerial photograph (Source: (Cswisstopo). Refinement is highest in the riparian zone and in steep areas. Care was also taken to ensure that nodes were placed at the precise coordinates of the observation points (piezometers, denoted by $\mathrm{N}$, and streamflow gauging stations, denoted by $\mathrm{S}$ ). 


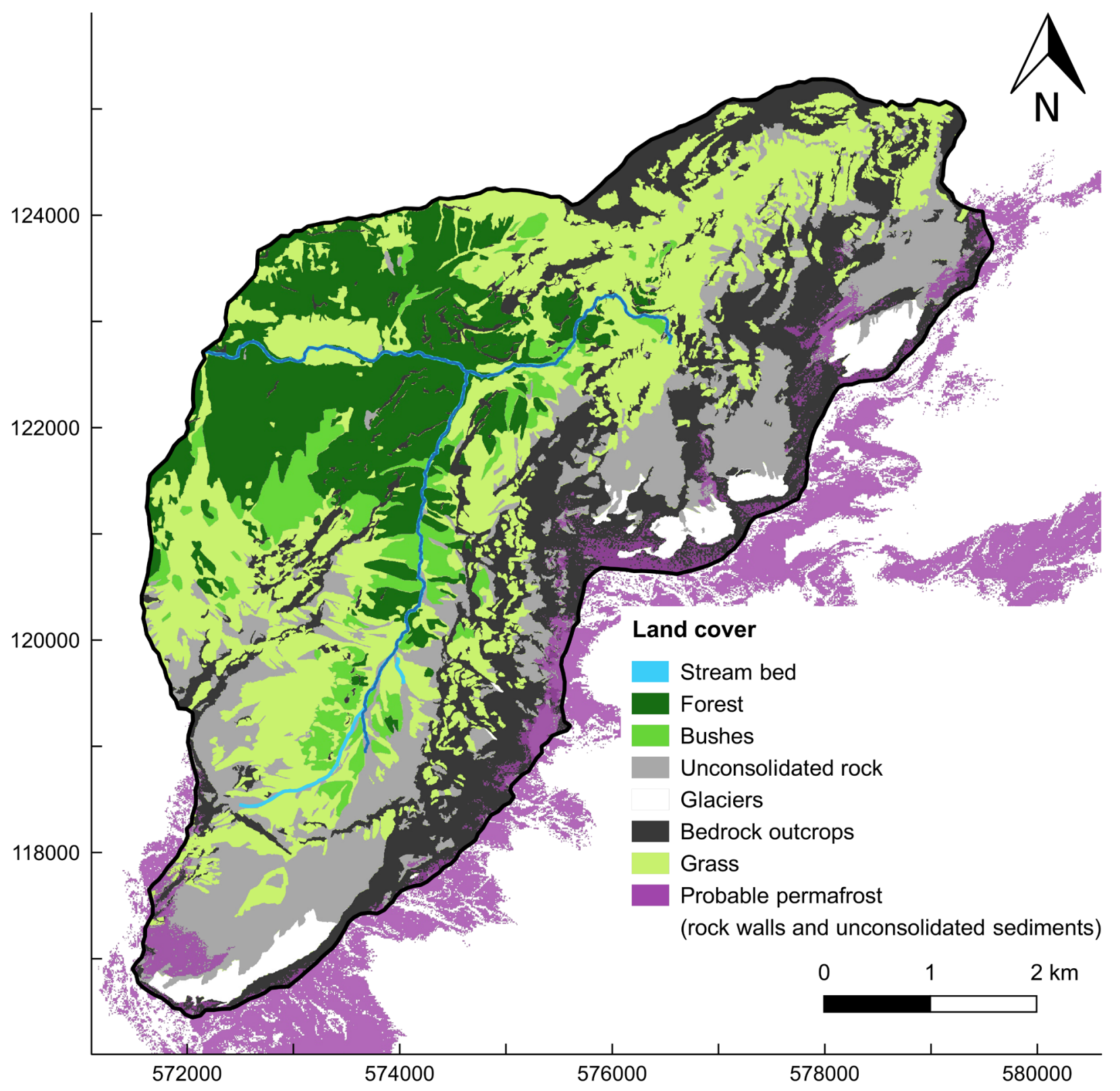

Figure S3. Land cover map of the study area, including estimated (present) permafrost distribution, that was used to define surface and evapotranspiration zones in the integrated model. 


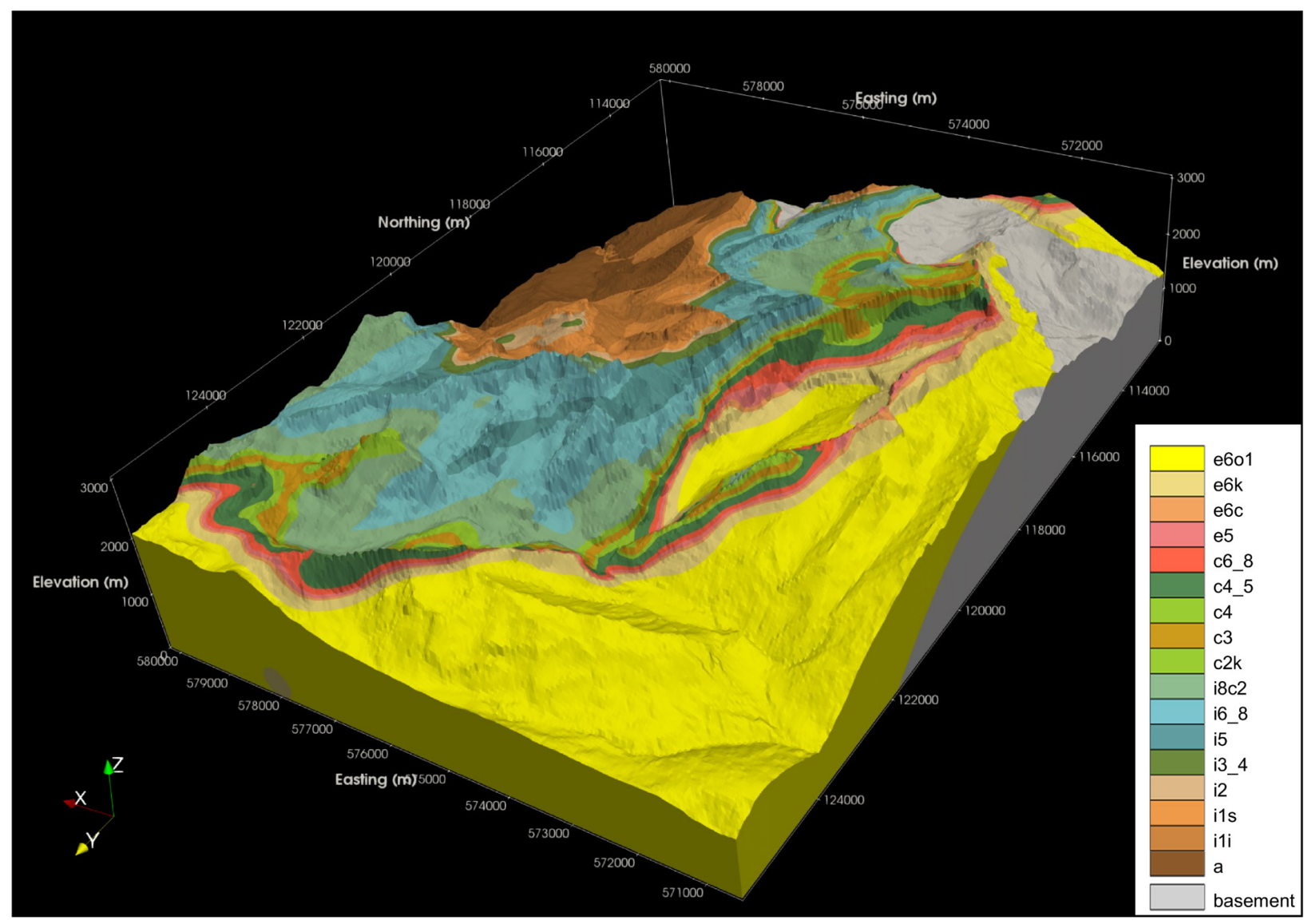

Figure S4. Illustration of the 3D bedrock geological model that contributed to the definition of subsurface zones in the integrated flow model. Source: Thornton et al. (2018). 


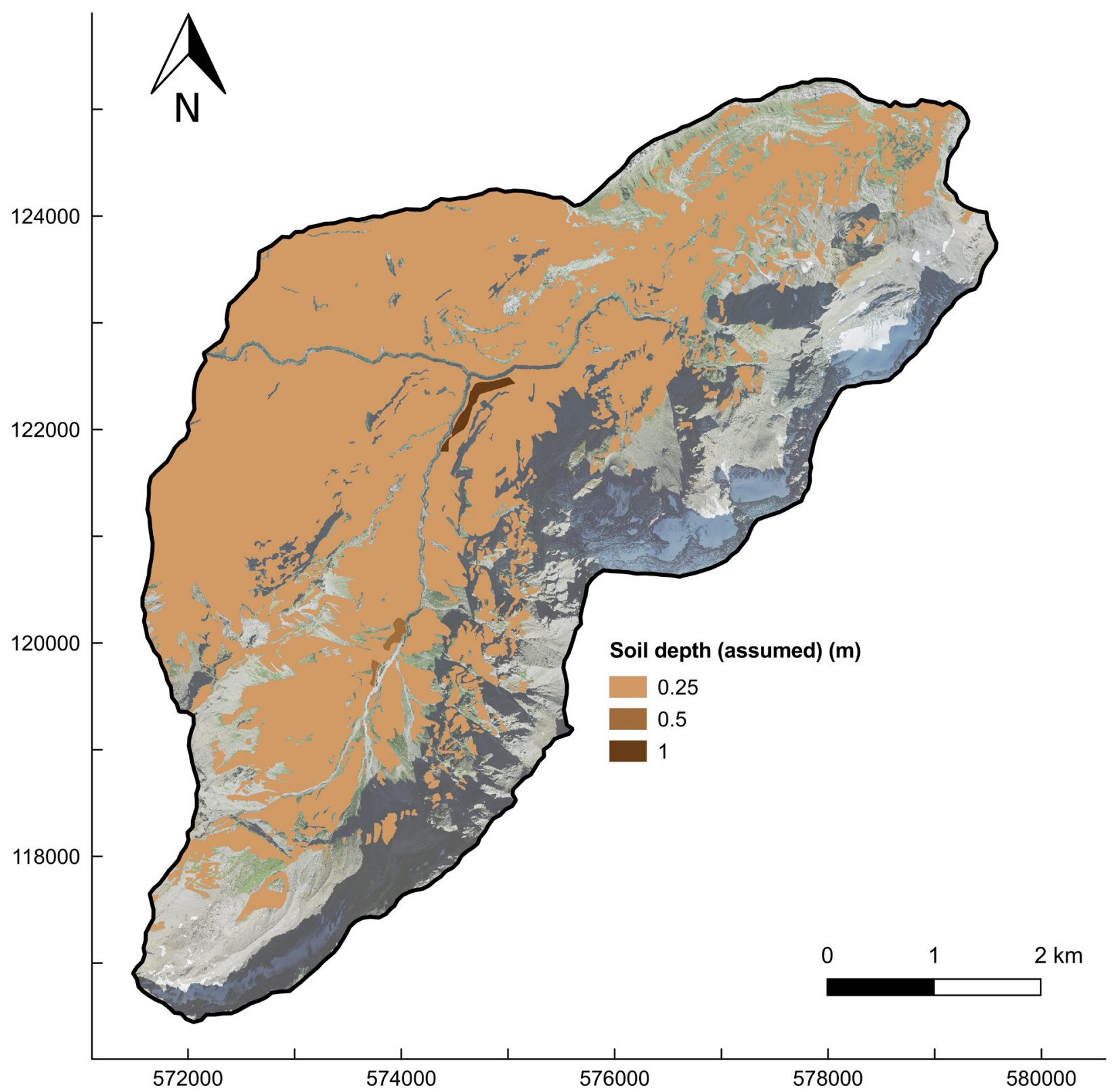

Figure S5. The spatial distribution of soil depth that was assumed in the integrated model in the absence of any detailed, high-resolution spatial information on soil depths and properties. Where the underlying aerial imagery is visible, no soil layer is represented. 


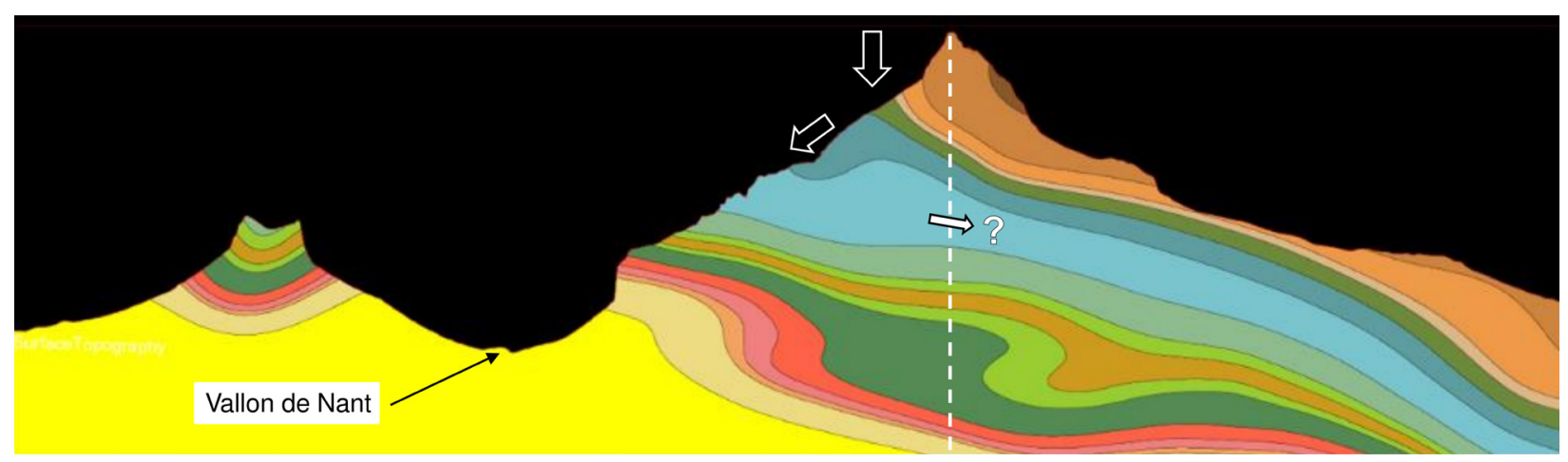

Figure S6. Cross-section through the 3D bedrock geological model showing the possibility for groundwater exportation across the topographic divide on the eastern flank of the Vallon de Nant, which is illustrated using the dashed white line (i.e. across the no-flow boundary in the model). 


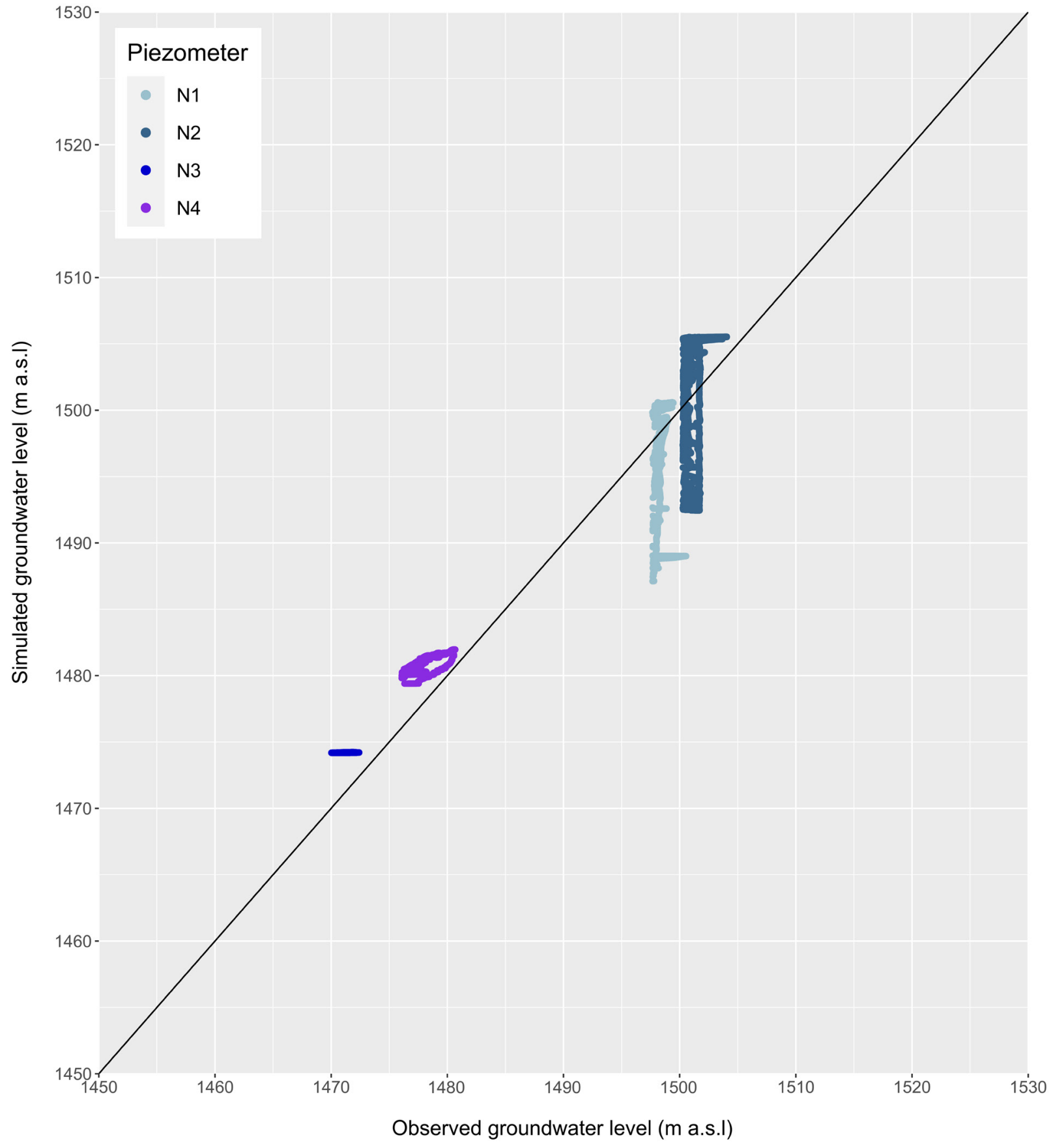

Figure S7. Pairwise plot of observed and simulated groundwater levels. The simulated levels were generated using the version of the model forced by daily frequency data. Model outputs were interpolated in time onto the half-hourly observation time-step to facilitate the plot. 

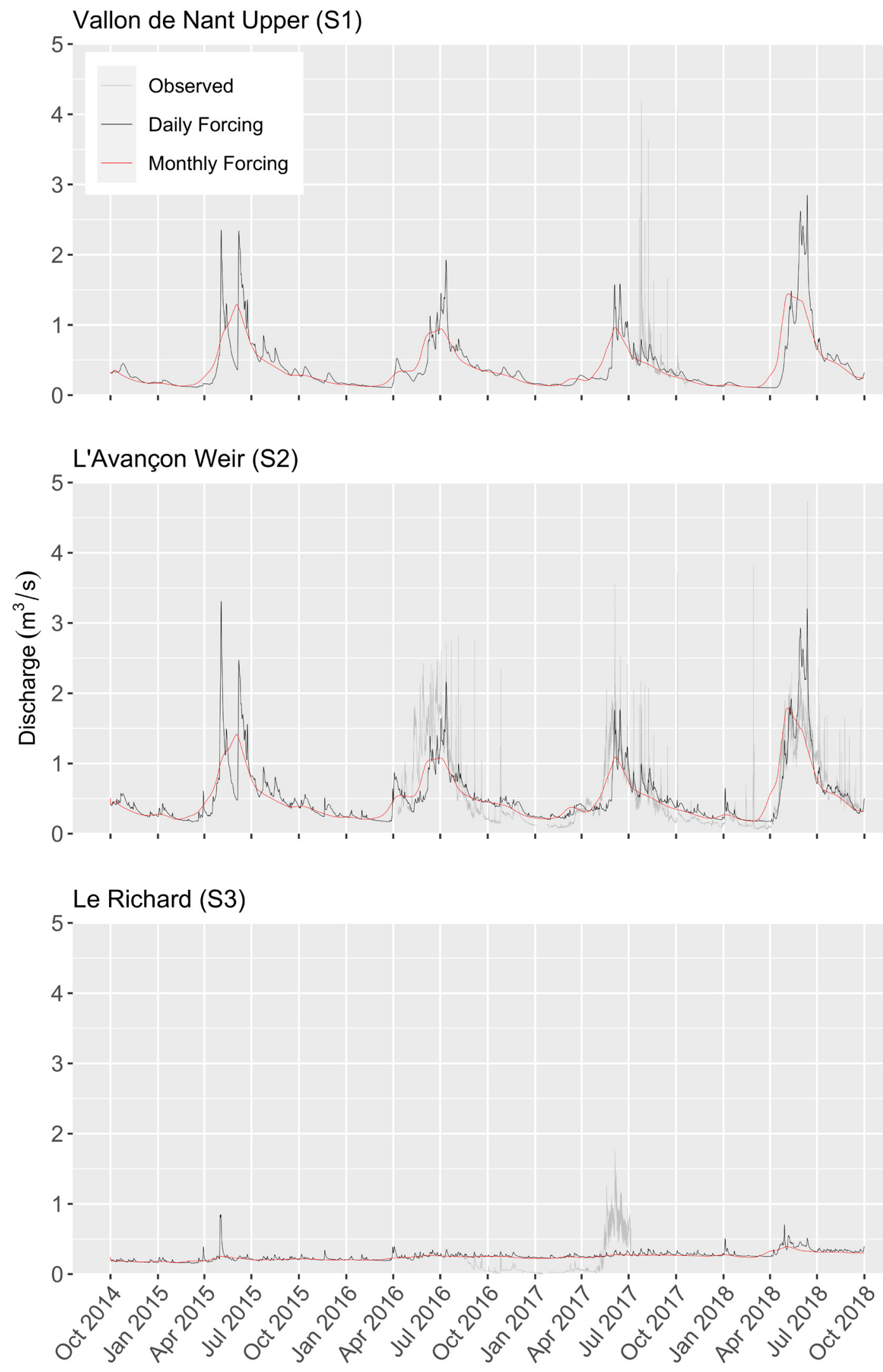

Figure S8. The impact of moving from monthly to daily frequency forcing on streamflow predictions generated by the fully-integrated model. 


\section{Piezometer N1}

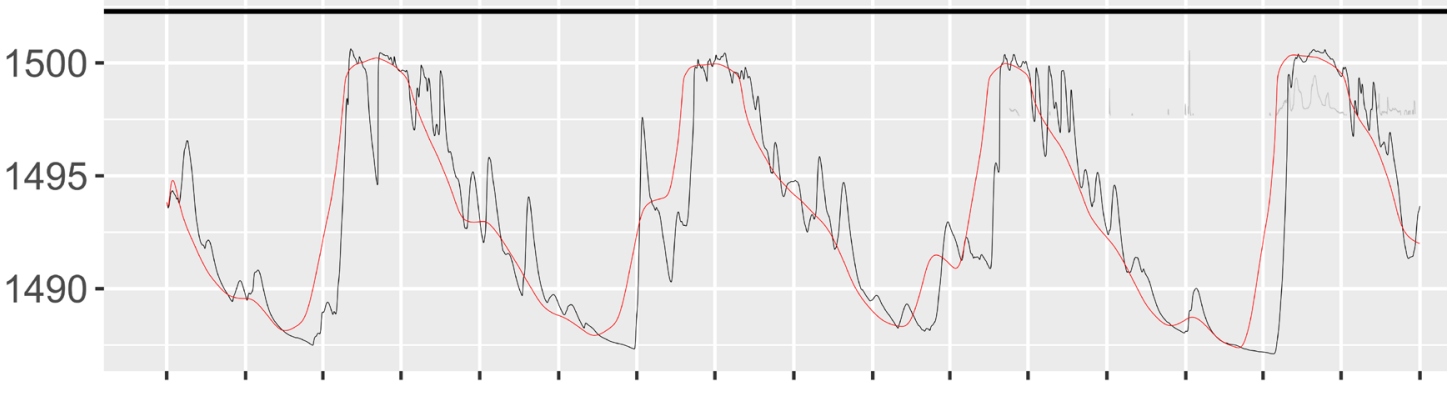

\section{Piezometer N2}

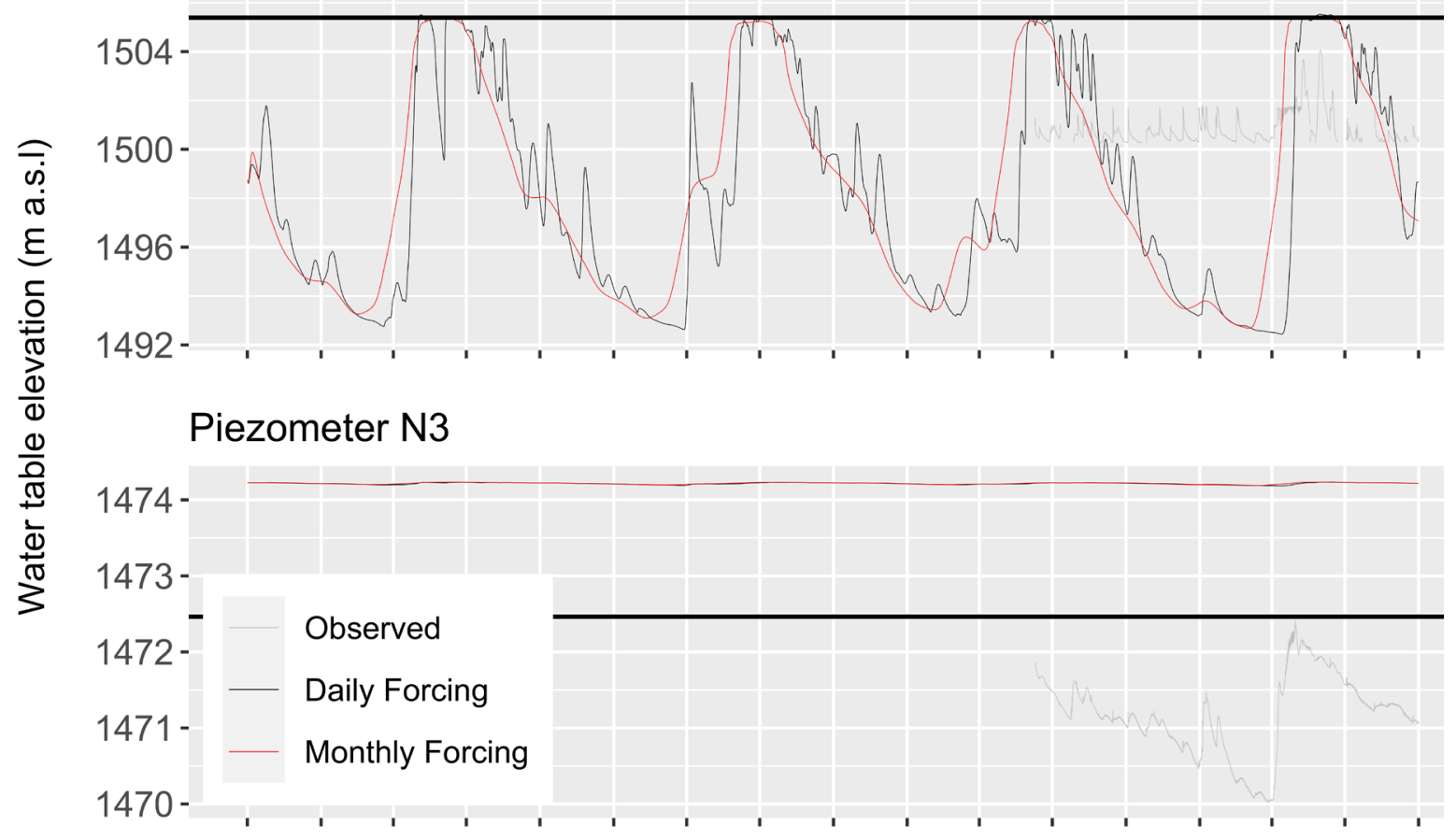

\section{Piezometer N4}

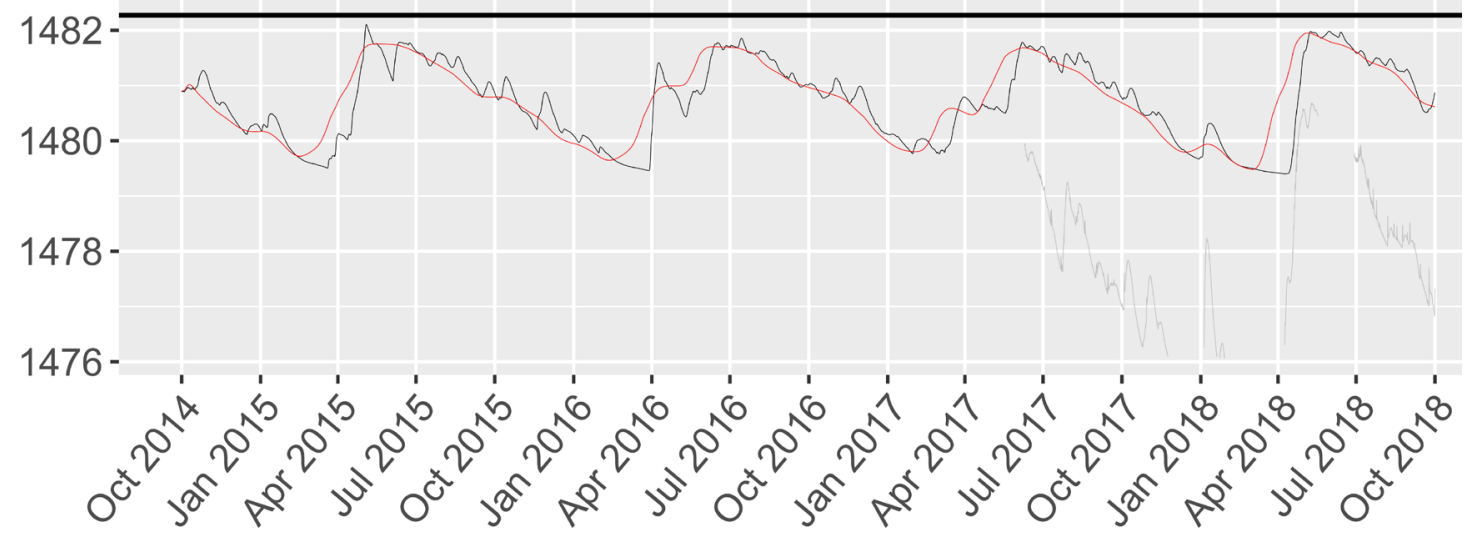

Figure S9. The impact of moving from monthly to daily frequency forcing on groundwater level predictions generated by the fully-integrated model. 


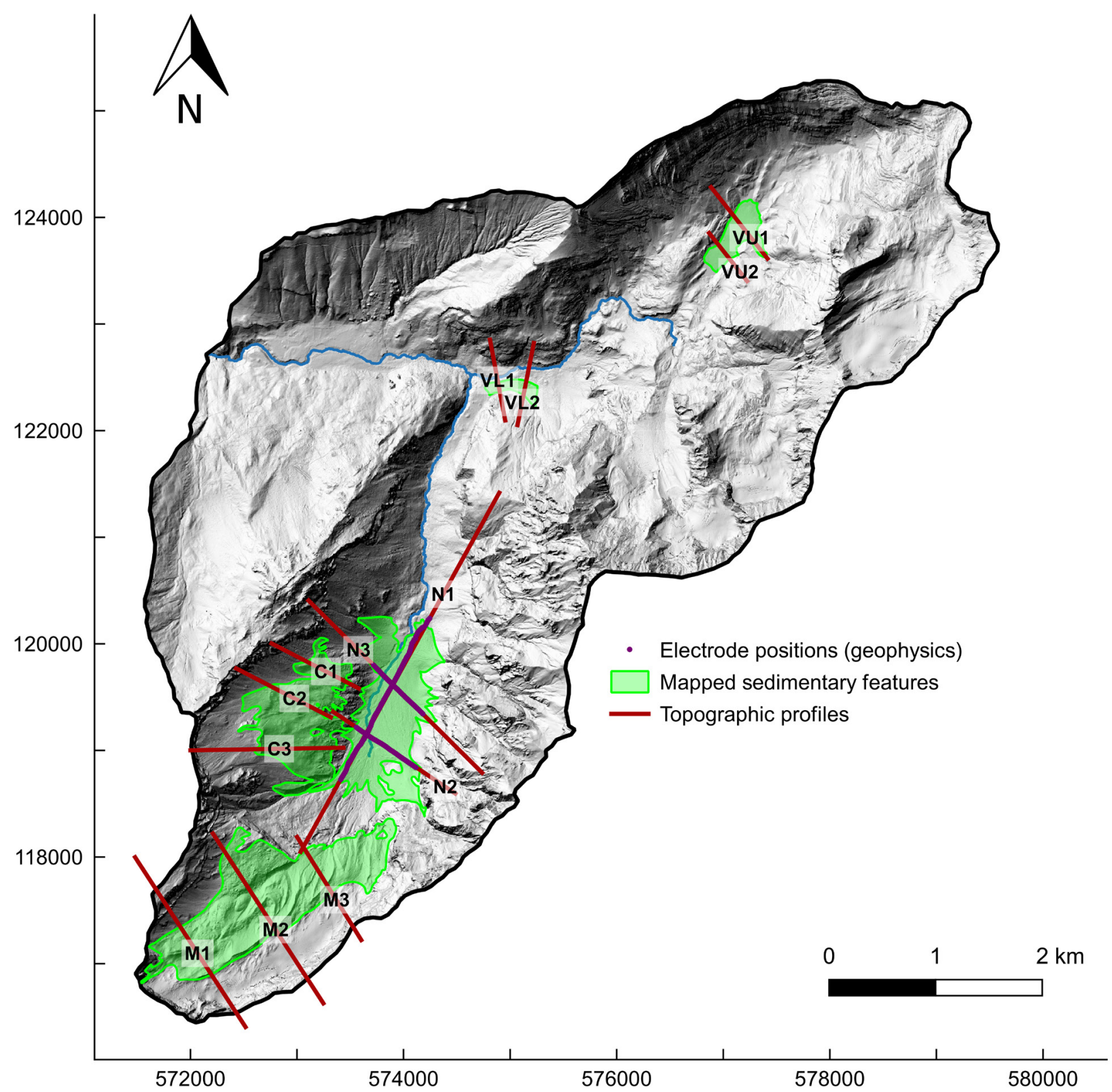

Figure S10. The major unconsolidated sedimentary feature extents considered in this study. The locations of electrodes that were placed during the geophysics campaign and the topographical cross-sections that were established as a basis for interpolating the bedrock interfaces are also shown. $\mathrm{N}$ denotes Nant, M Martinets, C La Chaux, and VU Vare Upper, and VL Vare Lower. The underlying hillshade map was generated from the swissALTI ${ }^{3 \mathrm{D}}$ digital terrain model $(\mathrm{C}$ swisstopo). 


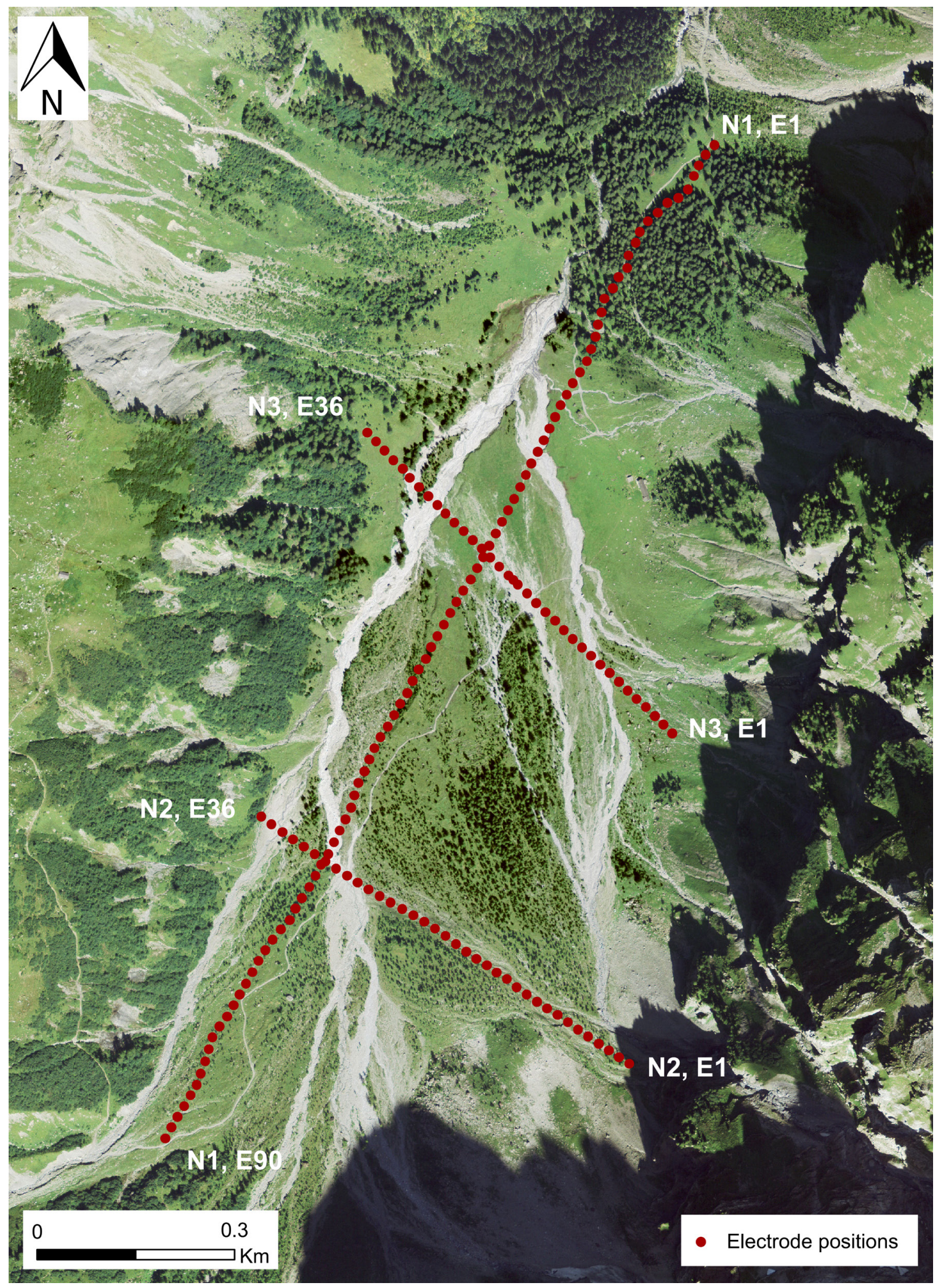

Figure S11. The arrangement of electrodes along the three transects in the Nant alluvial fan that were surveyed using electrical resistivity tomography (ERT). The profiles were named N1, N2, and N3, and the electrodes were numbered sequentially along each profile. 

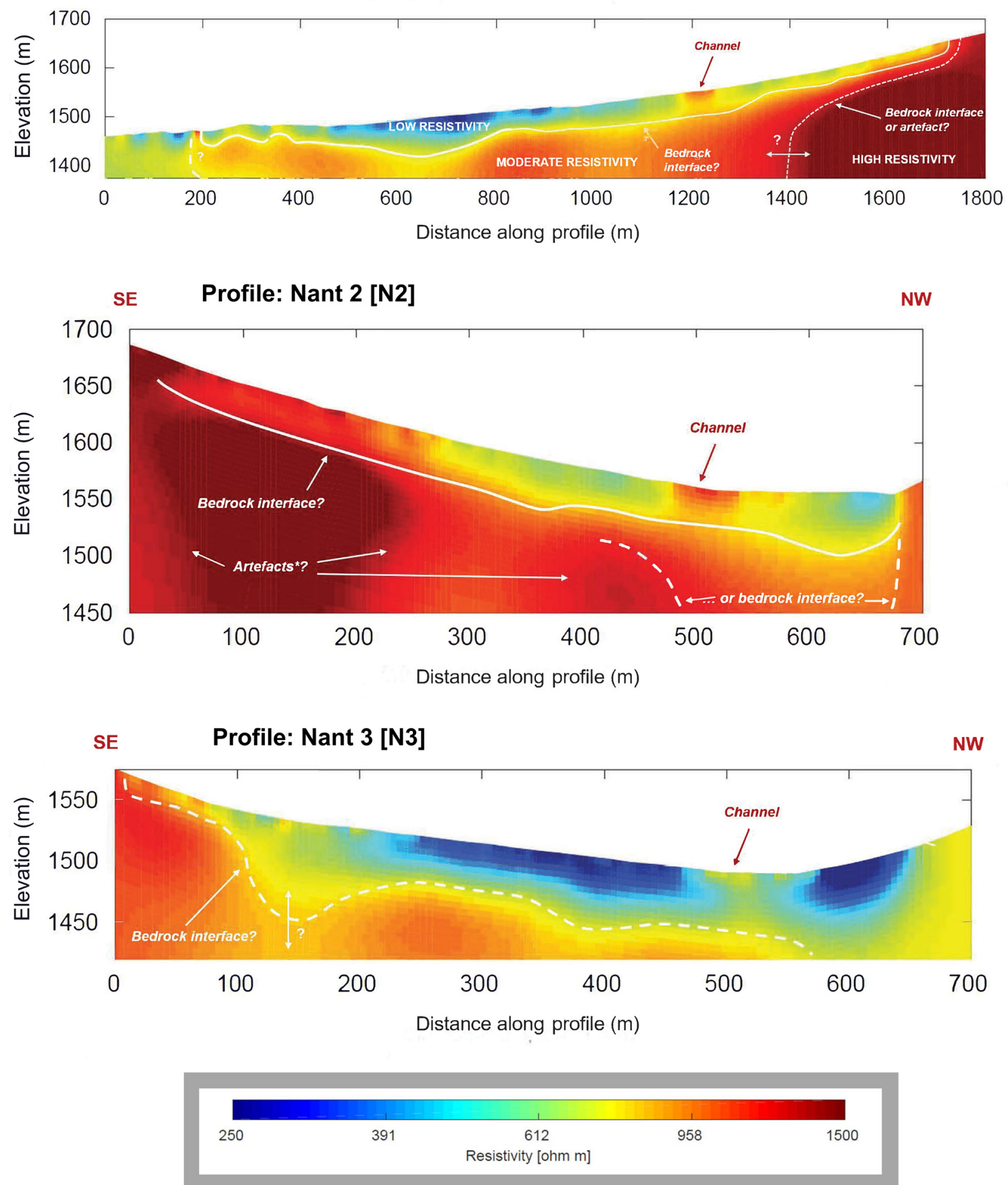

Figure S12. Inverted electrical resistivity fields for each of the three surveyed profiles in the Nant alluvial fan. A common resistivity scale is used. Annotations indicate the inferred bedrock interface and other interpretations, which in some cases are only tentative. 
Profile: Nant 1 (Geoelectric) [N1]

- Fitted spline

- Topographic surface within probable Quaternary aquifer extent

$\rightarrow$ Topographic surface beyond probable Quaternary aquifer extent and, within probable Quaternary aquifer extent, digitised interface elevations

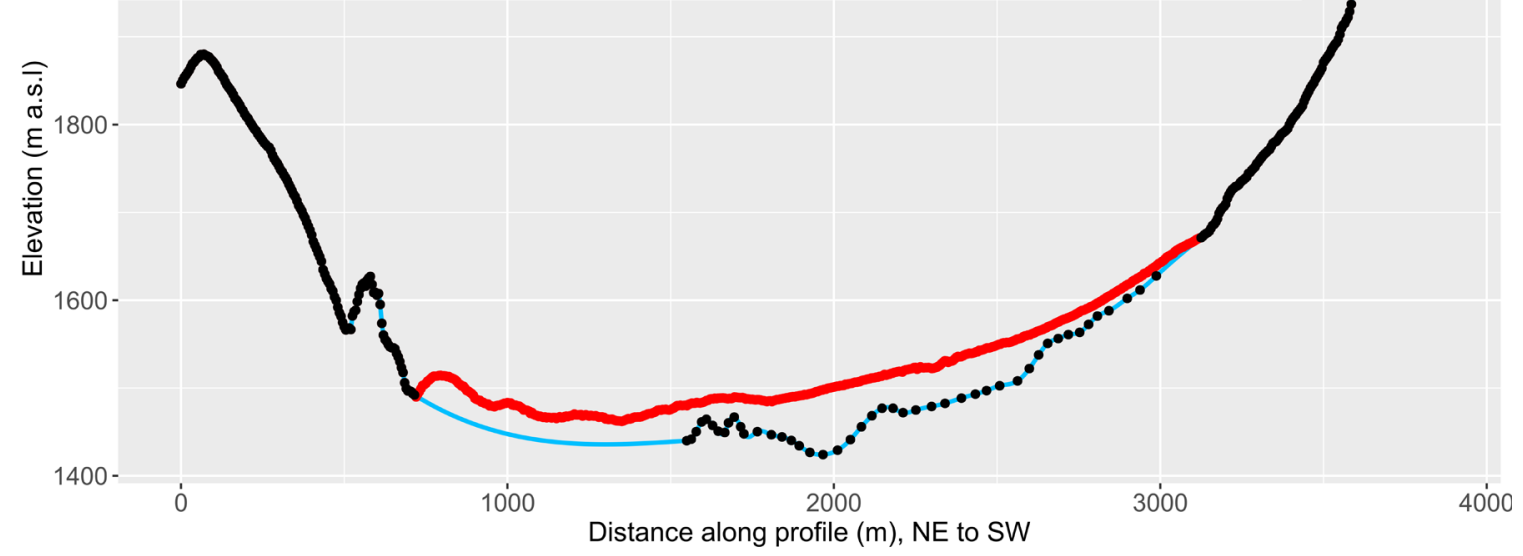

Profile: Nant 2 (Geoelectric) [N2]

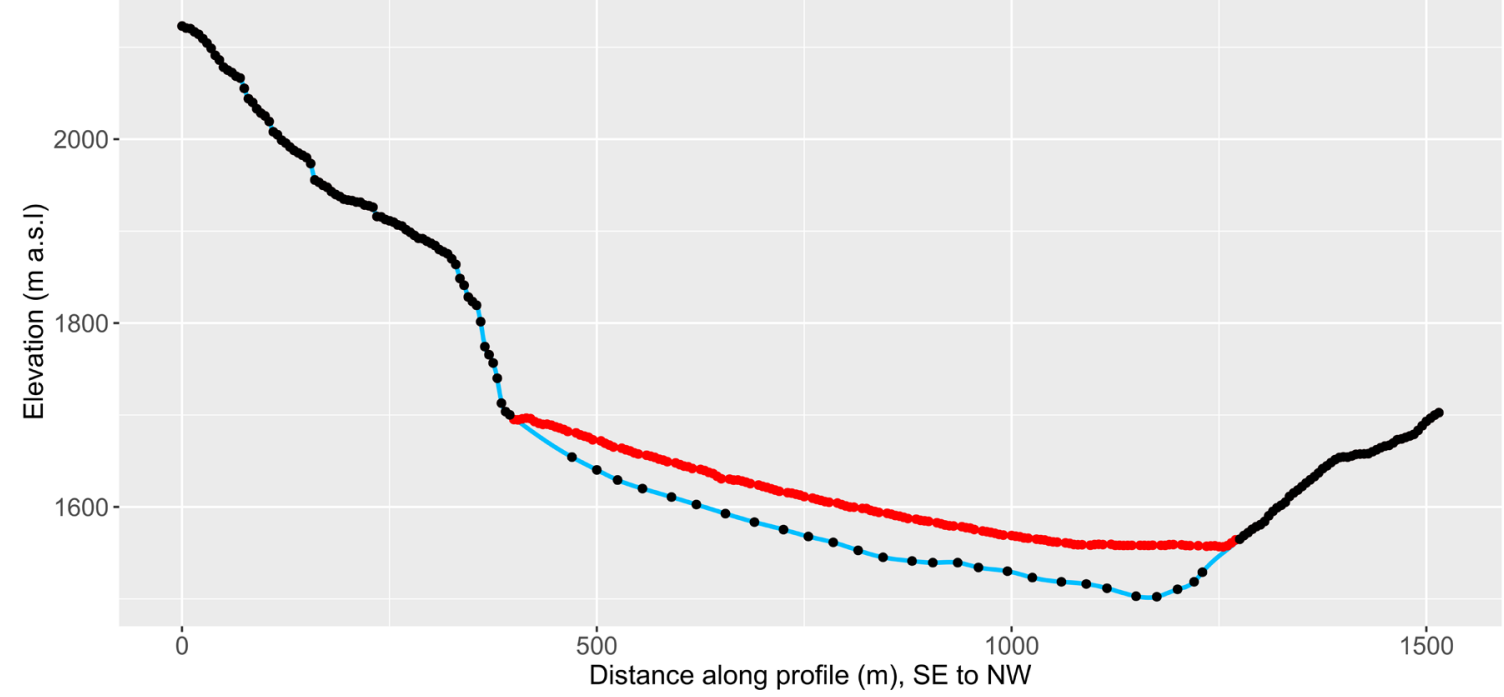

Profile: Nant 3 (Geoelectric) [N3]

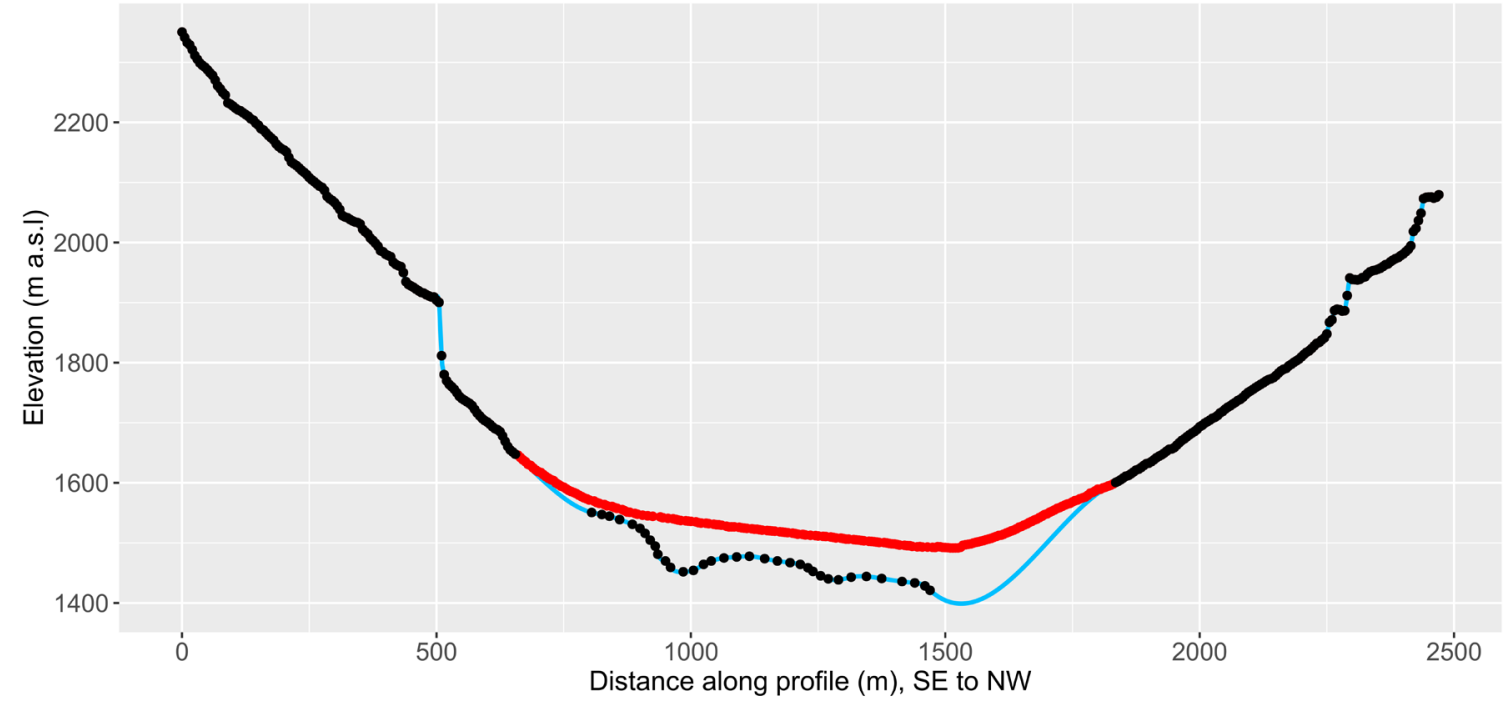




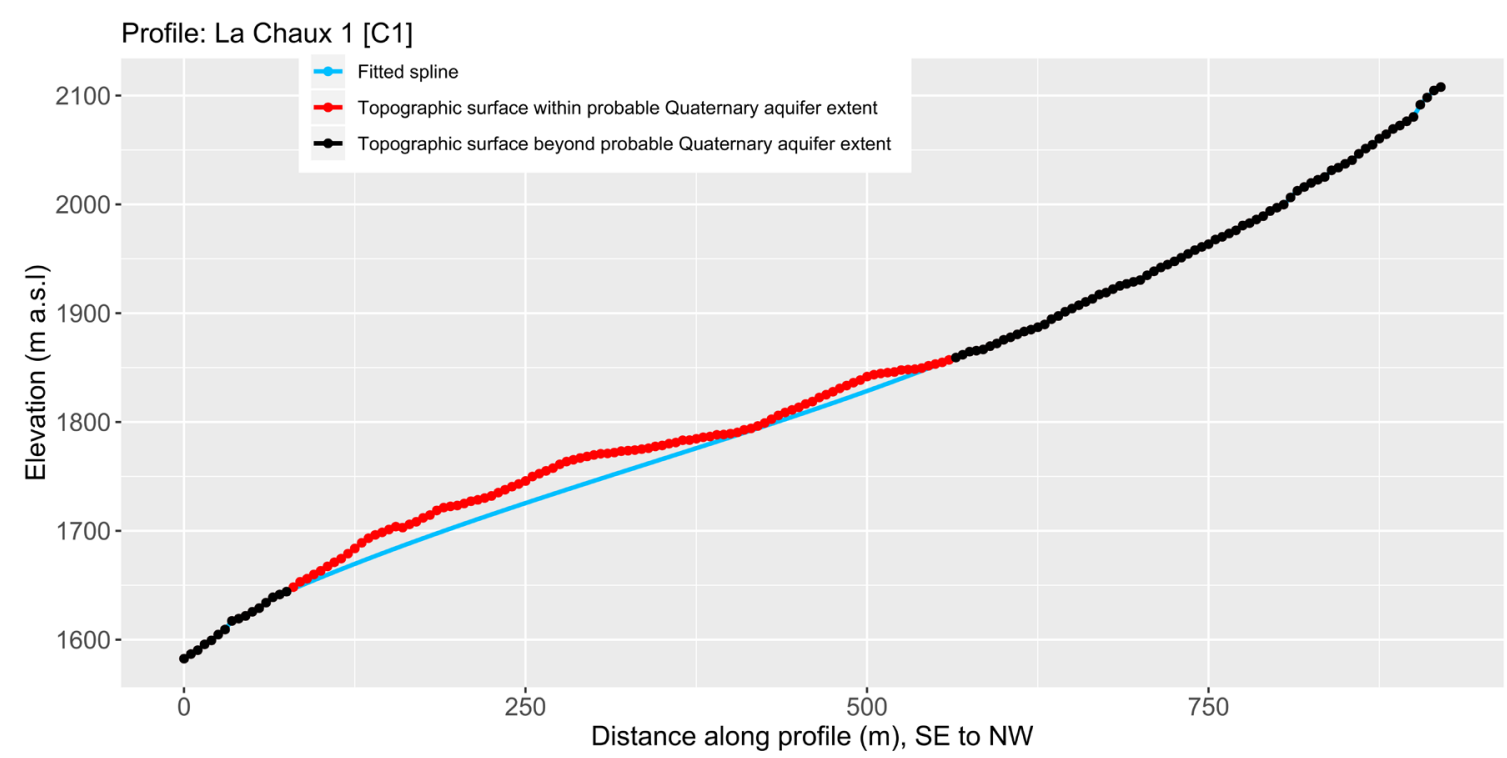

Profile: La Chaux 2 [C2]

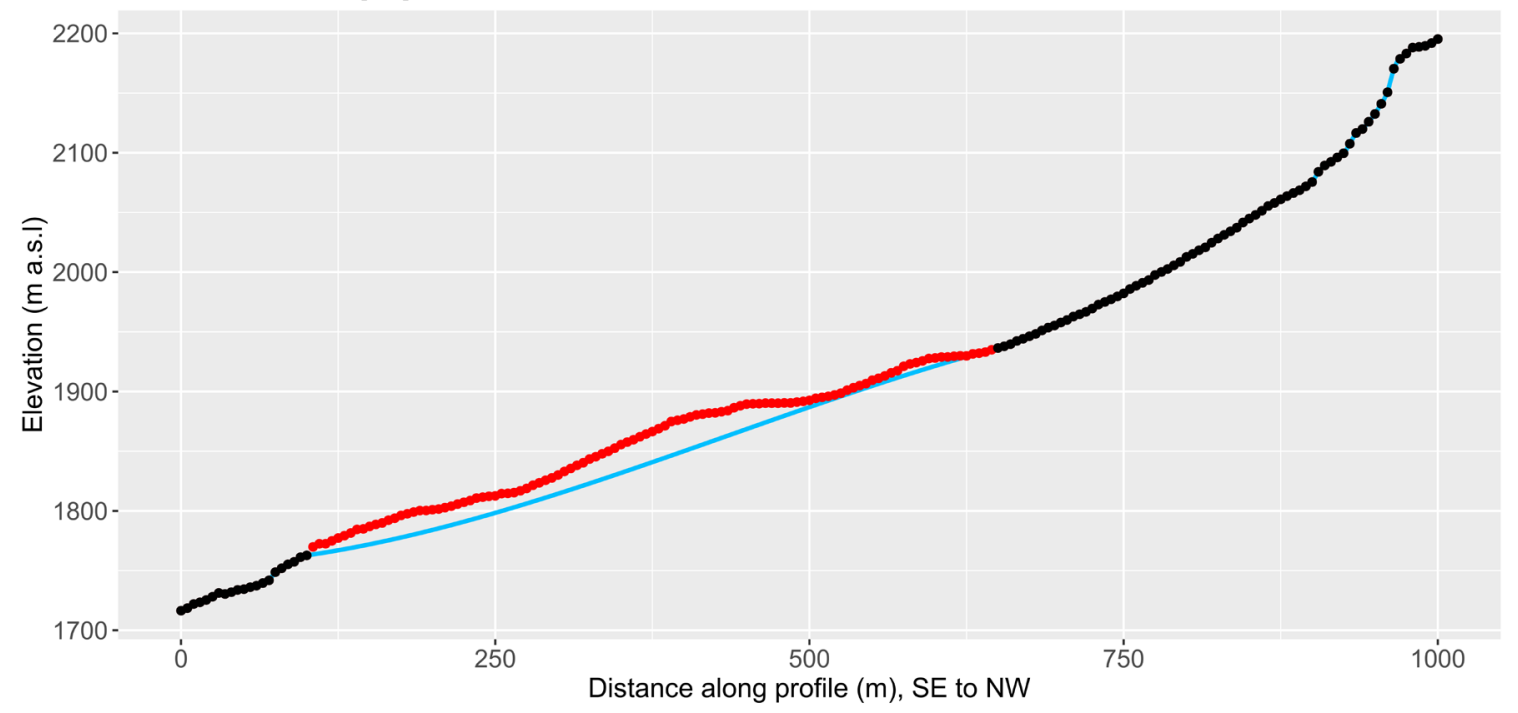

Profile: La Chaux 3 [C3]

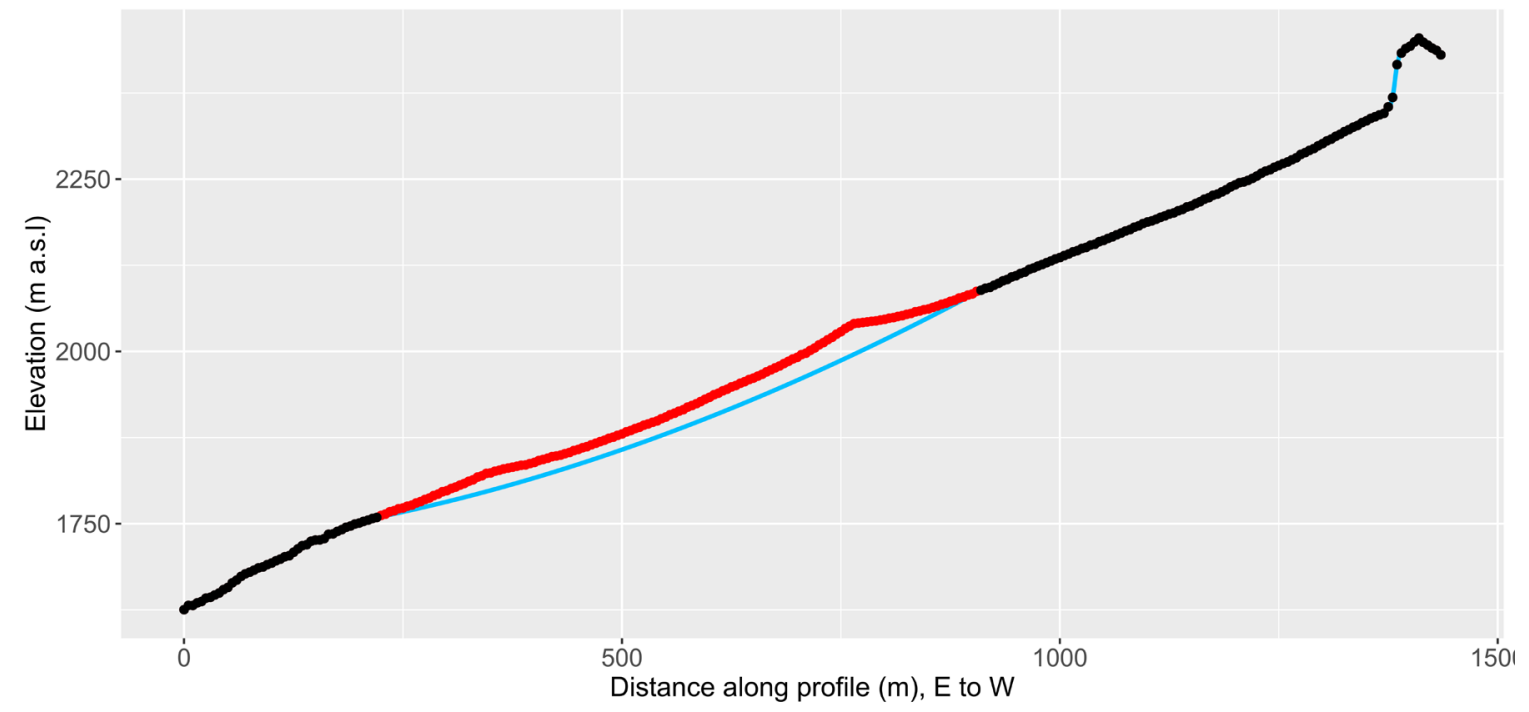




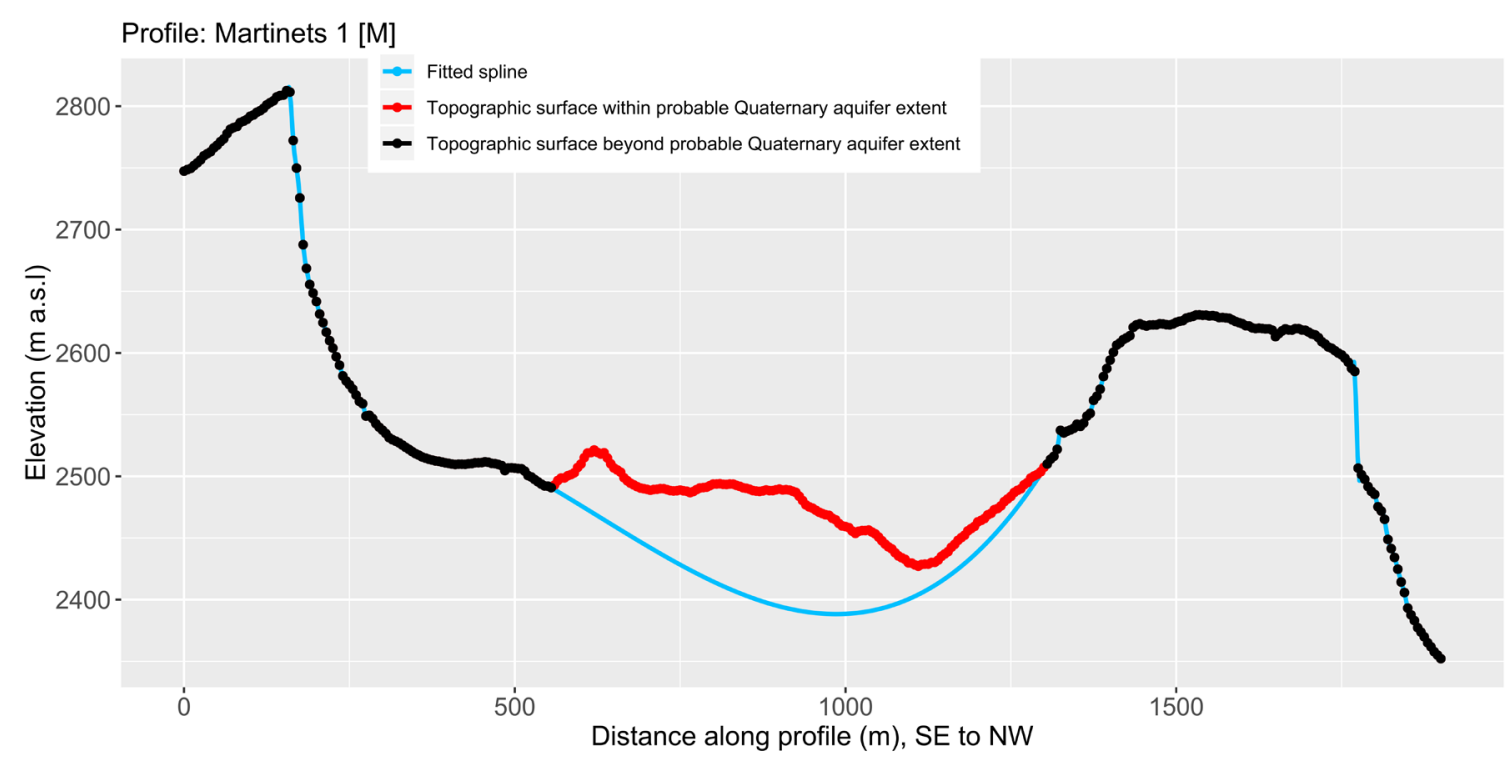

Profile: Martinets 2 [M2]

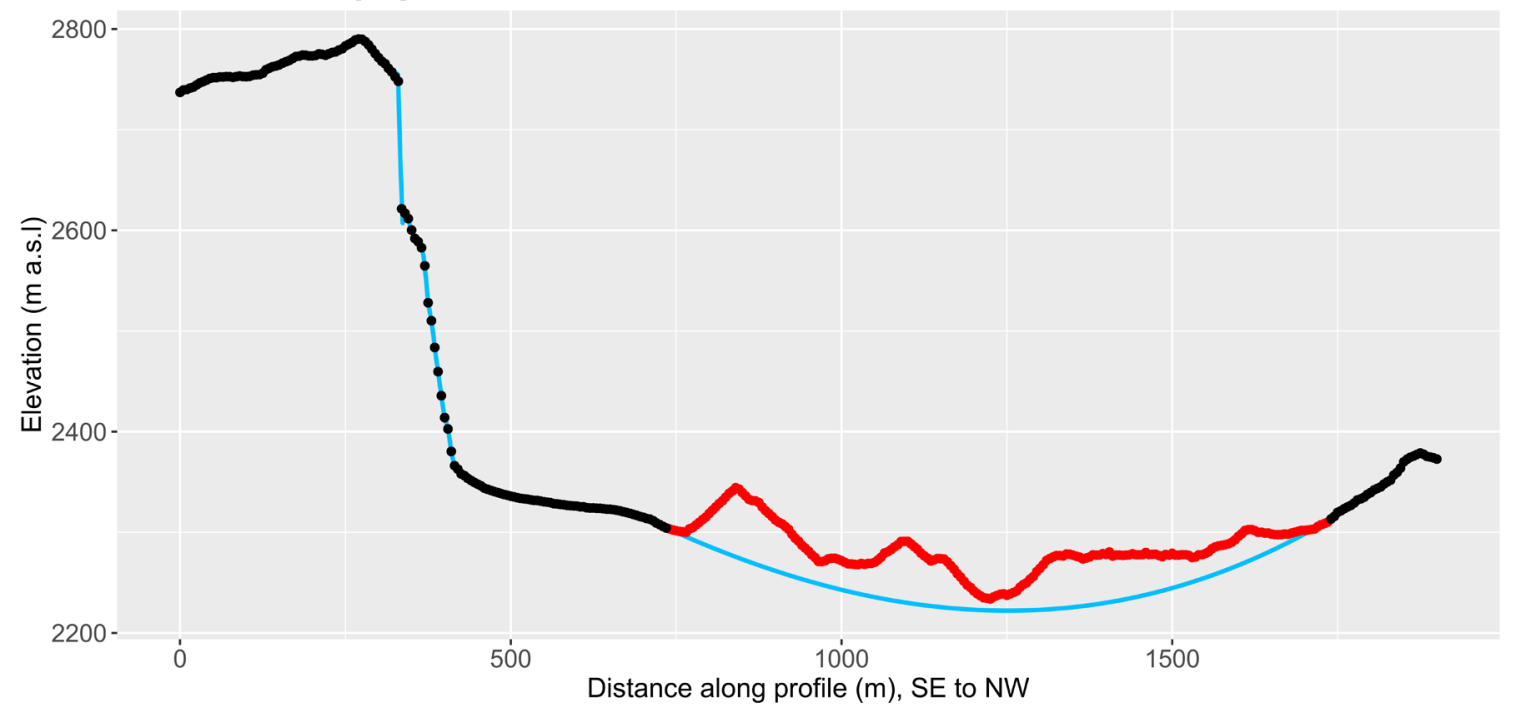

Profile: Martinets 3 [M3]

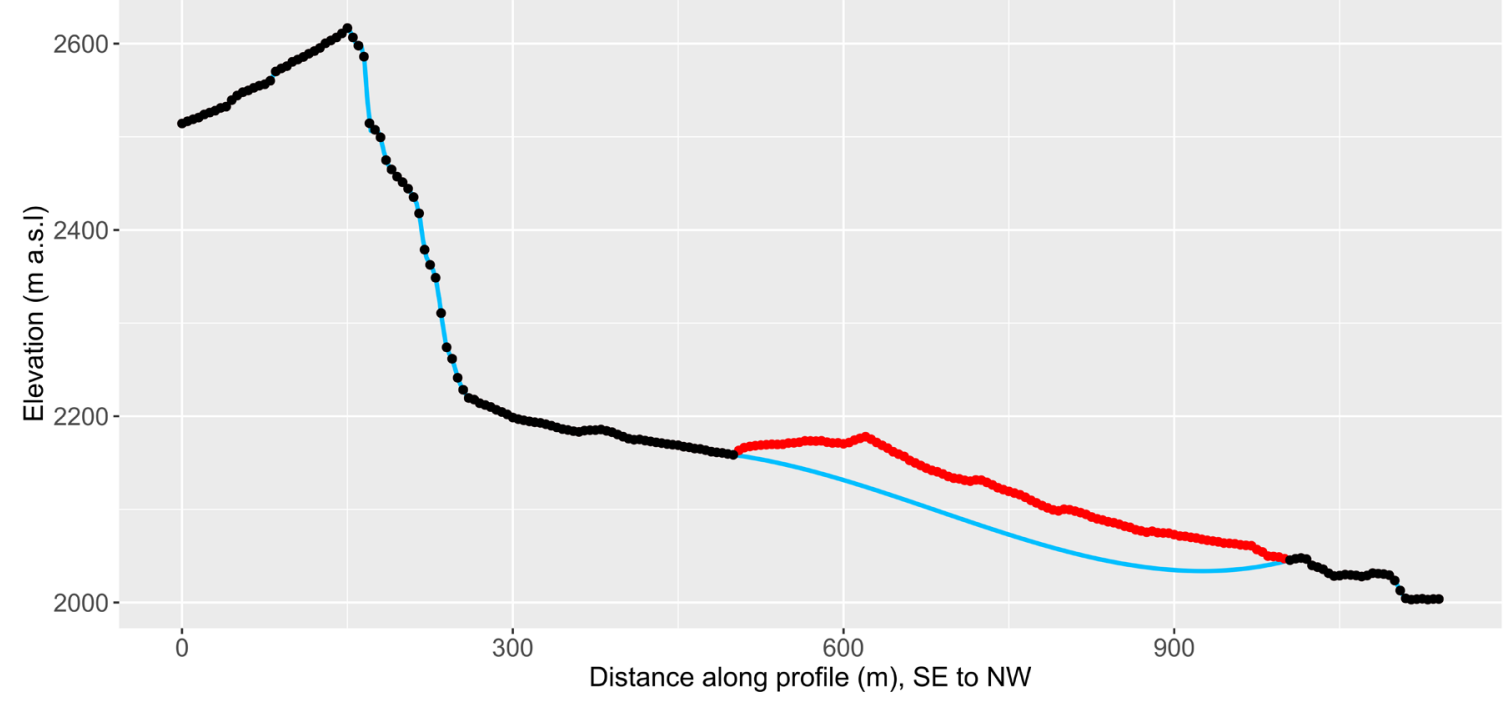


Profile: Vare Upper 1 [VU1]

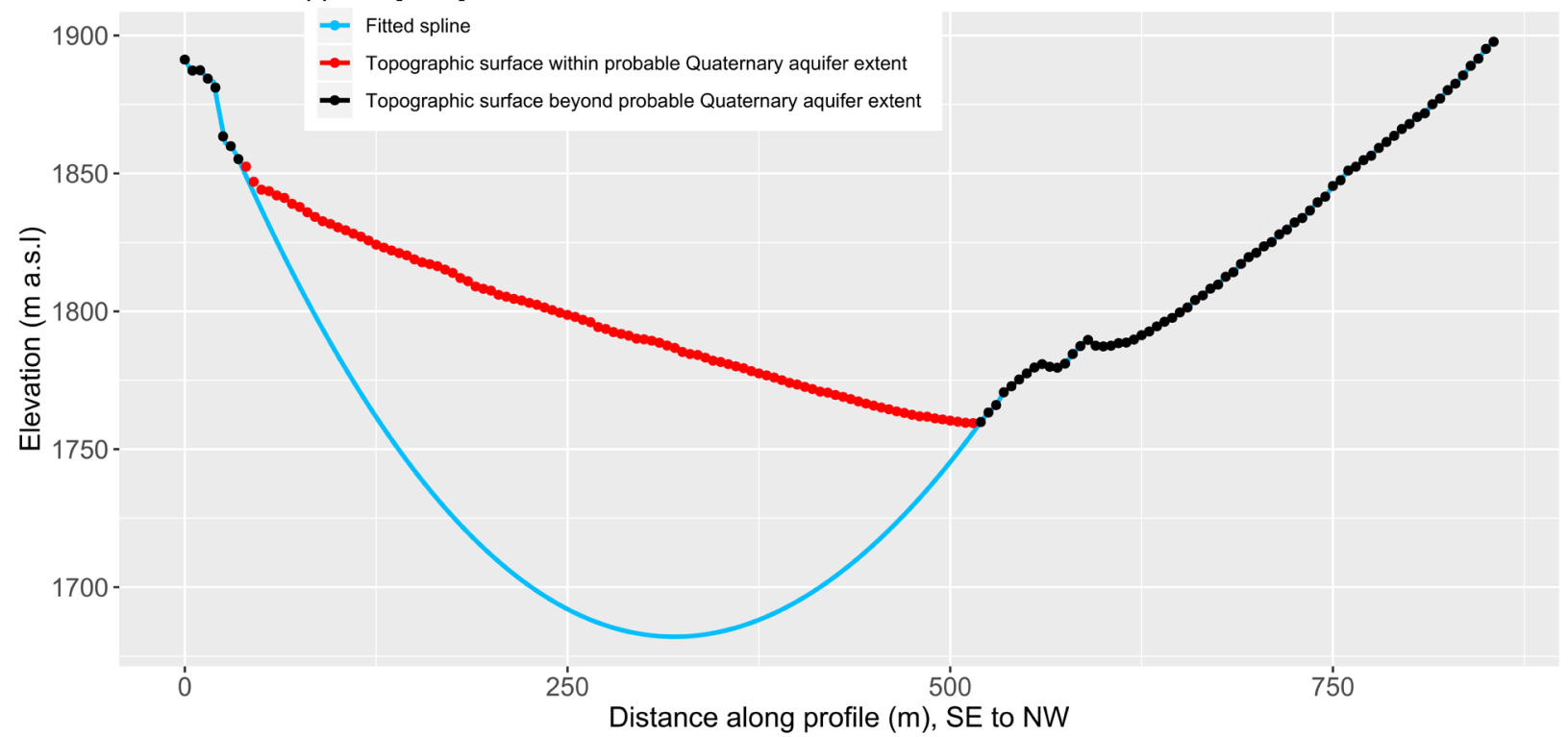

Profile: Vare Upper 2 [VU2]

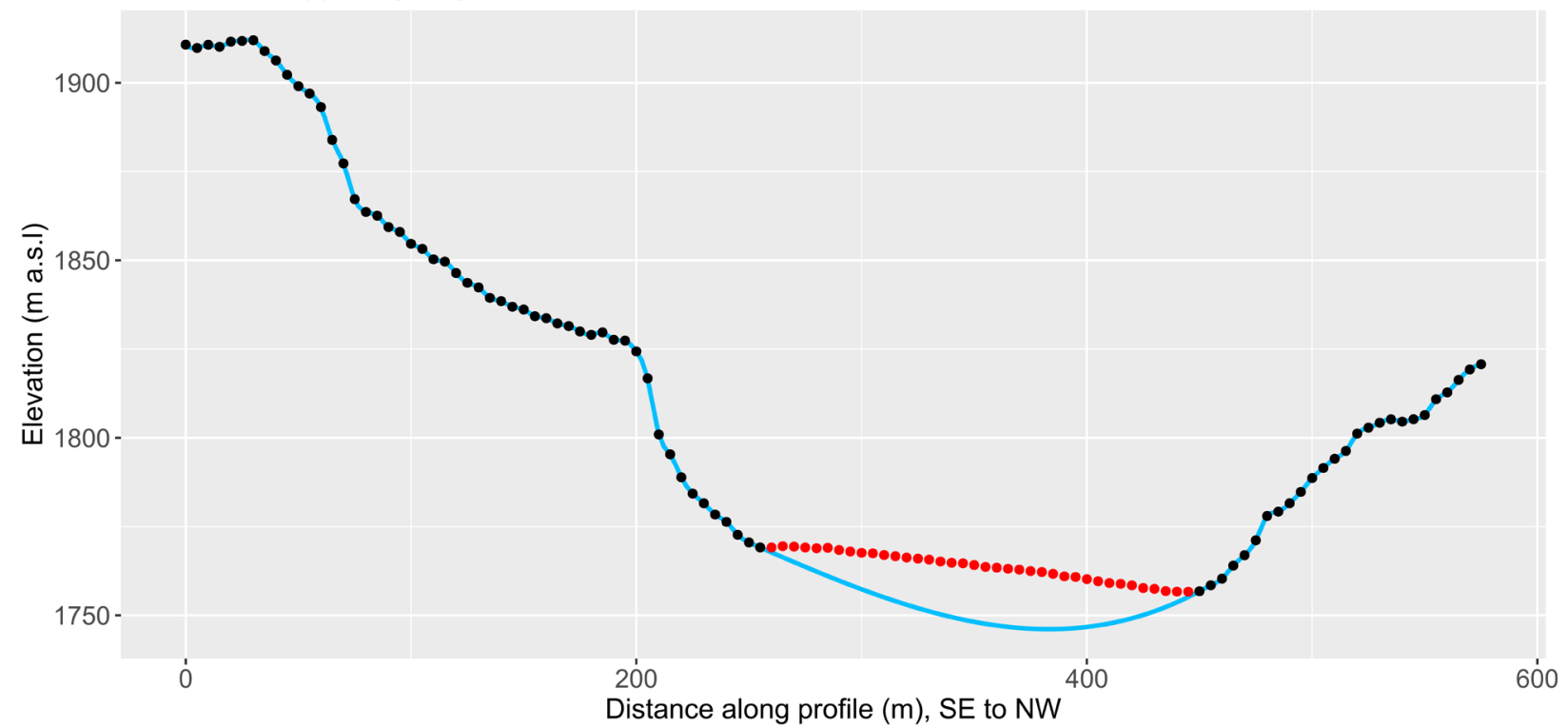


Profile: Vare Lower 1 [VL1]

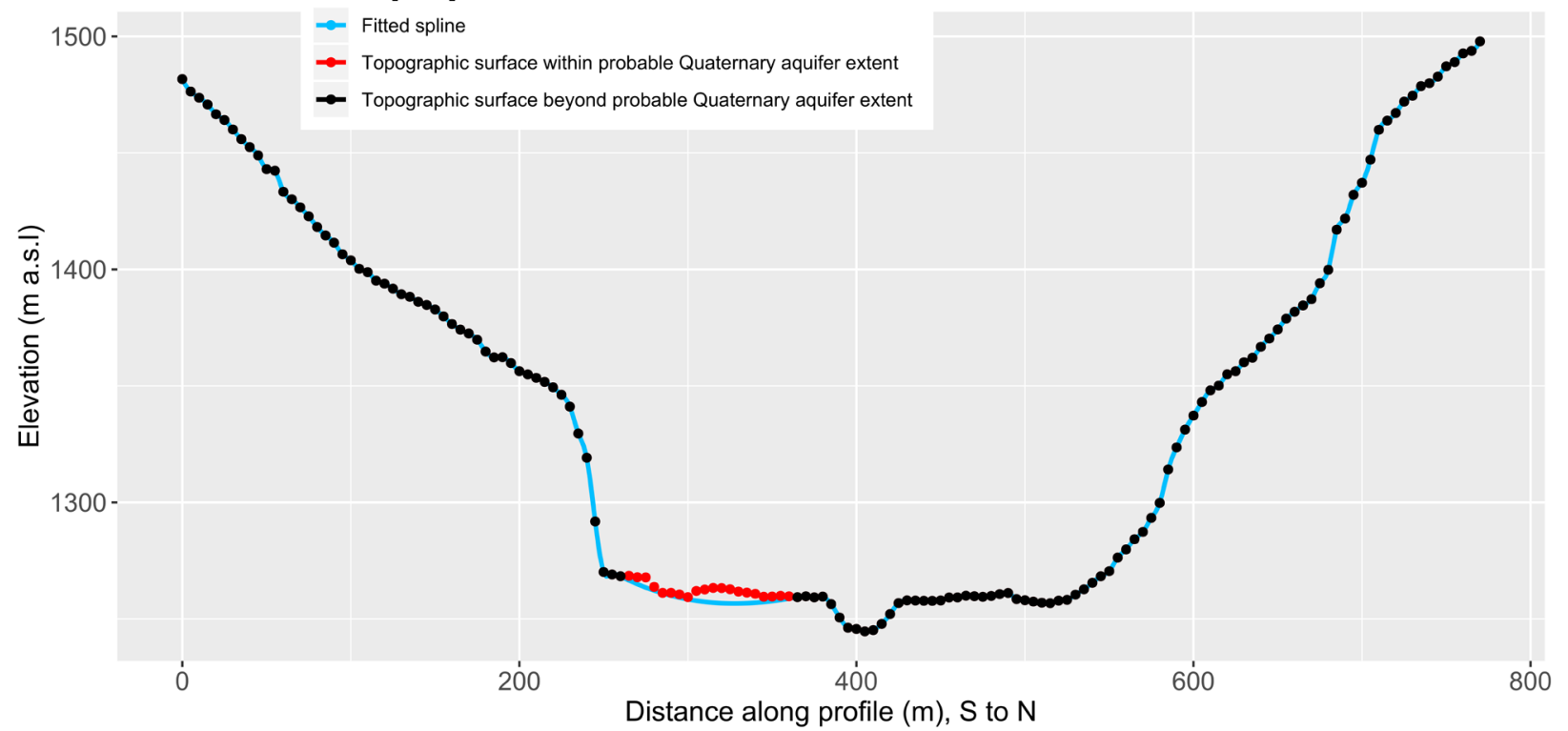

Profile: Vare Lower 2 [VL2]

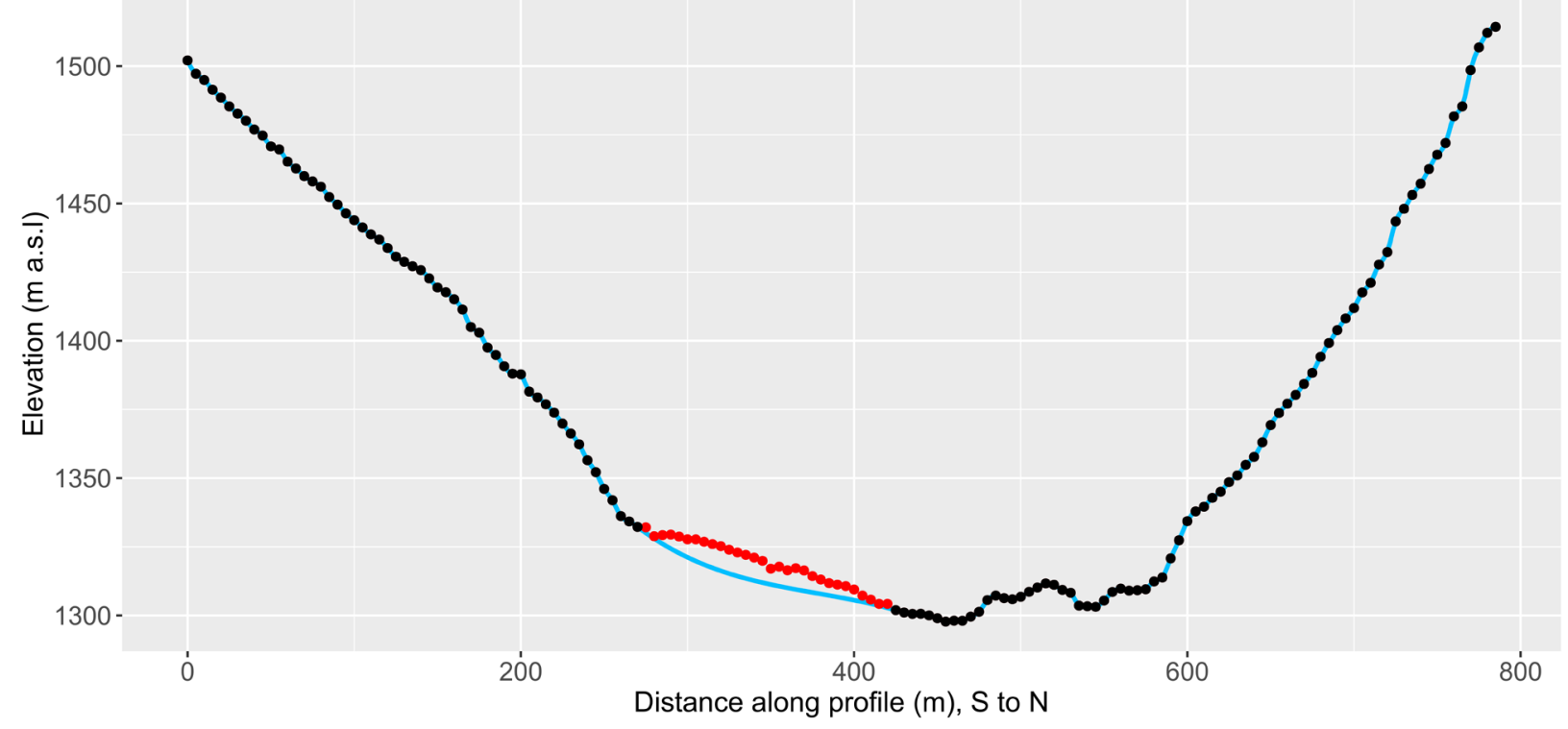

Figure S13. Interpolated 2D cross-sections for each of the 13 topographical transects. For the three profiles pertaining to Nant, interfaces derived from the geophysical surveys were included in addition to the topographic points immediately outside the sedimentary features in order to constrain the estimated 2D bedrock interface. Elsewhere, the $2 \mathrm{D}$ interpolations were informed solely by the bedrock gradients immediately beyond the sedimentary feature in question. 


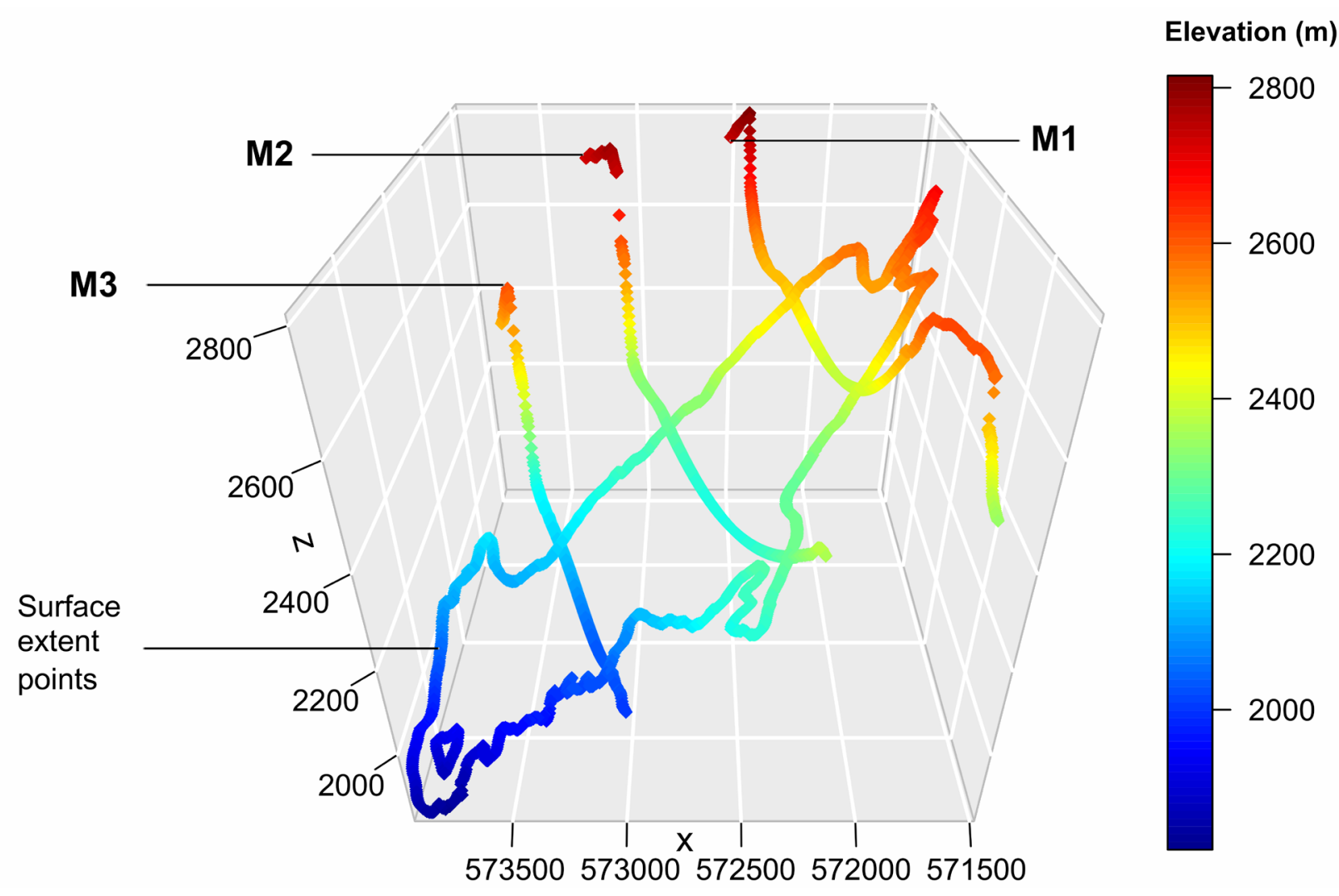

Figure S14. 3D points forming the input to the Thin Plate Spline (TPS) interpolation of the bedrock interface beneath the moraines of Les Martinets, looking due south. 


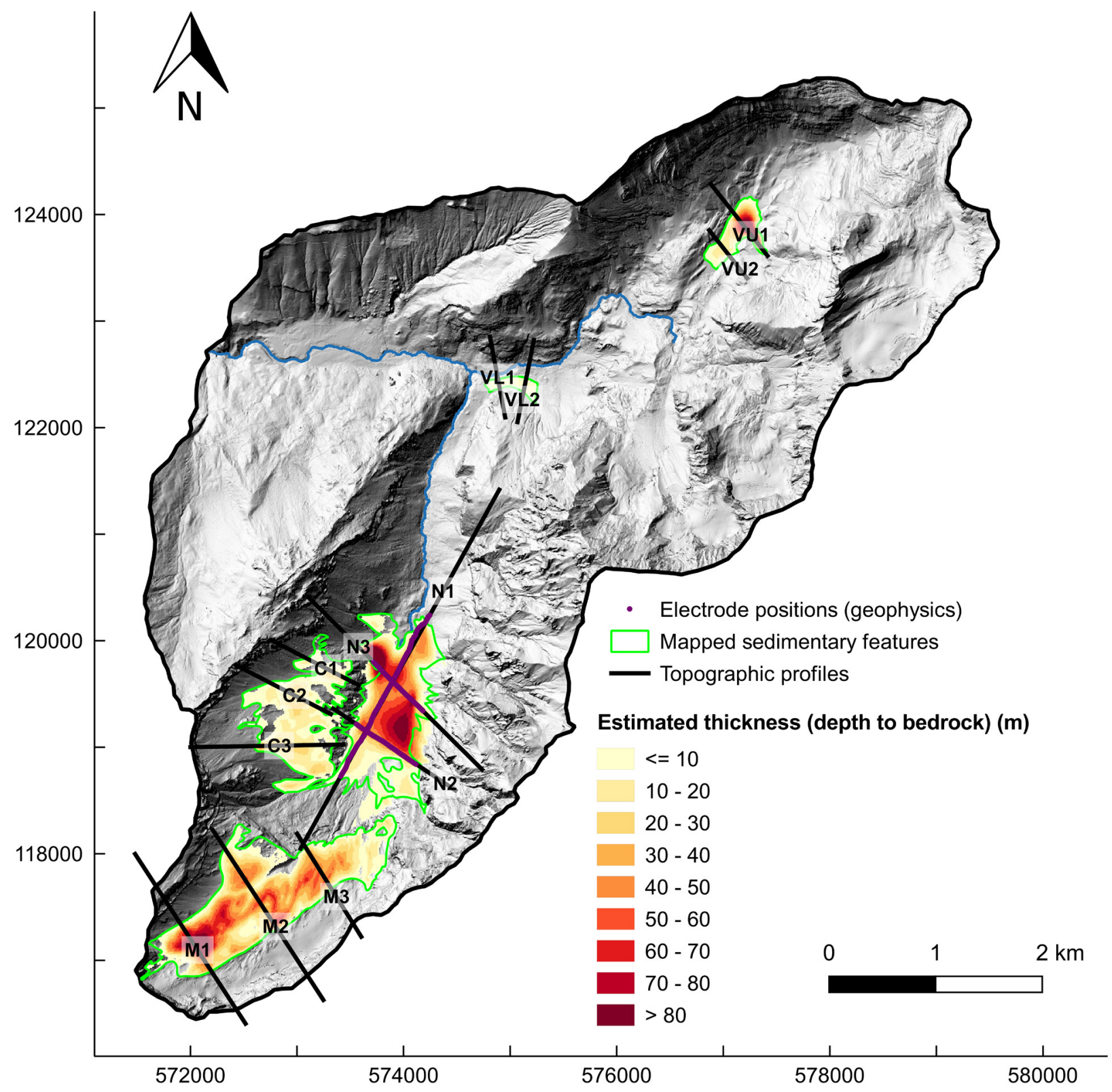

Figure S15. Estimated depth to bedrock within unconsolidated sedimentary features that were identified as potentially to host important aquifers. In the case of Nant, the result was generated by combining bedrock interfaces inferred from electrical resistivity images along the three profiles and the results from the geomorphometric method. The remaining features could not be practically surveyed with geophysics, and so the purely desk-based geomorphometric method was used here. 


\section{Text S1. Estimating geometries of potential unconsolidated Quaternary aquifers}

Recent dedicated field campaigns have elucidated the hydrological importance - in the sense of having the capacity to store and then subsequently release substantial quantities of groundwater - of various individual unconsolidated Quaternary sedimentary features, such as talus slopes, moraines, alluvial fans, and rock glaciers, that are commonly encountered in alpine settings (Hayashi, 2019; Somers \& McKenzie, 2020). However, researchers have few practical, cost-effective methods at their disposal to accurately estimate the 3D geometries of several such features across entire rugged, largely inaccessible mountainous headwater catchments. This is problematic because model structures should ideally be constrained as tightly as possible initially in order to limit the potential for parameter values to take on values that compensate for poor structures to reproduce the "right answers", but for the "wrong reasons" (which could have severe implications for subsequent predictions).

In absence of borehole information, geophysical methods (e.g. Sass, 2006; McClymont et al., 2011, 2012) generally yield the strongest geometrical constraints. Whilst therefore recommendable in principle, they are also very labour intensive. Given this and the fact that the routinely generated resultant data $2 \mathrm{D}$, it is generally not possible to survey more than perhaps one or two such features with sufficient density to provide meaningful 3D insights. In addition, environmental protection measures in sensitive mountain regions may preclude the use of certain geophysical techniques (e.g. seismic methods).

Traditional desk-based geomorphometrical methods, meanwhile, are certainly more efficient across larger areas, but the accuracy of the resultant estimate may be compromised, especially in light of the distinctive characteristics of alpine terrain. Several geomorphometical approaches to estimating the sediment/bedrock interface along 2D cross-sections perpendicular to the main valley axis have been considered. Perhaps the most straightforward approach involves simply projecting hillslope gradients into the subsurface (Hinderer, 2001). The fitting of power laws (Svensson, 1959) and quadratic functions (Wheeler, 1984) to empirical cross-section data have also proved rather popular (James, 1996; Li et al., 2001), even if much of this work was undertaken in attempts to try to better understand valley formation processes, whereby the fitted parameter values are interpreted (e.g. a power law exponent, $b$, approaching two is taken to be indicative of parabolic "U-shaped" glacial valleys, whilst values closer to one are considered to signify fluvially-incised "V-shaped" valleys), rather than current geometries.

Nevertheless, if elevation points along the profiles corresponding to the sedimentary fill are removed prior to curve fitting, erosional upper bedrock surfaces can be reconstructed (Harbor \& Wheeler, 1992). A fairly dense array of cross-sections must usually be considered to capture any longitudinal variability in the 2D profiles, and a final interpolation undertaken to produce a 3D result. Schrott et al. (2003), for instance, took such an approach in a small catchment in the Bavarian Alps, Germany, but found that the surfaces produced by polynomial fitting overestimated sediment thicknesses compared to coincident seismic refraction surveys. Not dissimilarly, Rogger et al. (2017) used a geomorphometrical approach to augment geophysical insights; sediment thicknesses were estimated at many different cross-sections by "extending the bare rock surface below the sediment deposit through a parabola fitted to the bedrock slopes at the outcrop boundaries".

Major drawbacks have been identified with both the power law and quadratic methods, however (Harbor \& Wheeler, 1992; Pattyn \& Van Huele, 1998). Specifically, power law functions must be fitted to both sides of a given valley cross-section independently, since the variable representing horizontal distance cannot take negative values. Additionally, power law functions must pass through the origin of the coordinate system used, yet where this location should be is generally unknown at the outset - above all when the very aim is

to interpolate the bedrock surface beneath sedimentary fill deposits. This issue renders the results sensitive 
to the choice of origin. The logarithmic transformation that is typically applied to solve for the constants of power law equations compounds the problem, since it causes more weight to be placed upon those points located near the origin than those towards the profile's extremities. Quadratic functions, meanwhile, assume that the cross-sectional form is parabolic and symmetrical, and are hence poorly suited to representing any form of asymmetry in such profiles.

A more modern but related approach to the estimation of glacial valley bedrock forms is the Sloping Local Base Level (LSBL) method (Jaboyedoff \& Derron, 2005). This technique requires a digital terrain model (DTM) as input. Via the iterative calculation of quadratic parabolas, the topographic surface within the region of sedimentary fill is then progressively "excavated", leaving a curved 3D bedrock surface. A crucial impediment to the wider implementation of this technique is that the maximum expected depth to bedrock, must be specified a priori (Otto et al., 2009), yet this is typically a key unknown to be determined. More recently, Mey et al. (2015) presented an approach to the estimation of valley fill thickness/bedrock surface topography that revolves around training a machine learning algorithm using geometrical landscape data specifically, the sectoral distance to the nearest bedrock hillslope, with the training data being generated by artificially filling DTMs. The approach hinges on the morphological similarity of the hillslope above the valley fill and the bedrock interface beneath it. Whilst results were promising with respect to estimating the thicknesses of sediments stored in the floor of large, almost horizontal intermontane valleys, the method would appear to be less immediately applicable to smaller alpine headwater catchments with their steeper sloping deposits.

As this last point alludes to, a further limitation of all the aforementioned geomorphometrical methods - and one which is particularly important given the complex nature of the bedrock geology at the present study site - is that geometric similarity above and below the fill level is assumed. In other words, no account is taken of lithological contrasts which, where present, bring about discontinuities in the cross-sectional profiles and terrain morphology more generally. The geostatistical approach developed by Castilla-Rho et al. (2014) used splines - a geomorphometrical technique that is better able to account for cross-sectional variability - in conjunction with various other datasets to estimate the bedrock interfaces of fluvial valleys.

As a consequence of these issues, it remains challenging to establish the extent to which the combination of these unconsolidated features contributes to the hydrological functioning of the broader catchment systems within which they are embedded, including their contributions to streamflow. Indeed, in integrated and other similar numerical model applications in mountainous areas, it remains common to rely on extremely simplified representations of potential unconsolidated aquifers (e.g. spatially uniform thicknesses) to be applied (Floriancic et al., 2018; Smoorenburg, 2015).

From this brief review, it seems unlikely that any ideal solution to this challenge presently exists, and that a combination of a geomorphological approach with constraints from geophysics might therefore represent be a pragmatic compromise. As such, with a view to informing development of the integrated model described in the main paper, a simple 2D and 3D spline-based geomorphometrical approach involving the targeted extraction of digital terrain and geological map data is presented. This is fairly similar to the approach of Castilla-Rho et al. (2014), but without stochastic quantification of uncertainty (which fell beyond our scope). It is shown that, where available, bedrock interface constraints inferred from geophysics - in the case of an electrical resistivity tomography (ERT) survey - can easily be incorporated. Ultimately, it is hoped that the approach provides a means by which catchment-scale groundwater and integrated surface-subsurface model structures can be refined compared to present practices.

The first step of the methodology involved identifying any major sedimentary features with the potential to act as aquifers (i.e. can store and subsequently release meaningful quantities of water) and establishing their 
surficial extents. This step required some general understanding of the hydrogeological system - especially qualitative knowledge of where the major aquifers are located. This understanding was developed by basic field measurements and reviewing various existing datasets.

More specifically, feature identification placed reliance on existing detailed (pre-digitised) surface geological maps (the swisstopo GeoCover25 dataset; https://shop.swisstopo.admin.ch/en/products/maps/geology/GC_VECTOR) and a high (2 m) resolution terrain "hillshade" map which was developed from the swissALTI ${ }^{3 \mathrm{D}}$ dataset (https://shop.swisstopo.admin.ch/en/products/height_models/alti3D). Unconsolidated sedimentary deposits were marked on the geological maps, and are furthermore clearly discernible in the "hillshade" map. Previous studies pertaining to the hydrogeological function of certain types of features (e.g. proglacial moraines) were also consulted as necessary. In this way, the following five principal features were identified:

- A large alluvial fan system, referred to henceforth as Nant;

- High proglacial moraine sediments of the Glacier des Martinets - Les Martinets;

- Glacial drift sediments - La Chaux;

- Generic unconsolidated fill sediments in a karstic, topographically closed depression (i.e. a doline) - Vare Upper, and;

- Generic unconsolidated fill sediments - Vare Lower.

These five features were treated as distinct zones so that in the subsequent integrated model, different hydraulic properties reflecting their specific histories and constituent materials could be assigned to each in the integrated flow model. The spatial extents of these features were extracted as shapefiles from the GeoCover25 maps and verified with reference to the hillshade map. The resultant areas are presented in Figure S10. In a final preliminary step, the $x, y$, and surface elevation, $z$, attributes of points spaced at $5 \mathrm{~m}$ intervals along the feature boundaries (i.e. where sediment thickness $=0$ ) were extracted from the DTM, and the resultant coordinate triplets recorded along with an identifier of the feature to which they correspond.

As previously discussed, in seeking to estimate Quaternary aquifer geometries, as much geophysics as possible should ideally be conducted. That said, the practical and monetary constraints to such approaches are elevated in rugged alpine terrain. With such considerations in mind, and within the very broad scope of this study, only one geophysical technique could be deployed here, and only a single unconsolidated formation surveyed. Since the main alluvial fan in the central part of the Vallon de Nant (i.e. Nant) was believed to constitute the most important unconsolidated formation in hydrological terms, attention was focussed here. This feature also happened to be comparatively accessible; having obtained the necessary special permissions, off-road vehicular access was possible as far as Chalet Nant - a now uninhabited farm building in the alpine pasture.

The survey's primary objective was to determine the spatial distribution of depth to bedrock; any potential insights that could be gleaned with regards to internal structure would be considered a bonus. Seismic methods (used by Schrott et al., 2003, amongst many others) were discounted due to the Natural Reserve's regulations, whilst the depth of information provided by ground-penetrating radar is too limited. Finally, we decided to rely on ERT, which we expected could provide information about the lithological structure down to depths $\sim 100-200 \mathrm{~m}$. A four-day long field campaign was conducted in favourable meteorological (dry and sunny conditions) in September 2018 - the first attempt to image the subsurface of this pristine Alpine valley.

With the objectives in mind, the intended profile layouts and electrode spacings were planned in advance. Three separate profiles were identified; one long one of 1,780 m running approximately parallel to the main valley axis (N1), and two shorter perpendicular profiles of $700 \mathrm{~m}$ each (N2 and N3) (Figure S11). The former 
sought to capture any longitudinal variability in the bedrock interface (i.e. along the valley axis), for instance due to glacial over-deepening, which is common in such settings. The two intersecting transverse profiles sought to provide some 3D constraints on the morphology of the upper bedrock surface (and hence the unconsolidated sediment thickness); the ultimate goal being to develop a 3D flow model after all. In order to image comparatively deep, a 20 -m electrode spacing was chosen.

Once in the field, where conditions allowed, the stainless-steel electrodes were hammered in to a depth of 10-20 cm. The length of N1 necessitated a "roll-along" technique. At locations without soil cover (see e.g. Figure $4.8 \mathrm{~b}$ ), electrodes were positioned firmly in the silty sediments between larger boulders and pebbles, and sponges dampened with salt water were applied to decrease the contact resistance. Typically, contact resistances between electrodes of less than $5 \mathrm{kOhm}$ were achieved. The electrode positions were measured accurately using a Leica Differential GPS device; these are plotted in Figure S11. Relatively straight profiles could be maintained, and so any corresponding $3 \mathrm{D}$ distortive effects in the results should be minimal.

The apparent resistivity measurements were acquired in both dipole-dipole and Wenner-Schlumberger configurations using an IRIS Syscal Pro instrument. The current injection cycles (500 ms) were repeated four times and the measurements were stacked in order to improve the signal-to-noise ratios. Prior to inversion, the data from the Wenner-Schlumberger and dipole-dipole surveys were combined, giving a total of 3,353 measurements for $\mathrm{N} 1$, and 793 measurements for $\mathrm{N} 2$ and N3, before any measurements whose standard deviation exceed 3\% were removed. The inversions were performed in a fairly standard fashion using the code BERT (Günther, Rücker and Spitzer, 2006). Robust data reweighting and compact inversion using iteratively-reweighted least-squares were employed to reduce the influence of outliers and to image sharper interfaces, respectively. The inversion process converged in 10 iterations, with a final relative root-mean square error of $<5 \%$.

The three resultant resistivity images (Figure S12) were interpreted both independently and in combination. To facilitate the latter, they were georeferenced and visualised in conjunction with the surface topography within a virtual environment (Movie 3). This step also enabled the coherence of the inversion results near the profiles' intersection points to be verified. Next, a plausible bedrock interface was tentatively identified and annotated on the images (along with other possible interpretations). Finally, the spatial coordinates $(x, y, z)$ of points placed at regular intervals along the identified subsurface interface were extracted.

The next phase of the methodology was to make a series of $2 \mathrm{D}$ interpolations at the various cross-sections. To achieve this, the geophysical transects and other topographical profiles were first extended, points were generated at $5 \mathrm{~m}$ intervals along the full profiles, the surface elevation (z) extracted from the DTM, and the horizontal distance from the respective profile start points calculated. Then, for each feature independently, the surface elevation points were plotted against the horizontal distances, and any points falling within the unconsolidated sediment extents (identified via spatial intersection with the feature shapefiles) were removed. These points are represented in red in Figure S13.

Following that, cubic splines were fitted to interpolate between the remaining points. As a class of functions, splines are local interpolators which seek to fit the empirical data points exactly (or extremely closely, by minimising the sum of the squared residuals) whilst simultaneously maximising smoothness, by penalising roughness (Mitas and Mitasova, 1999). They are generally favoured over high-order polynomials because the latter can result in strong oscillations. The specific technique of cubic spline fitting involves establishing piecewise third-order polynomials that pass through all of the control points. In this way, the upper bedrock surfaces along each transect were estimated. For the three profiles in the Nant feature, the additional subsurface interface derived from the geophysics results were included in the 2D interpolations in the same fashion as the topographic points beyond feature extents. 
The smoothness of the resultant interpolations makes splines well-suited to the task of reconstructing "Ushaped" glacial valleys; the smooth interfaces they propose beneath the sediment-obscured regions correspond to the simplest possible models. Simultaneously, in being able to follow sharp elevation discontinuities in the bedrock outcrops, which arise here due to lithological contrasts, these points do not influence the reconstructed interfaces. In other words, the upper bedrock surface estimates along each transect were consistent with the bedrock gradients immediately beyond the feature extents. It follows that should any lithological "steps" occur beneath the zones of sediment fill, these would not be captured. Such "steps" are generally not too problematic in this case, however.

In certain instances, the interpolated interfaces did demonstrate a fairly high degree of sensitivity to the elevation gradients immediately beyond the sedimentary feature extents, and hence to the inclusion/ exclusion of sampled points near the sediment/bedrock interfaces. This is similar to the finding of Mey et al. (2015), who also noted a certain sensitivity to the accuracy of the mapped feature "mask". In fact, here, there was no hard condition to stipulate that the resultant interpolated surface should remain beneath the topographic surface. That said, the original surficial extent mapping (and hence the distinction between which points lay within the unconsolidated region and which lay beyond it) was certainly not perfect. This observation justified the manual additional removal of a few points in certain cases in these boundary regions, leading to interface profiles that were i) more consistent with prior expectations, and ii) were sufficiently coherent with others in the same feature. The final resultant splines are shown as the light blue lines in Figure S13.

The surface coordinates (i.e. $x, y$ ) of regular points along the interpolated spline function beneath the sedimentary fill were calculated using trigonometry and recorded along with the elevation estimates $(z)$. Finally, the triplets $(x, y, z)$ were grouped by feature, and pooled with the corresponding surficial extent triplets (i.e. where thickness $=0$ ) that had been generated already. For illustration, Figure S11 shows all points prior to 3D interpolation for the Les Martinets feature.

Finally, the 3D interpolations could be undertaken. For each feature independently, all 3D (i.e. $x, y, z$ ) points which corresponded to an observed or estimated sediment thickness of zero (i.e the bedrock interface) were interpolated using Thin Plate Spline (TPS) functions - which imitate thin steel sheets forced to pass through the points - to give a spatially continuous 3D surface (with $10 \mathrm{~m}$ horizontal resolution). The smoothing parameter was identified automatically by generalised cross-validation. Where necessary, the resultant raster dataset was clipped to the feature boundaries. The final estimated unconsolidated sediment thickness distribution is shown in Figure S12.

Given the relative ambiguity of the bedrock interface from the geophysical results (essentially due to their being no strong contrasts in resistivity - the clay rich Flysch bedrock apparently having fairly similar properties to the unconsolidated materials), as well as the potential for the internal structure, which could not be determined using the large electrode-spacing used here, having potentially high hydrological importance (for instance, a very shallow clay layer could be observed in the field in regions of the main alluvial fan aquifer at Nant after an erosive flow event), the entire depth to bedrock beneath the alluvial fan was not defined as being eminently permeable for the purposes of the subsequent numerical modelling. Instead, only the upper third of the total thickness was considered as such, with the lower permeability till/clay assumed to comprise the remaining volume. This is essentially akin to defining the alluvial fan base according to a lower resistivity isosurface than the bedrock interface in S12; somewhere in the light blue region. Such an approach is justified by the fact the ERT appears to be mapping the fan and the till as a common lowresistivity feature above the bedrock interface. The technique is also known to have a tendency to somewhat overestimate the size of conductive anomalies - in this case the coarse gravel region of the fan. Since the 
geomorphometrical method provided no insight whatsoever in the other formations, they were assumed "hydrologically active" to their full depth.

For an extended description of the method and results, readers are directed to Chapter 4 of Thornton (2020). This doctoral thesis is currently under embargo but can be provided confidentially by the corresponding author upon written request.

\section{References}

Castilla-Rho, J. C., Mariethoz, G., Kelly, B. F. J., \& Andersen, M. S. (2014). Stochastic reconstruction of paleovalley bedrock morphology from sparse datasets. Environmental Modelling and Software, 53, 35-52. https://doi.org/10.1016/j.envsoft.2013.10.025

Floriancic, M. G., van Meerveld, I., Smoorenburg, M., Margreth, M., Naef, F., Kirchner, J. W., \& Molnar, P. (2018). Spatio-temporal variability in contributions to low flows in the high Alpine Poschiavino catchment. Hydrological Processes, 32(26), 3938-3953. https://doi.org/10.1002/hyp.13302

Günther, T., Rücker, C., \& Spitzer, K. (2006). Three-dimensional modelling and inversion of dc resistivity data incorporating topography - II. Inversion. Geophysical Journal International, 166(2), 506-517. https://doi.org/10.1111/j.1365-246X.2006.03011.x

Harbor, J. M., \& Wheeler, D. A. (1992). On the mathematical description of glaciated valley cross sections. Earth Surface Processes and Landforms, 17(5), 477-485. https://doi.org/10.1002/esp.3290170507

Hayashi, M. (2019). Alpine Hydrogeology: The Critical Role of Groundwater in Sourcing the Headwaters of the World. Groundwater, gwat.12965. https://doi.org/10.1111/gwat.12965

Hinderer, M. (2001). Late quaternary denudation of the alps, valley and lake fillings and modern river loads. Geodinamica Acta, 14(4), 231-263. https://doi.org/10.1080/09853111.2001.11432446

Jaboyedoff, M. I., \& Derron, M. . (2005). A new method to estimate the infilling of alluvial sediment of glacial valleys using a sloping local base level. Geografia Fisica e Dinamica Quaternaria, 28, 37-4.

James, A. L. (1996). Polynomial and power functions for glacial valley cross-section morphology. Earth Surface Processes and Landforms, 21(5), 413-432. https://doi.org/10.1002/(SICI)10969837(199605)21:5<413::AID-ESP570>3.0.CO;2-S

Li, Y., Liu, G., \& Cui, Z. (2001). Glacial valley cross-profile morphology, Tian Shan Mountains China. Geomorphology, 38(1-2), 153-166. https://doi.org/10.1016/S0169-555X(00)00078-7

McClymont, A. F., Hayashi, M., Bentley, L. R., \& Liard, J. (2012). Locating and characterising groundwater storage areas within an alpine watershed using time-lapse gravity, GPR and seismic refraction methods. Hydrological Processes, 26(12), 1792-1804. https://doi.org/10.1002/hyp.9316

McClymont, Alastair F., Roy, J. W., Hayashi, M., Bentley, L. R., Maurer, H., \& Langston, G. (2011). Investigating groundwater flow paths within proglacial moraine using multiple geophysical methods. Journal of Hydrology, 399(1-2), 57-69. https://doi.org/10.1016/j.jhydrol.2010.12.036

Mey, J., Scherler, D., Zeilinger, G., \& Strecker, M. R. (2015). Estimating the fill thickness and bedrock topography in intermontane valleys using artificial neural networks. Journal of Geophysical Research: Earth Surface, 120(7), 1301-1320. https://doi.org/10.1002/2014JF003270

Otto, J.-C., Schrott, L., Jaboyedoff, M., \& Dikau, R. (2009). Quantifying sediment storage in a high alpine valley (Turtmanntal, Switzerland). Earth Surface Processes and Landforms, 34(13), 1726-1742. 
https://doi.org/10.1002/esp.1856

Pattyn, F., \& Van Huele, W. (1998). Power law or power flaw? Earth Surface Processes and Landforms, 23(8), 761-767. https://doi.org/10.1002/(SICI)1096-9837(199808)23:8<761::AIDESP892>3.0.CO;2-K

Rogger, M., Chirico, G. B., Hausmann, H., Krainer, K., Brückl, E., Stadler, P., \& Blöschl, G. (2017). Impact of mountain permafrost on flow path and runoff response in a high alpine catchment. Water Resources Research, 53(2), 1288-1308. https://doi.org/10.1002/2016WR019341

Sass, O. (2006). Determination of the internal structure of alpine talus deposits using different geophysical methods (Lechtaler Alps, Austria). Geomorphology, 80(1-2), 45-58. https://doi.org/10.1016/j.geomorph.2005.09.006

Schrott, L., Hufschmidt, G., Hankammer, M., Hoffmann, T., \& Dikau, R. (2003). Spatial distribution of sediment storage types and quantification of valley fill deposits in an alpine basin, Reintal, Bavarian Alps, Germany. Geomorphology, 55(1-4), 45-63. https://doi.org/10.1016/S0169-555X(03)00131-4

Smoorenburg, M. (2015). Flood behavior in alpine catchments examined and predicted from dominant runoff processes. ETH Zürich.

Somers, L. D., \& McKenzie, J. M. (2020). A review of groundwater in high mountain environments. WIREs Water, December 2019, 1-27. https://doi.org/10.1002/wat2.1475

Svensson, H. (1959). Is the cross-section of a glacial valley a parabola? Journal of Glaciology, 3, 362-363.

Thornton, J. M. (2020). Fully-integrated hydrological modelling in steep, snow-dominated, geologically complex Alpine terrain. Doctoral Thesis. University of Neuchâtel.

Wheeler, D. A. (1984). Using parabolas to describe the cross-sections of glaciated valleys. Earth Surface Processes and Landforms, 9(4), 391-394. https://doi.org/10.1002/esp.3290090412

Table S1. Evapotranspiration parameter values in the integrated model, rounded to two significant figures. $\mathrm{d}_{e}$ is evaporation depth, $\mathrm{d}_{r}$ root depth, LIA range gives the annual minimum and maximum Leaf Area Index (with monthly variability between these values), $\mathrm{C} 1, \mathrm{C} 2$, and $\mathrm{C} 3$ are transpiration fitting parameters, and $\mathrm{H}_{w p}$, $\mathrm{H}_{f c}, \mathrm{H}_{o l}$, and $\mathrm{H}_{a l}$ are the pressure heads at the wilting point, field capacity, oxic limit, and anoxic limits, respectively. $\mathrm{H}_{t t l}$ is the pressure head below which evaporation is zero, and $\mathrm{H}_{t 2}$ the pressure head above which full evaporation can occur. $c_{i n t}$ is the canopy storage parameter. For parameters that were subjected to calibration, the initial values, lower and upper bounds permitted, and the final value obtained are specified. Evaporation from the bedrock, glaciers, unconsolidated rock, and streambed zones was deactivated in the model. All free parameters were log-transformed to improve the numerical robustness of the process.

Table S2. Surface parameter values in the integrated model, rounded to two significant figures. $\mathrm{n}_{x y}$ is the Manning's roughness coefficient, $\mathrm{h}_{d \mathrm{~s}}$ is the depression (or rill) storage height, $h_{o}$ is the obstruction storage height, $l_{\text {exch }}$ is the surface-subsurface coupling length. For parameters that were subjected to calibration, the initial values, lower and upper bounds permitted, and the final value obtained are specified. *Except where permafrost, in which case $1_{\text {exch }}$ was assigned a value of $50 \mathrm{~m}$. All free parameters were log-transformed to improve the numerical robustness of the process. 
Table S3. Subsurface parameter values in the hydrological model, rounded to an appropriate degree of precision. $k_{x y}$ is horizontal saturated hydraulic conductivity, $k_{z}$ is vertical saturated hydraulic conductivity, $q$ is effective porosity, $S_{s}$ is specific storage, and $\alpha$ and $\beta$ are parameters of the Van Genuchten unsaturated retention functions. These functions were simplified for all subsurface formations except soils. For parameters that were subjected to calibration, the initial values, lower and upper bounds permitted, and the final value obtained are specified. The "subsurface.mprops" file in the Supplementary Materials details the simplified unsaturated parameterization applied in non-soil zones. $k_{z}=k_{x y}$, except where indicated. All free parameters were log-transformed to improve the numerical robustness of the process.

Movie S1. Upper: The evolution the daily frequency forcing data prescribed to the fully-integrated model (left: all liquid water inputs, i.e. rain + snowmelt + icemelt, and right: potential evapotranspiration). Lower: actual evapotranspiration (right) and surface water depth (left) simulated using the fully integrated model with daily frequency forcing data. The period shown is the 2017/2018 hydrological year, and the time-step of the animation is half-daily. The "days" are days from 1 October 2014. Note that the $E T_{\mathrm{p}}$ and $E T_{\mathrm{a}}$ scales are inverted because HGS writes the latter as a negative flux by default.

Movie S2. The evolution of catchment (surface) saturation (left) and the response of water level at gauging station S2 (right) over the course of the 2017/2018 hydrological year simulated using the fully-integrated model with daily frequency forcing. The time-step of the animation is half-daily (the "days" are days from 1 October 2014).

Movie S3. Animation illustrating the three electrical resistivity profiles that were obtained for the Nant feature. To provide additional context to the georeferenced profiles, the surface topography according to the Alti ${ }^{3 \mathrm{D}}$ digital terrain model is also represented. The bedrock interface was interpreted to be located around the transition from an upper region of lower resistivity to a lower region of higher resistivity (see the annotations on the profiles). This interface, which appears to be consistent between the profiles, was digitized (pink dots). 